\title{
Regulation of Cellular Redox Signaling by Matricellular Proteins in Vascular Biology, Immunology, and Cancer
}

\author{
David D. Roberts, ${ }^{1}$ Sukhbir Kaur, and Jeffrey S. Isenberg ${ }^{2}$
}

\begin{abstract}
Significance: In contrast to structural elements of the extracellular matrix, matricellular proteins appear transiently during development and injury responses, but their sustained expression can contribute to chronic disease. Through interactions with other matrix components and specific cell surface receptors, matricellular proteins regulate multiple signaling pathways, including those mediated by reactive oxygen and nitrogen species and $\mathrm{H}_{2} \mathrm{~S}$. Dysregulation of matricellular proteins contributes to the pathogenesis of vascular diseases and cancer. Defining the molecular mechanisms and receptors involved is revealing new therapeutic opportunities.

Recent Advances: Thrombospondin-1 (TSP1) regulates $\mathrm{NO}, \mathrm{H}_{2} \mathrm{~S}$, and superoxide production and signaling in several cell types. The TSP1 receptor CD47 plays a central role in inhibition of NO signaling, but other TSP1 receptors also modulate redox signaling. The matricellular protein $\mathrm{CCN} 1$ engages some of the same receptors to regulate redox signaling, and ADAMTS1 regulates NO signaling in Marfan syndrome. In addition to mediating matricellular protein signaling, redox signaling is emerging as an important pathway that controls the expression of several matricellular proteins.

Critical Issues: Redox signaling remains unexplored for many matricellular proteins. Their interactions with multiple cellular receptors remains an obstacle to defining signaling mechanisms, but improved transgenic models could overcome this barrier.

Future Directions: Therapeutics targeting the TSP1 receptor CD47 may have beneficial effects for treating cardiovascular disease and cancer and have recently entered clinical trials. Biomarkers are needed to assess their effects on redox signaling in patients and to evaluate how these contribute to their therapeutic efficacy and potential side effects. Antioxid. Redox Signal. 27, 874-911.
\end{abstract}

Keywords: thrombospondin-1, CD47, matricellular proteins, nitric oxide, reactive oxygen species, hydrogen sulfide

\section{Table of Contents}

I. Introduction

A. What are matricellular proteins?

B. Historical evidence linking matricellular proteins and redox signaling 876

II. Thrombospondin-1 and NO Signaling 877

A. Thrombospondin-1 structure and receptors

B. Thrombospondin-1 regulation of NO synthesis

C. Thrombospondin-1 regulation of soluble guanylate cyclase and downstream targets

1. Soluble guanylate cyclase

2. cGMP-dependent protein kinase

Reviewing Editors: Jennifer Collins, Gabor Csanyi, Yves Gorin, Jangho Kim, Herve Kovacic, and Merry Lindsey

\footnotetext{
${ }^{1}$ Laboratory of Pathology, Center for Cancer Research, National Cancer Institute, National Institutes of Health, Bethesda, Maryland.

${ }^{2}$ Division of Pulmonary, Allergy and Critical Care, Heart, Lung, Blood and Vascular Medicine Institute, University of Pittsburgh School of Medicine, Pittsburgh, Pennsylvania.
} 
D. Physiological functions of TSP1/CD47 regulation of NO signaling 880

$\begin{array}{lr}\text { 1. Platelet homeostasis } & 880\end{array}$

$\begin{array}{lr}\text { 2. Vascular perfusion } & 881\end{array}$

$\begin{array}{lr}3 . & 881\end{array}$

E. NO regulation of TSP1 expression 881

III. NO Signaling and Other Matricellular Proteins 882

A. NO signaling and other thrombospondins 882

1. Regulation of NO signaling $\quad 882$

2. Regulation of expression by NO 882

B. Regulation of iNOS-derived NO production and signaling 882

1. ADAMTS1 2882

2. Osteopontin and NOS2 signaling $\quad 883$

3. Regulation of other matricellular protein expression by NO 884

IV. Thrombospondin-1 Regulation of $\mathrm{H}_{2} \mathrm{~S}$ Biosynthesis and Signaling 884

A. Role of $\mathrm{H}_{2} \mathrm{~S}$ in T cell activation 884

B. TSP1 inhibition of $\mathrm{H}_{2} \mathrm{~S}$ biosynthesis in T cells 884

C. Potential role of TSP1 in other $\mathrm{H}_{2} \mathrm{~S}$ signaling 884

V. $\mathrm{H}_{2} \mathrm{~S}$ Regulation of Matricellular Protein Expression 884

A. Osteopontin

B. Tenascin C

C. Laminin- $\gamma 1$

VI. TSP1 Regulation of ROS

A. TSP1 and ROS signaling in inflammatory cells 887

1. Historical context $\quad 887$

2. Roles of TSP1 receptors $\quad 887$

3. Role of the CD47 counter-receptor $\operatorname{SIRP} \alpha \quad 888$

B. TSP1 and ROS signaling in vascular and renal cells 888

C. TSP1 and ROS signaling in vivo 890

VII. ROS Regulation by Other Matricellular Proteins 890

A. CCN1

B. Periostin $\quad 891$

C. Tenascin-C 891

D. Caveats 891

VIII. CD47 Regulation of Redox Homeostasis in Irradiated Cells 891

A. NO and radiosensitivity 891

B. CD47-dependent regulation of redox metabolites in irradiated cells 892

C. CD47 regulation of mitochondrial redox 893

IX. TSP1/CD47 Regulation of Stem Cell and Tissue Self-Renewal 893

A. Redox signaling in stem cells 893

B. TSP1 and CD47 in stem cell self-renewal and tissue regeneration 893

X. Therapeutic Opportunities to Improve Redox Signaling 895

A. Dysregulation of NO signaling by TSP1/CD47 in clinical disease 895

1. Association of elevated TSP1 with impaired NO signaling in cardiovascular disease 895

2. Genetic dysregulation of TSP1 in cardiovascular disease $\quad 895$

3. Circulating TSP1 as a biomarker of redox dysregulation 895

4. TSP1 in pulmonary disease $\quad 895$

5. TSP1 and heart disease $\quad 896$

6. TSP1 in aging 896

B. Therapeutic targeting of the TSP1 receptor CD47 896

1. Applications for cardiovascular disease 896

2. Therapeutic applications for cancer $\quad 897$

XI. Conclusions and Outlook $\quad 897$

\section{Introduction}

\section{A. What are matricellular proteins?}

$\mathbf{M}$ ATRICELLULAR PROTEINS ARE a functional family of secreted proteins that was first described by Paul Bornstein in 1995 (16). Matricellular proteins are not constitutive structural elements of extracellular matrix, rather they function as regulatory molecules that are present in extracellular matrix at specific times during development, tissue remodeling, and responses to injury or chronic disease states. Thrombospondin-1 (TSP1) is a prototypical member of this family, which has grown to include four additional thrombospondins (TSPs), tenascins, periostin, the secreted protein acidic and rich in cysteine (SPARC) family, the five 
small integrin-binding ligand N-linked glycoprotein (SIBLING) family members, the CCN (CYR61, CTGF [connective tissue growth factor], and NOV [nephroblastoma overexpressed gene]) family, and other thrombospondinrepeat (TSR)-containing proteins such as the a disintegrin and metalloproteinase with thrombospondin motifs (ADAMTS) family $(142,169,209)$ (Fig. 1). Most matricellular proteins are multidomain proteins, whereas osteopontin, the prototypical member of the SIBLING family, is a small intrinsically disordered protein (252).

The first members of the TSP and SPARC families emerged in early metazoa and underwent gene duplications that diverged into their current family members (169). Gene deletion studies indicate relatively little overlap in functions of the five TSPs $(3,196)$, although some receptor interactions are conserved between family members. Integrins are the only known receptor class interacting with the primordial TSP in insects that remains functional for the modern proteins (26). Modern trimeric forms of TSP1 and TSP2 trace back at least to fish. TSP1 and TSP2 share $>80 \%$ homology between their C-terminal domains, which mediates TSP1 binding to CD47, and homology decreases to $25 \%$ between their N-terminal domains. The TSP1 receptor CD47 originated in early land-dwelling vertebrates, roughly coincident

\section{Thrombospondin family}
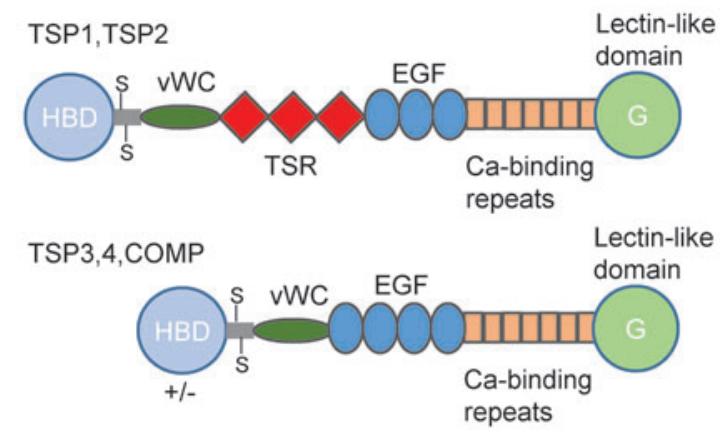

SPARC family
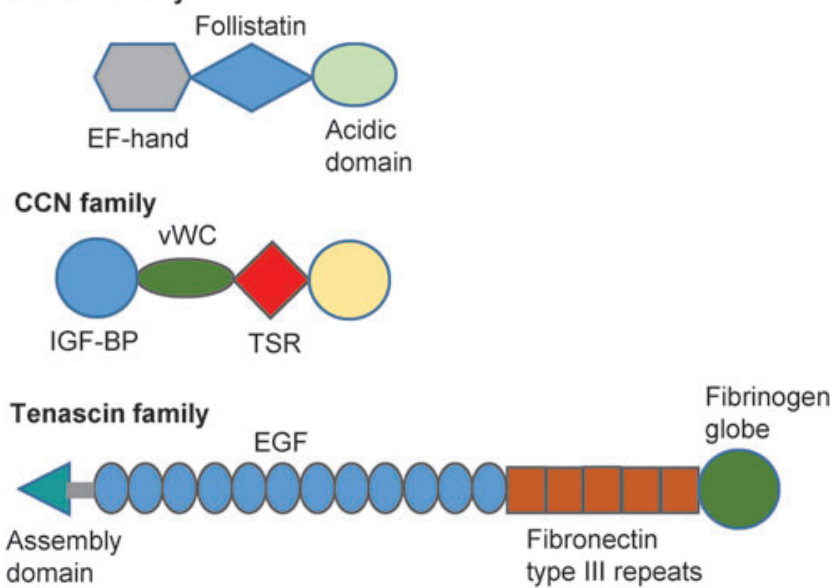

ADAMTS family

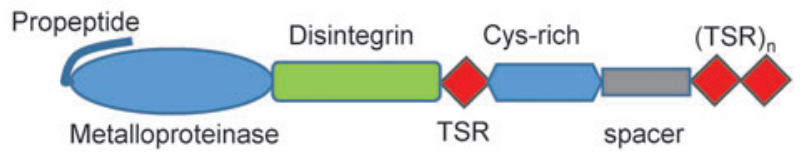

with the appearance of endothelial nitric oxide synthase (eNOS/NOS3) (63).

In common with classical extracellular matrix proteins, most matricellular proteins contain several functional domains that mediate interactions with other extracellular matrix components and with specific receptors. This capacity for multifarious interactions has contributed to confusion in the literature because a given matricellular protein can elicit opposing responses in cells that express different subsets of its receptors, and responses of a given cell type can change over time as the expression of receptors and composition of the surrounding extracellular matrix microenvironment respond to external stimuli.

With a few exceptions, matricellular protein genes are generally not essential for life. Phenotypes of null mutants may only become evident when mice are subjected to a specific stress that induces matricellular protein expression or signaling. Despite these challenges, studies of matricellular protein function in transgenic mouse models and identification of genetic diseases linked to structural and regulatory mutations in specific matricellular protein genes have proven that they play important roles in physiology and pathophysiology $(126,142,171,243)$.

\section{B. Historical evidence linking matricellular proteins and redox signaling}

Earlier studies of TSP1 provided clues that altered redox signaling could mediate some cellular responses controlled

FIG. 1. Matricellular protein families. The thrombospondin family in vertebrates consists of five members. TSP1 and TSP2 are trimeric proteins linked through disulfides in the coiled-coil region that follows the N-terminal HBDs. TSP1 and TSP2 contain three TSRs, which are absent in TSP3, TSP4, and COMP. The latter constitute a second subfamily of homopentamers linked through their coiledcoil regions. A HBD is absent in COMP. The SPARC family consists of SPARC, SPARC-like 1/Hevin, two SPARC-related modular calcium binding proteins (SMOC1 and SMOC2), follistatin-like 1, and three PARC/osteonectin, cwcv, and kazal-like domains proteoglycan proteins (SPOCK1-3). The follistatin and acidic domains are conserved among the family members, but the EF-hand of SPARC is not conserved. The CCN family consists of six members: CCN1, CYR61 (cysteine-rich angiogenic protein 61); CCN2, CTGF; CCN3, NOV; CCN4, WISP1 (WNT1inducible signaling pathway protein-1); CCN5, WISP2 (WNT1-inducible signaling pathway protein-2); and CCN6, WISP3 (WNT1-inducible signaling pathway protein-3). Tenascins are a family of hexameric proteins consisting of tenascin- $\mathrm{C}$, tenascin- $\mathrm{R}$, tenascin- $\mathrm{X}$, and tenascin-W. The number of EGF-like repeats and fibronectin type 3 repeats are variable. The ADAMTS family contains 19 members with variable number of TSRs. ADAMTS, a disintegrin and metalloproteinase with thrombospondin motifs; CCN, CYR61, CTGF (connective tissue growth factor), and NOV (nephroblastoma overexpressed gene); COMP, cartilage oligomeric matrix protein; EF-hand, helix-loop-helix calciumbinding domain; EGF, epidermal growth factor; HBDs, heparin-binding domains; SPARC, secreted protein acidic and rich in cysteine; TSR, type 1 thrombospondin repeat. To see this illustration in color, the reader is referred to the web version of this article at www.liebertpub.com/ars 
by this protein. Immobilized TSP1 inhibited the ability of tumor necrosis factor- $\alpha(\mathrm{TNF} \alpha)$ to induce an oxidative burst response in polymorphonuclear cells (PMN) (179). Conversely, TSP1 enhanced superoxide production by neutrophils stimulated with the chemoattractant formyl-MetLeu-Phe (fMLP), and fMLP upregulated the binding of TSP1 to presumed receptors on these cells (257).

In retrospect, several earlier studies suggested an association between TSP1 and nitric oxide signaling. The ability of TSP1 to disrupt focal adhesions in vascular smooth muscle cells (VSMCs) required the activity of cGMP-dependent protein kinase (170), and treatment with TSP1 acutely decreased cGMP levels in a human melanoma cell line (68). A specific role of TSP1 in regulating NO-induced synthesis of cGMP was first identified in endothelial cells (93), and subsequent studies have revealed a broad role for TSP1 signaling through its receptor CD47 to adversely regulate cytoprotective cellular redox signaling (243).

Here we review studies that have established specific mechanisms by which TSP1 and other matricellular proteins including CCN1, periostin, osteopontin, and ADAMTS1 regulate the production of nitric oxide, $\mathrm{H}_{2} \mathrm{~S}$, superoxide, and other reactive oxygen species (ROS) (Fig. 2A), and TSP1, conversely, regulates cellular redox signaling downstream of $\mathrm{NO}$ and $\mathrm{H}_{2} \mathrm{~S}$ (Fig. 2B).

Redox and hypoxia signaling, in turn, regulate the expression, secretion, post-translational modification, and extracellular interactions of matricellular and other extracellular matrix proteins (Fig. 2C), which is discussed in more detail elsewhere in this Forum $(34,81,119,124,128,178)$. We review the emerging physiological functions of this regulation and the evidence that pathological dysregulation of matricellular protein expression contributes to acute and chronic disease states that are characterized by insufficient NO signaling and/or increased oxidative stress. Finally, we consider the progress made toward developing therapeutic approaches to restore NO function and other aspects of redox homeostasis by targeting the TSP1 receptor CD47.

\section{Thrombospondin-1 and NO Signaling}

\section{A. Thrombospondin-1 structure and receptors}

TSP1 is a trimeric protein consisting of identical subunits linked covalently through intersubunit disulfide bonds in the oligomerization domain (Fig. 3). The N-terminal domain of each subunit consists of a globular heparin-binding domain that

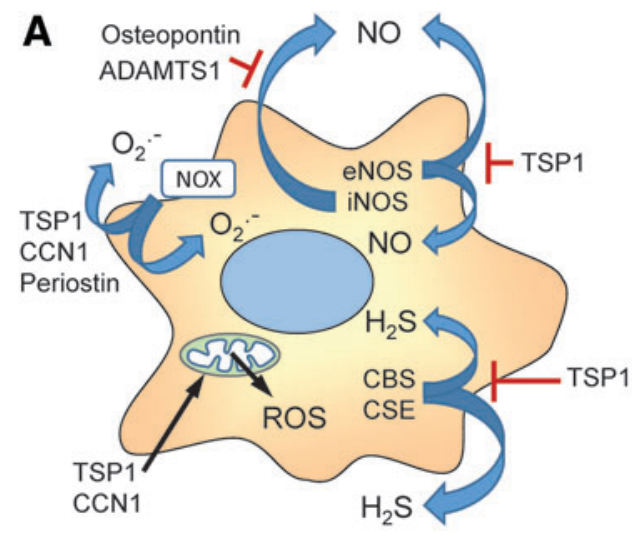

B
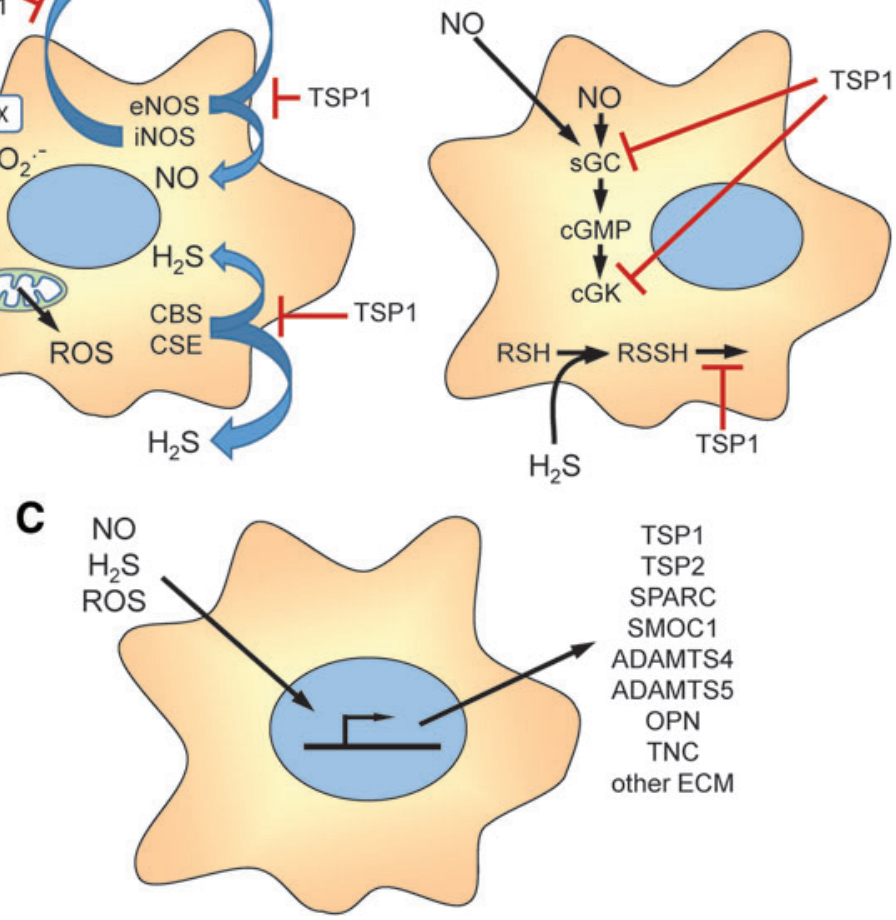

FIG. 2. Overview of matricellular protein functions in cellular redox signaling. (A) Several matricellular proteins regulate the biosynthesis of redox molecules that mediate cell autonomous and paracellular signaling. TSP1 limits the activation of eNOS. TSP1, CCN1, and periostin regulate the activity of NADPH oxidases (Nox) that produce intracellular and extracellular superoxide $\left(\mathrm{O}_{2}{ }^{--}\right)$. TSP1 and CCN1 also regulate mitochondrial production of ROS. TSP1 regulates the biosynthesis of $\mathrm{H}_{2} \mathrm{~S}$ by controlling the expression of CBS and CSE. ADAMTS1 and osteopontin regulate NO production by controlling the expression of iNOS. (B) TSP1 regulates cellular responses to endogenous or exogenous NO by inhibiting the activation of sGC and cGK and cellular responses to $\mathrm{H}_{2} \mathrm{~S}$ by inhibiting known targets of protein sulfhydration and others that remain to be identified. (C) Redox signaling, in turn, regulates the gene expression, post-translational modification, secretion, and extracellular interactions of the indicated matricellular proteins and other extracellular matrix proteins. CBS, cystathionine $\beta$-synthase; cGMP; cGK, cGMP-dependent protein kinase; CSE, cystathionine $\gamma$-lyase; eNOS, endothelial nitric oxide synthase; iNOS, inducible nitric oxide synthase; ROS, reactive oxygen species; sGC, soluble guanylate cyclase. To see this illustration in color, the reader is referred to the web version of this article at www.liebertpub.com/ars 
interacts with several $\beta 1$-integrins, sulfated glycoconjugates, several hyaluronan-binding proteins, and calreticulin. This is followed by a coiled-coil oligomerization domain, a von Willebrand $\mathrm{C}$ domain, three TSRs, three epidermal growth factor (EGF)-like repeats, seven calcium-binding repeats, and the Cterminal lectin-like G-domain (Fig. 3) (23). The TSRs mediate binding of TSP1 to the cell surface receptor CD36 and to transforming growth factor- $\beta 1$ (TGF $\beta$ ). Additional low-affinity integrin binding sites are present in the TSRs and EGF repeats (21), and the EGF repeats mediate binding to the gabapentin receptor $\alpha 2 \delta 1$ (49). In the presence of physiological $\mathrm{Ca}^{2+}$ concentrations, the calcium-binding repeats wrap around the $\mathrm{G}$ domain to form the "signature domain" of TSP1 (23). The signature domain mediates binding of TSP1 to CD47 and to stromal interaction molecule 1 (STIM1) (48). The last Ca repeat also contains a RGD sequence that can be recognized by $\alpha \mathrm{v} \beta 3$ integrin but is cryptic in the Ca-replete protein (259).

Specific peptide sequences have been identified that are involved in binding of TSP1 to several of its receptors. Although two TSP1 peptides containing a Val-Val-Met (VVM) consensus sequence were initially identified as potential CD47 binding sites and could be used to affinity purify CD47 $(31,46,58)$, the crystal structure of the C-terminal domain of TSP1 indicated that the VVM sequences are not exposed to solvent (121). A potential conformation change that exposes one of the VVM sequences has been proposed based on dynamic modeling studies (54), but structure function and mutagenesis studies have not been performed to determine whether the VVM sequences are involved in binding of native TSP1 to CD47. Furthermore, both TSP1-derived CD47 binding peptides have well-documented CD47-independent activities, and they cannot be used as reliable surrogates for TSP1 to investigate CD47 signaling $(9,129,279)$.

In addition to the undefined protein-protein interaction, binding of TSP1 to CD47 requires post-translational modification of CD47 with a heparan sulfate glycosaminoglycan at $\operatorname{Ser}^{64}$ (110). Because glycosylation can be cell-type specific, CD47 may vary in its ability to interact with TSP1 to control NO signaling. Such variation in functional activity to control

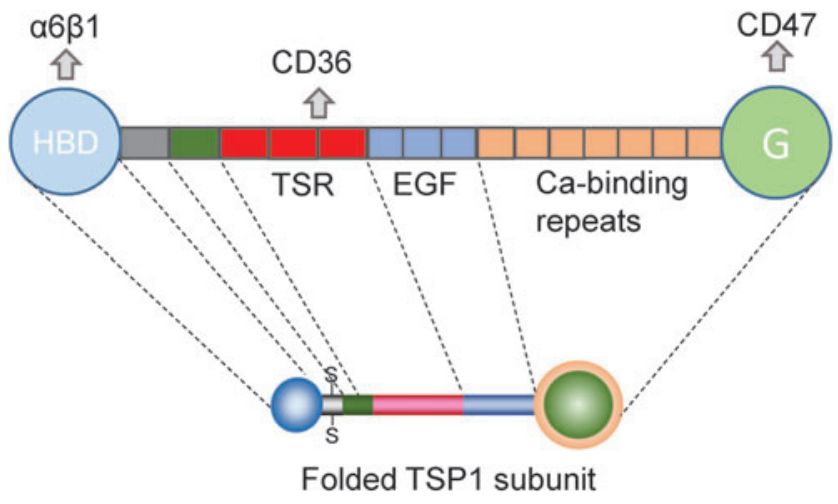

FIG. 3. Thrombospondin-1 structural domains and receptor binding sites. TSP1 is a homotrimer of $\sim 150 \mathrm{kDa}$ subunits linked by interchain disulfide bonds. In each folded TSP1 subunit, the Ca-binding repeats wrap around the Cterminal $\mathrm{G}$ domain to form the signature domain of TSP1. Binding domains for TSP1 receptors that regulate redox signaling are indicated. To see this illustration in color, the reader is referred to the web version of this article at www .liebertpub.com/ars
NO signaling has been reported in a T cell line (202), but further studies are needed to define the molecular mechanism.

\section{B. Thrombospondin-1 regulation of NO synthesis}

TSP1 regulates both the production of NO in vascular cells (Fig. 4) and responses of such cells to exogenous NO mediated by soluble guanylyl cyclase (Fig. 5). Depending on the cell type, TSP1 can regulate NO production by several mechanisms. In endothelial cells, TSP1 signaling inhibits the basal and acetylcholine-stimulated conversion of arginine to NO and citrulline by eNOS, whereas $T h b s 1^{-1-}$ and $C d 47^{-1}$ murine endothelial cells display increased basal eNOS activity compared with wild type (WT) cells (10). This result was subsequently confirmed in choroidal endothelial cells (53). Choroidal capillary endothelial cells from the eyes of Thbs $1^{-/-}$mice had elevated phosphorylation of eNOS relative to WT cells, and intracellular NO in the null cells assessed using 4-amino-5-methylamino-2,7-difluorofluorescein (DAF) was sixfold higher than in WT cells. One should bear in mind that DAF is primarily detecting an oxidative product of NO rather than NO itself (176).

eNOS is a highly regulated enzyme (55), and CD47 controls several of the pathways known to regulate eNOS

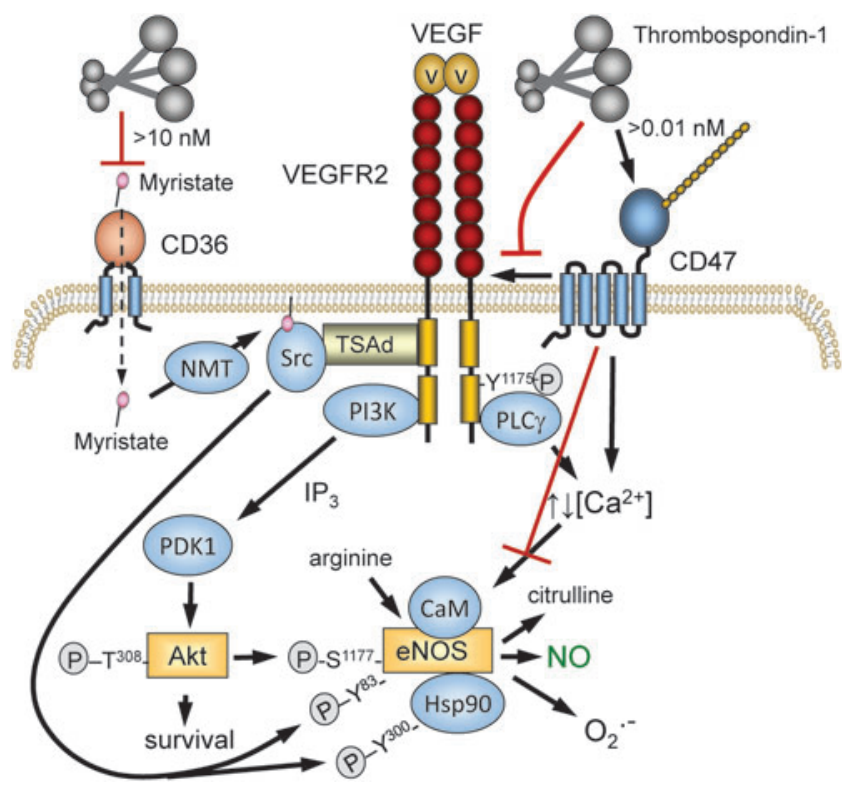

FIG. 4. TSP1 regulation of NO synthesis. TSP1 binding to its receptor $\mathrm{CD} 47$ on the plasma membrane transduces signals by dissociating its lateral interaction with VEGFR2, by altering cytoplasmic calcium, and by other undefined pathways. Signaling downstream of VEGFR2 through Src and the PI3kinase/Akt pathway controls the phosphorylation of eNOS at several sites and the phosphorylation of HSP90 associated with eNOS. TSP1, via CD47, also limits eNOS activation separate from effects mediated through VEGFR2. Altered cytoplasmic calcium regulates the binding of calmodulin, which controls the activity of eNOS and its production of NO versus $\mathrm{O}_{2}{ }^{\bullet-}$. At higher concentrations $(>10 \mathrm{n} M)$, TSP1 inhibits CD36mediated uptake of myristic acid (87), limiting substrate for NMT to acylate Src. This modification is necessary for optimal tyrosine phosphorylation of eNOS. NMT, N-myristoyl transferase; VEGFR2, vascular endothelial growth factor receptor2. To see this illustration in color, the reader is referred to the web version of this article at www.liebertpub.com/ars 


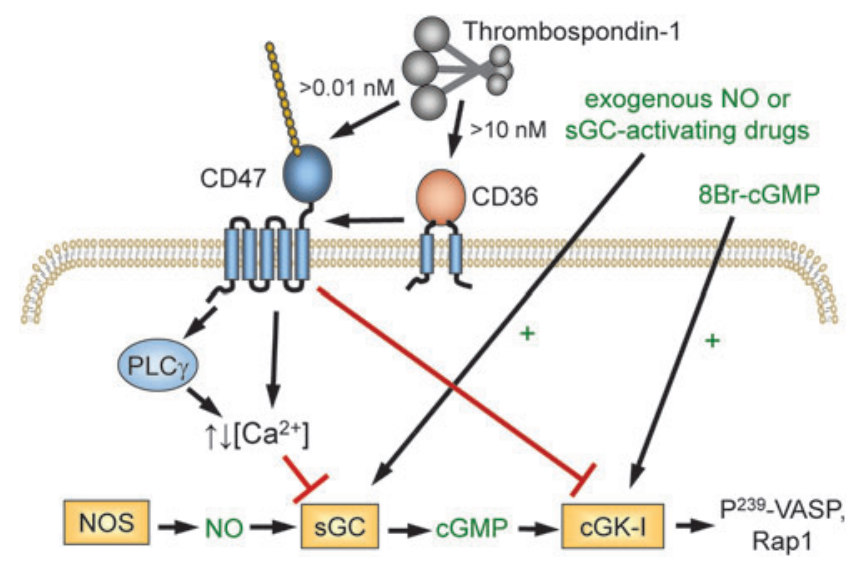

FIG. 5. TSP1 regulation of cellular responses to NO. TSP1 binding to CD47 redundantly inhibits signaling induced by endogenous or exogenous NO at the level of sGC and inhibits cGMP-mediated activation of cGK. In platelets, this limits phosphorylation of VASP and Rap1-mediated integrin activation. Picomolar concentrations of TSP1 are sufficient to inhibit sGC via CD47 in vascular cells, whereas $>10 \mathrm{n} M$ TSP1 can engage CD36 to inhibit sGC activation in a CD47-dependent manner (92). VASP, vasodilator-stimulated phosphoprotein. To see this illustration in color, the reader is referred to the web version of this article at www.liebertpub.com/ars

activity. CD47 constitutively associates with the tyrosine kinase vascular endothelial growth factor receptor-2 (VEGFR2) in endothelial cells and T cells (111). TSP1 binding to CD47 displaces CD47 from VEGFR2 and inhibits VEGFR2 autophosphorylation. Activated VEGFR2 controls several downstream pathways that control eNOS activation (Fig. 4). TSP1 inhibits vascular endothelial growth factor (VEGF)-stimulated phosphorylation of Akt at $\operatorname{Ser}^{473}$ (111). The PI-3-kinase/Akt pathway activates eNOS by phosphorylation of $\operatorname{Ser}^{117}$ on eNOS (55), and TSP1 inhibits this phosphorylation (10). TSP1 inhibits VEGFR2-mediated phosphorylation of Src kinase at $\mathrm{Tyr}^{416}$ in a CD47-dependent manner (108). Src phosphorylates Tyr residues on eNOS and the associated Hsp90 that regulate eNOS activity, and TSP1 inhibits acetylcholine-mediated coassociation of eNOS and Hsp90 (10).

VEGFR2-mediated activation of phospholipase $\mathrm{C} \gamma$ controls cytoplasmic calcium levels, which activate eNOS by inducing calmodulin binding (55). TSP1 signaling via CD47 has been reported to regulate calcium signaling in endothelial cells and $\mathrm{T}$ cells, but in opposing directions (10, 202). Therefore, the coupling between CD47 ligation by TSP1 and cytoplasmic calcium levels may be cell-type specific and may depend on whether ligand binding induces clustering of CD47 (155). Acylation by the fatty acid myristic acid is also important for maximal eNOS function $(14,143)$. In endothelial cells, TSP1, TSP1-derived peptides, and a CD36-binding TSP1 mimetic further limit eNOS activity by restricting myristic acid uptake through the fatty acid translocase and TSP1 receptor CD36 (87, 97) (Fig. 4), although the in vivo relevance of this remains to be determined.

Notably, Fei et al. also reported that inducible nitric oxide synthase (iNOS) expression was elevated in $\mathrm{Thbsl}^{-/}$choroidal endothelial cells relative to WT cells, suggesting that negative regulation of NO synthesis by TSP1 is not limited to eNOS (53), although it was not determined whether these findings in null cells were reversed by exogenous TSP1.
Phosphorylation of STAT3 was markedly elevated in the Thbs ${ }^{-/}$cells, which was suggested to mediate the upregulation of iNOS, but additional studies are needed to confirm this mechanism. Negative regulation of STAT3 phosphorylation by TSP1 was also reported in colon tissues (69). Phosphorylation of STAT3 at $\mathrm{Ser}^{727}$ was increased twofold in $\mathrm{Thbs} \mathrm{I}^{-/}$ colon tissue, and this was inhibited by a TSP1 mimetic designed to engage the TSP1 receptor CD36 (ABT898). Functional inhibition of STAT3 by TSP1 was further indicated by increased plasma interleukin (IL)-6 levels in the $T h b s 1^{-/-}$mice.

\section{Thrombospondin-1 regulation of soluble guanylate cyclase and downstream targets}

1. Soluble guanylate cyclase. TSP1/CD47 signaling also controls signaling downstream of $\mathrm{NO}$ by limiting the activation of the primary NO sensor/receptor soluble guanylate cyclase (sGC) (Fig. 5) (93). This opens the potential for controlling signaling by NO produced by all three nitric oxide synthase (NOS) isoforms and for regulating paracellular signaling wherein NO produced by one cell diffuses into an adjacent cell.

The mechanism by which CD47 signaling inactivates sGC remains to be fully characterized, but some details are known. Inhibition of $\mathrm{sGC}$ in immortalized $\mathrm{T}$ cells by a recombinant $\mathrm{C}$ terminal fragment of TSP1 $(\mathrm{E} 3 \mathrm{CaG} 1)$ is mediated by increased cytoplasmic $\mathrm{Ca}^{2+}$, and elevation of $\mathrm{Ca}^{2+}$ after treatment with angiotensin-II resulted in a similar inhibition (202). The NOinsensitive state of sGC persisted in cell-free lysates and was prevented by the protein kinase inhibitor staurosporine, which suggests that TSP1/CD47 signaling induces an inhibitory phosphorylation of sGC. Inhibition of sGC by TSP1 was first reported in endothelial cells, but subsequent studies have confirmed this result in VSMCs (96), platelets $(95,162), \mathrm{T}$ cells (202), and macrophages (206) of human and nonhuman origin, broadly implicating TSP1 as limiter of sGC activity.

The initial studies in endothelial cells suggested that TSP1 regulates $\mathrm{sGC}$ in a CD36-dependent manner (93). A recombinant type 1 repeats construct from TSP1 inhibited NOinduced chemotaxis of human umbilical vein endothelial cells and cGMP accumulation in the cells, whereas a recombinant N-terminal region of TSP1 that engages integrins, calreticulin/low-density lipoprotein receptor-related protein1 (LRP1), and heparan sulfate proteoglycans did not. Furthermore, the CD36 antibody $\mathrm{SM} \Phi$, which is a reported agonist of CD36 signaling (37), significantly inhibited NOstimulated proliferation of human umbilical vein endothelial cells and dermal microvascular endothelial cells and inhibited NO-induced cGMP accumulation. Similar inhibition of NO responses by the CD36-binding domain of TSP1 and the CD36 antibody was reported in VSMCs (96).

These studies established that engaging CD36 is sufficient to inhibit NO-stimulated activation of sGC. However, additional studies challenged the hypothesis that CD36 directly mediates this inhibitory activity of TSP1 (92). NO-stimulated vascular outgrowth was inhibited by TSP1 to the same extent in skeletal muscle explants from WT and $C d 36^{-/-}$mice. TSP1 also inhibited NO-stimulated adhesion of VSMCs from $C d 36^{-1-}$ mice, and NO-stimulated accumulation of cGMP in these cells. Therefore, engaging CD36 is sufficient but not necessary to inhibit sGC activity.

In contrast, the TSP1 receptor CD47 is both necessary and sufficient to mediate inhibition of NO signaling by TSP1 
(92). NO-stimulated vascular outgrowth from muscle tissue explants from $C d 47^{-1}$ mice was completely insensitive to inhibition by TSP1. Ligation of CD47 by two CD47-binding peptides derived from TSP1 or by recombinant E3CaG1, containing the CD47 binding domain of TSP1, potently inhibited cGMP accumulation and functional responses to NO signaling. In the absence of exogenous TSP1, ligation of CD47 by the CD47 antibodies C1Km1 and B6H12 also inhibited NO signaling. This inhibitory activity of B6H12 is notable because B6H12 inhibits TSP1 binding to CD47 (84), suggesting that this antibody can, under TSP1-depleted conditions, act as a mimic of TSP1 and activate CD47 signaling to inhibit NO stimulation of sGC independent of its ability to prevent TSP1 binding to CD47.

Further examination of the roles of CD36 versus CD47 revealed that CD47 is also necessary for the inhibitory activity of CD36 ligands, but CD36 is not necessary for the inhibitory activity of CD47 ligands (92). A CD47-binding peptide from TSP1 and a recombinant C-terminal domain of TSP1 inhibited NO-stimulated cGMP accumulation in VSMCs from $C d 36^{-1-}$ mice, but a CD36 binding peptide did not inhibit cGMP accumulation in VSMCs from $\mathrm{Cd} 47^{-}$ mice. Finally, basal and NO-stimulated cGMP levels were elevated relative to WT in $C d 47^{-1}$ cells but not in $C d 36^{-1-}$ cells. Therefore, CD47 is the necessary and sufficient receptor for mediating the inhibitory effect of TSP1 on NO-mediated activation of sGC. CD47 is also necessary for CD36-mediated inhibition of this pathway, but the molecular mechanism of this receptor cross-talk remains to be determined.

From a physiological perspective, another important distinction between the CD36 and CD47 pathways is their TSP1 dose dependence. Inhibition through CD47 is observed at 10 $\mathrm{p} M$ TSP1, but inhibition through CD36 requires $10 \mathrm{n} M$ TSP1. Circulating TSP1 levels in healthy individuals are 100-200 $\mathrm{p} M$. Therefore, physiological TSP1 concentrations are sufficient to tonically limit sGC activation in vascular cells through CD47 but not through CD36. The higher relative affinity of TSP1 for signaling through CD47 also has pathophysiological significance, which is demonstrated by the observation that Thbs $1^{-/-}$mice and $C d 47^{\prime-}$ mice show similar resistance to ischemic injuries and vascular remodeling after ischemic injury, but $C d 36^{-1-}$ mice rather than exhibiting an advantage over WT mice when subjected to the same ischemic injuries tended to be more sensitive to injury $(90,94)$.

A major focus of the pharmaceutical industry has been to develop drugs to overcome impaired NO signaling by directly activating sGC. TSP1/CD47 signaling in platelets inhibits sGC activation by the heme-dependent sGC activators YC-1 and BAY 41-2272 and the heme-independent activator meso-porphyrin IX (162). Because TSP1 expression is now known to be elevated in many of the diseases for which sGC activators could be useful, such pathological elevation in extracellular TSP1 levels may limit the efficacy of drugs that target sGC. However, YC-1 and BAY 41-2272 could overcome sGC inhibition by E3CaG1 in Jurkat T cells, suggesting that such regulation of sGC by TSP1 may be context dependent (202). However, the ability of these drugs to overcome TSP1 inhibition of sGC in primary vascular cells and in vivo remains to be determined.

CD47-dependent inhibition of sGC activation was also observed when cells were exposed to $\beta$-amyloid (163). $\beta$ Amyloid interacts with the TSP1 receptor CD36 but not with CD47. $\beta$-Amyloid inhibition also extends to activation of
sGC by BAY 41-2272. The NO inhibitory activity of $\beta$ amyloid is maintained in $T h b s 1^{-/}$endothelial cells, indicating that this effect is TSP1 independent (163). Given the role of $\beta$-amyloid in certain neurodegenerative processes, these findings in vascular cells invite further inquiry.

2. cGMP-dependent protein kinase. TSP1 also inhibited endothelial cell adhesion stimulated by 8 -Br-cGMP, indicating that TSP1 has a second inhibitory target downstream of sGC (93). TSP1 limited the antithrombotic activity of NO and the cell-permeable cyclic analogue 8 -Br-cGMP in WT platelets (95) (Fig. 5). 8-Br-cGMP activates cGMP-dependent protein kinase, and this was identified as the downstream target of CD47 signaling based on the ability of TSP1 to inhibit phosphorylation of the cGMP-dependent protein kinase-I selective substrate Arg-Lys-Arg-Ser-Arg-Ala-Glu stimulated by NO or by 8-Br-cGMP.

TSP1 also inhibited phosphorylation of the cGMP-dependent protein kinase target protein vasodilator-stimulated phosphoprotein (VASP) at $\operatorname{Ser}^{239}$ that was induced by 8 -Br-cGMP. The downstream activation of the GTPase Rap1 was also inhibited in a CD47-dependent manner. The molecular mechanism by which CD47 inhibits cGMP-dependent protein kinase remains to be determined. To summarize, TSP1 via CD47 acts redundantly on the canonical NO pathway, limiting production, receptor activation, and cGMP signaling.

\section{Physiological functions of TSP1/CD47 regulation of NO signaling}

1. Platelet homeostasis. NO is a physiological inhibitor of platelet activation and aggregation. NO is produced by eNOS expressed in platelets and vascular endothelium (199). The resulting tonic inhibition of platelet activation contributes to preventing thrombosis but must be suppressed for platelets to effectively limit bleeding at sites of vascular injury. Because TSP1 is a major protein in platelet $\alpha$-granules and is rapidly released after their activation by thrombin, it was an obvious candidate for mediating this function.

Earlier studies reported contradictory evidence regarding the role of TSP1 in platelet activation $(135,280)$, and the first evaluation of platelet function in $T h b s 1^{-1-}$ mice reported normal hemostatic function as assessed by tail bleeding and thrombin activation of washed platelets (127). Therefore, TSP1 was concluded to not be required for normal platelet function. However, the buffer used to assess activation of the washed platelets did not provide the arginine required for platelet eNOS to maintain physiological NO concentrations. When this experiment was repeated in the presence of either arginine or an exogenous NO donor, Thbs ${ }^{-/}$and $C d 47^{\prime-}$ platelets showed clear defects in thrombin-mediated activation (95). Correspondingly, cGMP levels were elevated in Thbs $1^{-/}$platelets but restored to normal levels by addition of exogenous TSP1 or a CD47-binding peptide. Concentrations of TSP1 that limited platelet NO signaling were comparable with those that circulate in plasma.

Consistent with its capacity to engage in multiple interactions, other studies have revealed additional physiological functions of TSP1 in platelet hemostasis that are independent of NO signaling (13), but an NO-dependent prothrombotic activity is one clear physiological function of platelet TSP1. This function is consistent with the evolutionary record. The presumed gene 
duplication that gave rise to TSP1 in tetrapods (2) was followed soon thereafter in amphibians and higher land-dwelling vertebrates by the gene duplication that yielded eNOS to enable local vascular control of NO production in high pressure circulatory systems (274) and the appearance of CD47, presumably by a recombination event that joined a primordial $\mathrm{IgV}$ domain with a presenilin transmembrane domain $(208,210)$.

2. Vascular perfusion. Functional magnetic resonance imaging of WT and Thbs ${ }^{-/}$mice provided the first evidence that TSP1 functions as a physiological regulator of NO in the local control of tissue vascular perfusion (85). Functional imaging of blood oxygenation in the proximate hind limb muscle of mice was assessed after intestinal administration of a rapidly releasing NO donor. The resulting increase in per-

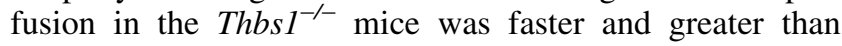
(roughly double) that observed in WT mice. This demonstrated that endogenous TSP1 in the vasculature constitutively limits responsiveness to NO-mediated vasodilation by $\sim 50 \%$. cGMP levels were correspondingly elevated in Thbs $1^{-1-}$ tissues and VSMCs.

Mechanistic studies demonstrated that TSP1 blocked the dephosphorylation of myosin light chain-2 induced by treating these cells with $\mathrm{NO}$ and thereby promoted F-actin assembly and contraction of the smooth muscle cells. Notably, the elevated tissue cGMP levels found in young male Thbs ${ }^{-/}$mice persisted as those mice were aged to 12-16 months, but cGMP levels fell significantly with age in male WT mice (86), consistent with the reported elevations in tissue TSP1 and CD47 levels with aging (19, 105, 207, 213). Thus, TSP1 physiologically opposes the activity of NO to regulate vascular tone, but this balance becomes perturbed with increasing age. The reasons for the progressive and, in regard to NO signaling, maladaptive upregulation of TSP1 with age are not known.

3. Central blood pressure. Analysis of blood pressure using telemetry implants in young $T h b s 1^{-1-}$ and $C d 47^{-1}$ mice revealed that the physiological regulation by this pathway extends to control of central blood pressure (91). Thbs $1^{-/-}$ mice have decreased pulse pressure than WT mice, and during the active period of their diurnal cycle they exhibited increases in heart rate and central diastolic and mean arterial blood pressure. $C d 47^{-1}$ mice have normal pulse pressure but lower resting mean arterial pressure, systolic blood pressure, and diastolic blood pressure than WT mice (10). Further studies of responses to vasoactive agents in the mice and isolated perfused vessels confirmed that endogenous TSP1 in the vessels and in circulation functions as a pressor agent supporting blood pressure.

Loss of this pressor activity in $T h b s 1^{-1-}$ and $C d 47^{--}$mice increases the sensitivity of these mice to pharmacological challenges that impair blood pressure homeostasis, including isoflurane anesthesia, nitrovasodilators, and chemical sympathectomy with hexamethonium chloride (91), suggesting a major role for the autonomic outflow track in stabilizing blood pressure in null animals lacking the supporting role of the TSP1/CD47 axis. Therefore, in healthy young animals, TSP1 and CD47 play relatively minor roles in blood pressure homeostasis at rest, but their function is more important for cardiovascular responses required for normal activity and to adapt to stress conditions.

\section{E. NO regulation of TSP1 expression}

In parallel with the developing understanding that TSP1 regulates NO signaling, evidence was accumulating suggesting a negative feedback loop, wherein NO controls expression of TSP1. Indirect evidence for NO inhibition of TSP1 expression was first provided by studies in endothelial cells. Endothelial cells treated with the arginine analogue $\mathrm{L}_{-} \mathrm{N}^{\mathrm{G}}$ nitroarginine methyl ester (L-NAME) to suppress endogenous NO production displayed increased TSP1 expression (193). Additional studies revealed a more complex regulation of TSP1 by NO in human umbilical vein endothelial cells (205).

Treatment of human umbilical vein endothelial cells with exogenous NO using $0.1-1 \mu M$ diethyltriamine NONOate (DETA/NO) suppressed TSP1 mRNA and protein expression at 2 and $24 \mathrm{~h}$, respectively. Inhibition could be reversed by treating cells with the sGC inhibitor $1 \mathrm{H}-[1,2,4]$ oxadiazole[4,3a]quinoxalin-1-one (ODQ, $\mathrm{IC}_{50}=20 \mathrm{n} M$ ). This is consistent with the finding that inhibition of glucose-induced TSP1 expression in mesangial cells by an NO donor was reversed by ODQ and by the inhibitor of cGMP-dependent protein kinase Rp-8-pCPTcGMPS (291). Constitutive expression of cGMP-dependent protein kinase in mesangial cells also prevented induction of TSP1 expression in mesangial cells (293). Therefore, inhibition of TSP1 expression in mesangial and endothelial cells by nanomolar concentrations of exogenous NO is mediated by sGC.

In a rat model of mesangial proliferative glomerulonephritis, oral administration of a phosphodiesterase- 5 inhibitor, to increase the half-life of cGMP, resulted in decreased renal TSP1 expression (76). The mitogen-activated protein kinase kinase (MEK) inhibitor U0126 (1,4-diamino-2,3dicyano-1,4-bis(o-aminophenylmercapto)butadiene) partially reversed low dose NO-mediated inhibition of TSP1 mRNA and protein expression in human umbilical vein endothelial cells, indicating that the MEK/extracellular-regulated protein kinase (ERK) pathway is also involved in negative regulating TSP1 expression (205). Consistent with this hypothesis, addition of L-arginine to the medium increased ERK phosphorylation, and L-NAME inhibited ERK phosphorylation in human umbilical vein endothelial cells.

DETA/NO concentrations between 1 and $100 \mu M$ modestly increased TSP1 protein expression in human umbilical vein endothelial cells, whereas $1000 \mu M$ DETA/NO strongly suppressed TSP1 expression, suggesting a triphasic regulation of TSP1 expression by NO (205). The inhibition of TSP1 expression at $1000 \mu M$ DETA/NO coincided with increased phosphorylation of p53 at $\operatorname{Ser}^{15}$ and increased expression of MAP kinase phosphatase-1 (MKP1/DUSP1). Oxidative stress induces MKP1/DUSP1 expression in a p53-dependent manner (146), and both alterations are likely mediated by reactive nitrogen species (RNS) rather than directly by NO (272). MKP1 levels varied inversely with ERK phosphorylation across the NO dose response, suggesting that MKP1 inhibits the ERK-dependent regulation of TSP1 expression.

The inhibition of TSP1 expression by high concentrations of NO donors or the resulting RNS has been replicated in a second cell type. Treatment of rat renal mesangial cells with the NO donor and nitrosating agent S-nitroso-L-glutathione at $500 \mu M$ resulted in decreased TSP1 mRNA expression (295). Downregulation of TSP1 mRNA was confirmed using rat and human mesangial cells treated with the more specific NO donor spermine-NONOate. Downregulation was sustained 
from 4 to $24 \mathrm{~h}$. Further studies using human mesangial cells in medium containing $30 \mathrm{~m} M$ glucose and treated with spermineNONOate, DETA/NO, or S-nitroso-N-acetyl-DL-penicillamine demonstrated downregulation of TSP1 protein expression.

Data indicate that decreased/absent TSP1 expression is associated with enhanced NO responses in vascular cells and platelets (95). Furthermore, male $T h b s 1^{-1-}$ and $C d 47^{-1}$ mice enjoy elevated NO signaling, and this is associated with loss of TSP1 induction with injury or hypoxia compared with WT. These and other findings suggest possible feedback regulatory control of TSP1 by anti-inflammatory low dose NO.

VSMC chemotaxis to a supraphysiological concentration of TSP1 $(20 \mu \mathrm{g} / \mathrm{ml})$ was altered by exogenous NO, with low concentrations limiting TSP1 chemotaxis and high concentrations enhancing it (227). Similarly, VSMCs treated with the NO-prodrug sodium nitroprusside were resistant to TSP1stimulated chemotaxis. Endothelial progenitor cells exposed to laminar flow, a known activator of eNOS, upregulated NO concurrent with downregulation of TSP1 protein (7). In contrast to these results in primary vascular and renal cells, treatment of human hepatoma3 B cancer cells with the NO prodrug O2-(2,4-dinitrophenyl) 1-[(4-ethoxyxarbonyl)piperazin-1-yl] diazen-1-ium 1,2-diolate ( 1 to $10 \mu M$ ) increased TSP1 mRNA expression and cell surface expression of the TSP1 receptor CD36 (44). Conversely, treatment of NIH 3T3 cells with high concentrations of NO ( $1 \mathrm{~m} M$ DETA/NO) for $24 \mathrm{~h}$ suppressed TSP2 promoter activity and mRNA (149).

Beyond cell culture, limiting NO for 28 days in male rats by daily feeding of L-NAME in the drinking water was associated with increased TSP1 protein expression in distal mesenteric arteries and elevated blood pressure (17). In a small clinical study, 4 weeks of aerobic training in healthy young men was associated with increased eNOS protein expression in vastus lateralis muscle samples. Although TSP1 protein levels were not significantly changed, TSP1 levels trended lower in postexercise samples (77).

The mechanism by which NO limits TSP1 expression at the pre- and post-transcriptional levels remains to be determined. Furthermore, it will be interesting to consider the effects of NO and NO surrogate drugs on changes in TSP1 and TSP1 receptor expression as a possible index of clinical effect. Some data suggest a role for ROS to increase TSP1 expression (infra vide Section VI). If confirmed, the chemical quenching of superoxide by NO may represent yet another mechanism by which the biogas limits TSP1 expression.

\section{NO Signaling and Other Matricellular Proteins}

\section{A. NO signaling and other thrombospondins}

1. Regulation of NO signaling. The C-terminal domain of TSP1 that interacts with CD47 shares 53-82\% sequence homology with the other four members of the TSP family, the highest being with TSP2 (23). This suggested that TSP2 and other TSPs may also inhibit NO signaling via interaction with CD47. A comparison of recombinant signature domains of TSP1, TSP2, and TSP4 showed moderate competition between the signature domains of TSP2 and TSP1 for binding to cells expressing CD47 but no significant inhibition by the signature domain of TSP4 (84). Consistent with these data, the three paralogs showed decreasing potency for inhibiting NO-stimulated cGMP accumulation in VSMCs in the order TSP1 $>$ TSP2>TSP4.
One study has also implicated CD47 as a receptor for cartilage oligomeric matrix protein (COMP) (211). Attachment of ligament cells to COMP was inhibited by a peptide derived from the globular C-terminal domain of COMP (SFYVVMWK) that resembles the known CD47-binding peptide 4N1 from TSP1 (RFYVVMWK). A CD47 blocking antibody also inhibited adhesion, but the study did not establish that CD47 directly binds to COMP or exclude the possibility that the ligands including TSP1, by engaging CD47 on the ligament cells, indirectly inhibit adhesion by inactivating $\alpha \mathrm{v} \beta 3$ integrin, which also serves as a COMP receptor on these cells.

To assess whether TSP2 contributes significantly to regulating physiological NO signaling, primary lung endothelial cells were prepared from $T h b s 2^{-1-}$ mice (84). No difference was seen in basal cGMP levels, but surprisingly NOstimulated cGMP was moderately but consistently lower in the Thbs $2^{-/}$cells. No difference in NO-stimulated proliferation was observed. These results demonstrate that endogenous TSP2 does not contribute significantly to regulating basal NO signaling in vascular endothelial cells, but it should be noted that expression of TSP2 in these cells was significantly lower than that of TSP1, which may mask potential inhibitory signaling from TSP2. Thbs $2^{-/}$mice also exhibited no significant advantage over WT mice when analyzed for recovery from an ischemic injury (84).

Thus, to date no physiological or pathophysiological regulation of NO signaling by TSP2 has been demonstrated, but conditions may be found in the future wherein increased TSP2 expression is sufficient to inhibit NO signaling. However, given the homology in structure and domains, it is predicted that TSP2 will act via CD47 to limit NO in such instances.

2. Regulation of expression by NO. Studies in endothelial cells lacking the monooxygenase cytochrome P450 1B1 first implicated regulation of TSP2 expression by eNOSderived NO (266). Genetic evidence for this regulation was later provided using $N_{o s} 3^{-/-}$mice, which exhibited elevated TSP2 expression in ischemic and wound tissues (149). Studies using $A k t 1^{-/}$mice demonstrated that Akt1 signaling, which phosphorylates eNOS, also negatively regulates TSP2 expression at sites of injury (8). However, a recent study reported elevated TSP2 levels produced by $T h b s 1^{-/}$choroidal endothelial cells despite having elevated eNOS phosphorylation and NO production as assessed by 4-amino-5-methylamino$2^{\prime}, 7^{\prime}$-difluorofluorescein diacetate fluorescence (53).

Additional RNS may be involved in the observed induction of TSP2 because iNOS was also strongly induced in the Thbs $1^{-/-}$ cells, and 4-amino-5-methylamino- $2^{\prime}, 7^{\prime}$-difluorofluorescein is currently believed to directly detect $\mathrm{NO}_{2}{ }^{\bullet}$ rather than $\mathrm{NO}$ (176). Further investigation is needed to identify the RNS that proximally regulates TSP1.

\section{B. Regulation of iNOS-derived NO production and signaling}

1. ADAMTS1. A recent study has extended matricellular protein regulation of NO signaling to the TSR family. Marfan syndrome is a genetic disorder caused by inherited or sporadic mutations in fibrillin-1 (223). Fibrillin-1 provides a scaffold for deposition of elastin, and in Marfan syndrome patients the resulting defect in elastic tissue integrity is associated with the formation of thoracic aortic aneurysms (Fig. 6). 


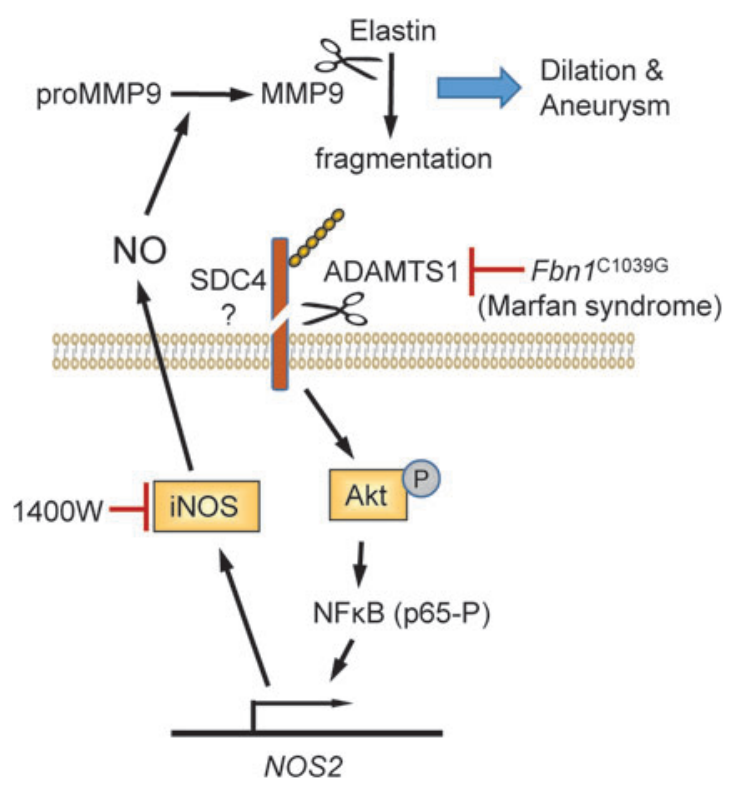

FIG. 6. ADAMTS1 regulation of iNOS. Mutation of fibulin-1 (Fbn1) that causes Marfan syndrome results in decreased expression of ADAMTS1 (186). ADAMTS1 cleaves proteins including SDC4 that regulate the induction of NOS2 via an Akt-NF- $\kappa$ B. The resulting production of NO increases proteolytic cleavage of elastin via MMP9, and the loss of elastic fibers in the aorta leads to formation of aneurysms. MMP9, matrix metalloproteinse-9; SDC4, syndecan4. To see this illustration in color, the reader is referred to the web version of this article at www.liebertpub.com/ars

Expression of the matricellular protease ADAMTS1 was found to be lower in the medial layer of aortic sections from patients with Marfan syndrome, whereas iNOS (NOS2) expression was generally elevated at the same location (186). A role of altered ADAMTS1 expression in Marfan syndrome was suggested by similarities in the aortic pathology of Adamts $I^{+/-}$and $F b n 1^{\mathrm{C} 1039 \mathrm{G} /+}$ mice. Aortic sections from $F b n 1^{\mathrm{C} 1039 \mathrm{G} /+}$ mice had reduced levels of ADAMTS1, comparable with that seen in Marfan syndrome patients, whereas aortic NO levels and NOS2 expression were elevated. Aortic NO levels and NOS2 expression were similarly elevated in the Adamts $1^{+/-}$mice. Lentiviral siRNA knockdown of ADAMTS1 in WT mice rapidly induced aortic dilation, hypotension, and medial degeneration, which could be prevented by treating the mice with the pan-NOS inhibitor L-NAME.

In contrast, siRNA knockdown of ADAMTS1 in $\mathrm{Nos}^{-/-}$ mice exhibited no aortic pathology, and aortic NO levels remained normal. Specific inhibition of NOS2 using the selective inhibitor $1400 \mathrm{~W}$ also prevented aortic dilation when used to treat both young and aged Adamts $I^{+/-}$or $F b n I^{\mathrm{C} 1039 \mathrm{G} /+}$ mice. The elevated levels of NO produced by NOS2 were proposed to increase MMP9-mediated fragmentation of elastin because MMP9 activation and elastin fragmentation in the aorta of Adamts1-deficient mice were sensitive to NOS inhibition.

Others have reported that NO (as S-nitrosoglutathione, GSNO) enhances the expression of MMP9, its inhibitor TIMP1, and elastin in VSMCs (240). In addition, the resulting active MMP9 can lead to fragmentation of other matricellular proteins in the vessel wall, including osteopontin and the TSP1 receptor CD36 $(38,141)$. These studies suggest that a selective therapeutic NOS2 inhibitor could be protective for patients with Marfan syndrome. However, such a therapeutic strategy would need to be balanced against compromising the role of NOS2 in host defense.

The effects of ADAMTS1 knockdown on NOS2 expression in VSMCs were mediated by increased Akt phosphorylation and nuclear factor kappa B (NF- $\kappa$ B) activation (186). Inhibition of Akt signaling in Adamts $1^{+/-}$mice using the mammalian target of rapamycin (mTOR) inhibitor AZD8055 decreased aortic dilation, inhibited NO production in the aortic wall, and reduced NOS2 levels. It is interesting to consider whether mTOR blockade could provide therapeutic benefit to Marfan syndrome patients. However, as mTOR is a proximate promoter of VSMC growth, long-term mTOR blockade could lead to vascular hypoplasia, although this may be of benefit in conditions such as pulmonary hypertension $(\mathrm{PH})$ wherein pulmonary vascular smooth muscle growth is accentuated (see ClinicalTrials.gov NCT02587325).

2. Osteopontin and NOS2 signaling. Earlier characterization of the matricellular protein osteopontin revealed that it inhibits NO synthesis induced by interferon- $\gamma$ and lipopolysaccharide (LPS) in primary mouse kidney proximal tubule epithelial cells (82). Purified osteopontin inhibited NOS2 mRNA and protein expression in these cells. Similar inhibition of NOS2 induction by inflammatory mediators was reported in RAW264.7 macrophages (218) and rat thoracic aortas (226). Conversely, LPS in the presence of NO induced transcription of the Opn gene, suggesting a negative function of osteopontin to limit inflammatory production of NO (67). A similar negative feedback role was found for limiting NO production in rat pancreatic islets and RINm5F $\beta$ cells (6).

Several correlative studies support a protective role of osteopontin in animal injury models and patients, but the strongest evidence for an NO-dependent protective role comes from a liver ischemia-reperfusion model. After $45 \mathrm{~min}$ of warm hepatic ischemia, $\mathrm{Opn}^{-1-}$ mice exhibited elevated release of liver enzymes, increased necrosis, and increased expression of NOS2 and inflammatory cytokines (189).

Two potential mechanisms were identified: (i) loss of osteopontin cell autonomously impairs hepatocyte resistance to stress and (ii) osteopontin limits the production of toxic iNOS-derived NO by macrophages. The relative contributions of these mechanisms to the protective function of osteopontin remain to be determined.

In contrast, osteopontin was proposed to enhance lung injury secondary to intestinal ischemia-reperfusion, and an osteopontin blocking antibody protected mice from this injury (73). Comparing renal ischemia-reperfusion in WT versus $\mathrm{Opn}^{-1-}$ mice found no differences in functional impairment in the first 7 days after reperfusion, but collagens I and IV expression was decreased and macrophage infiltration was significantly diminished in the nulls consistent with decreased inflammation and fibrosis (191). Another study found decreased natural killer (NK) cell recruitment in reperfused kidneys of $\mathrm{Opn}^{-/-}$mice, and osteopontin activated NK cells to kill tubular epithelial cells in vitro (310). Therefore, consistent evidence is currently lacking to conclude that osteopontin regulation of $\mathrm{NO}$ production has a major role in ischemic injuries or that osteopontin is tissue protective.

Characterization of bone cells from mice lacking osteopontin revealed a deficit in NO production, assessed as nitrite using the Griess reagent, when the cells were subjected to 
pulsatile flow (40). However, it is unclear which NOS isoform is regulated by osteopontin in these cells.

3. Regulation of other matricellular protein expression by NO. Induction of NOS2 in rat mesangial cells by treatment with IL- $1 \beta$ and TNF $\alpha$ resulted in a cAMP-dependent decrease in SPARC mRNA and protein levels (287). SPARC expression was also decreased in cells treated with NO donors, and downregulation of SPARC in kidneys of rats treated with endotoxin was reversed by the NOS2-specific inhibitor L-N6-1-(iminoethyl)-lysine dihydrochloride.

A subsequent study identified that the SPARC/BM-40 family member secreted modular calcium-binding protein 1 (SMOC1) as another matricellular protein downregulated by NO signaling in rat mesangial cells (47). The same NOS2 inhibitor prevented downregulation of SMOC1 in kidneys of nephritic rats. Expression of TSP2 in ischemic tissues is regulated by NOS3-dependent NO signaling (149).

Treatment of human meniscal cells obtained from nondegenerative hip meniscus with the NOS inhibitor L-NAME inhibited the mRNA expression of two ADAMTS family members that function as aggrecanases (ADAMTS-4 and -5) (231). This was identified as an upregulated catabolic pathway associated with induction of autophagy by the NOS inhibitor. An earlier study using bovine cartilage explants reported no effect of inhibiting NOS using $\mathrm{L}-\mathrm{N}^{\mathrm{G}}$-monomethyl arginine citrate on ADAMTS-4 and ADAMTS-5 mRNA expression, but found that their enzymatic activity induced by $\mathrm{TNF} \alpha$ was significantly inhibited (255). The mechanism by which NO post-transcriptionally regulates ADAMTS-4 and ADAMTS-5 remains to be defined.

\section{Thrombospondin-1 Regulation of $\mathrm{H}_{2} \mathrm{~S}$ Biosynthesis and Signaling}

\section{A. Role of $\mathrm{H}_{2} \mathrm{~S}$ in $\mathrm{T}$ cell activation}

$\mathrm{H}_{2} \mathrm{~S}$ is a toxic gas at high concentrations, but it is also synthesized in mammalian tissues by three enzymes that yield physiological $\mathrm{H}_{2} \mathrm{~S}$ concentrations of $0.1-2 \mu M$ (233, 234). Several functions of endogenous $\mathrm{H}_{2} \mathrm{~S}$ signaling have been identified using mice lacking specific genes required for $\mathrm{H}_{2} \mathrm{~S}$ biosynthesis. $\mathrm{H}_{2} \mathrm{~S}$ can act as an intracellular and paracrine signaling molecule through sulfhydrylation of thiols on specific target proteins $(172,173)$ and by formation of persulfides and polysulfides $(66,83) . \mathrm{H}_{2} \mathrm{~S}$ plays both pro- and anti-inflammatory roles in immune cells. This apparently contradictory statement can be rationalized by the bimodal dose dependence of $\mathrm{H}_{2} \mathrm{~S}$ responses. Higher concentrations of $\mathrm{H}_{2} \mathrm{~S}$ generally induce proinflammatory responses, whereas concentrations $<10 \mu M$ are anti-inflammatory. $\mathrm{H}_{2} \mathrm{~S}$ inhibits IL-2 production by and proliferation of $\mathrm{T}$ cell lymphocytes (283). Similar effects were also reported for polymorphonuclear cells, wherein $1 \mathrm{mM} \mathrm{H_{2 }}$ S induced PMN apoptosis (153).

Duration of $\mathrm{H}_{2} \mathrm{~S}$ exposure is also important in defining its effects on cells. For example, the slow-releasing $\mathrm{H}_{2} \mathrm{~S}$ donor GYY4137 inhibited an LPS-induced proinflammatory response and increased expression of the anti-inflammatory chemokine IL-10, whereas rapid exposure to $\mathrm{H}_{2} \mathrm{~S}$ produced from $\mathrm{NaHS}$ induced the opposite responses on the same type of cells (298). In addition, $\mathrm{H}_{2} \mathrm{~S}$ effects can be species- and organ-specific, depending on differences in the activities of different $\mathrm{H}_{2} \mathrm{~S}$ biosynthetic and catabolic pathways (290).
Higher pharmacological concentrations of $\mathrm{H}_{2} \mathrm{~S}$ inhibit T cell functions by inhibiting mitochondrial function. Exposure of Jurkat T cells to $1-5 \mathrm{~m} M$ NaHS at $\mathrm{pH}$ 6.0-8.0 induced blebbing and apoptosis by activation of the Rho-Rock pathway and cleavage of caspase-3 and poly-ADP ribose polymerase (PARP) (107). In contrast, $\mathrm{H}_{2} \mathrm{~S}$ at physiological concentrations $(<10 \mu M)$ is a positive physiological enhancer of $\mathrm{T}$ cell function (166) (Fig. 7). In primary mouse $\mathrm{CD}^{+} \mathrm{T}$ cells, OT-II CD4 ${ }^{+} \mathrm{T}$ cells, and the human Jurkat T cell line, physiological levels of $\mathrm{H}_{2} \mathrm{~S}$ potentiated $\mathrm{T}$ cell receptor-induced activation. $\mathrm{H}_{2} \mathrm{~S}$ at 50 $500 \mathrm{n} M$ enhanced $\mathrm{T}$ cell activation assessed by CD69 expression, IL-2 expression, and CD25 levels. $\mathrm{H}_{2} \mathrm{~S}$ dose-dependently enhanced $\mathrm{T}$ cell receptor-stimulated proliferation. Furthermore, activation increased the capacity of $\mathrm{T}$ cells to make $\mathrm{H}_{2} \mathrm{~S}$ by increasing expression of cystathionine $\gamma$-lyase (CSE) and cystathionine $\beta$-synthase (CBS). Disrupting this response by using siRNA to target these enzymes impaired $\mathrm{T}$ cell activation and proliferation, which could be rescued by the addition of $300 \mathrm{n} M$ $\mathrm{H}_{2} \mathrm{~S}$. At physiological concentrations, $\mathrm{H}_{2} \mathrm{~S}$ also induced formation of the immunological synapse by altering cytoskeletal actin dynamics in the microtubule organizing center during $\mathrm{T}$ cell activation (166).

\section{B. TSP1 inhibition of $\mathrm{H}_{2} \mathrm{~S}$ biosynthesis in $\mathrm{T}$ cells}

Analogous to its inhibition of NO signaling, TSP1 signaling through $\mathrm{CD} 47$ inhibits $\mathrm{H}_{2} \mathrm{~S}$ signaling in T cells. Murine Thbs $1^{-1} \mathrm{~T}$ cells are more sensitive to activating signals in the presence of $\mathrm{H}_{2} \mathrm{~S}$, resulting in elevated levels of IL-2 and CD69 mRNA and cell proliferation than WT-activated murine T cells (164). The increased IL-2 and CD69 expression is reversed by physiological concentrations $(0.2-2 \mathrm{n} M)$ of exogenous TSP1. Resting and activated $T h b s 1^{-1-}$ murine T cells have upregulated CBS and CSE mRNA expression. This suggested that TSP1 endogenously regulates $\mathrm{H}_{2} \mathrm{~S}$ signaling by limiting the expression of $C b s$ and $C s e$ genes, which, in turn, limits $\mathrm{T}$ cell activation.

A CD47-binding peptide derived from TSP1 (7N3, FIRVVMYEGKK) recapitulated the inhibitory activity of TSP1, whereas $C d 47^{-1}$ murine T cells were resistant to inhibition by TSP1 (164). This indicates that TSP1 signaling through CD47 has a homeostatic inhibitory role that limits the autocrine role of $\mathrm{H}_{2} \mathrm{~S}$ in $\mathrm{T}$ cell activation and, therefore, may play a role in inflammatory diseases that are associated with induction of $\mathrm{H}_{2} \mathrm{~S}$.

\section{Potential role of TSP1 in other $\mathrm{H}_{2} \mathrm{~S}$ signaling}

$\mathrm{H}_{2} \mathrm{~S}$ signaling also plays important roles in angiogenesis, including activation of VEGFR2 (267). CBS expression is necessary for optimal VEGF signaling (222). $\mathrm{H}_{2} \mathrm{~S}$ is also a physiological regulator of VSMCs (104). Extrapolating from its regulation of $\mathrm{H}_{2} \mathrm{~S}$ biosynthesis and signaling in $\mathrm{T}$ cells, TSP1 could be a global antagonist of $\mathrm{H}_{2} \mathrm{~S}$ biosynthesis and signaling. If so, TSP1 would be an even more comprehensive regulator of angiogenesis and blood flow than indicated by its highly redundant inhibition of VEGF/NO signaling pathways (88). The emerging role of $\mathrm{H}_{2} \mathrm{~S}$ signaling in cancer also merits future studies to investigate whether TSP1 and CD47 regulate tumor cells in a $\mathrm{H}_{2} \mathrm{~S}$-dependent manner (261).

\section{V. $\mathrm{H}_{2} \mathrm{~S}$ Regulation of Matricellular Protein Expression}

\section{A. Osteopontin}

Osteopontin has emerged as an important target of $\mathrm{H}_{2} \mathrm{~S}$ signaling in several cell types, but the nature of this regulation 


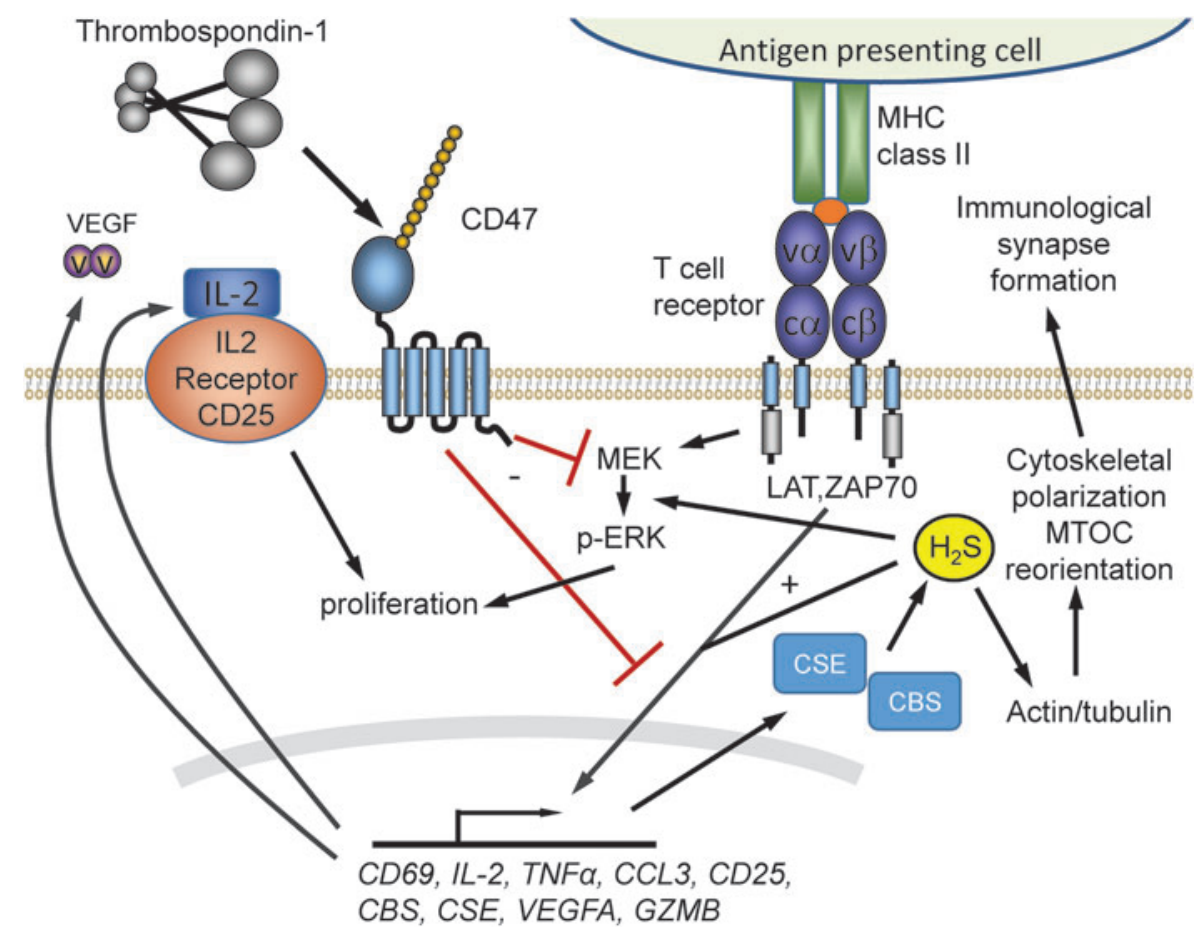

FIG. 7. TSP1/CD47 signaling in T cells. Presentation of antigen in the context of MHC induces the formation of the immunological synapse and activation of TCR signaling through mediators, including LAT and ZAP70. CD47 signaling acts downstream of these mediators to limit the induction of multiple genes involved in $\mathrm{T}$ cell activation and effector function. In addition to cell autonomous inhibition, CD47 signaling inhibits expression of genes encoding the T cell cytokine IL-2 and the $\alpha$-subunit of the IL-2 receptor (CD25). CD47 also limits activation-dependent induction of the $\mathrm{H}_{2} \mathrm{~S}$ biosynthetic enzymes CBS and CSE. In T cells their activity is required for reorientation of the MTOC, which is required for immune synapse formation. In cytotoxic $\mathrm{CD}^{+} \mathrm{T}$ cells, CD47 regulates expression of the effector GZMB, which mediates antigen-dependent killing of tumor cells. GZMB, granzyme B; IL, interleukin; MHC, major histocompatibility complex; MTOC, microtubule-organizing center; TCR, T cell receptor. To see this illustration in color, the reader is referred to the web version of this article at www.liebertpub.com/ars

appears to be cell-type specific. Osteopontin plays a major role in regulation of vascular calcification and mineral depositions in humans (61). During vascular calcification of arteries, smooth muscles cells, pericytes, fibroblasts, and macrophages transform into an osteoblast-like phenotype, which is characterized by upregulation of osteopontin. During calcification induced with vitamin D3 plus nicotine in rats, aortic $\mathrm{H}_{2} \mathrm{~S}$ content and CSE mRNA were decreased significantly but osteopontin mRNA was increased (302). Daily treatment of vitamin D+nicotine exposed rats with NaHS at 2.8 or $14 \mu \mathrm{mol} / \mathrm{kg}$ downregulated osteopontin mRNA to control levels. This suggests that $\mathrm{H}_{2} \mathrm{~S}$ inhibits mRNA expression of osteopontin. Similarly, osteopontin mRNA was upregulated in hyperhomocysteinemia, and $\mathrm{H}_{2} \mathrm{~S} / \mathrm{CSE}$ expression was downregulated (294). This led to enhanced proliferation of VSMCs from rat thoracic aortas. Treatment with $100 \mu M$ NaHS significantly decreased proliferation of VSMCs via an ERK1/ERK2dependent pathway and partially inhibited the induction of osteopontin by homocysteine.

In contrast, endogenous $\mathrm{H}_{2} \mathrm{~S}$ produced by CSE induces differentiation and maturation of primary osteoblasts, resulting in induction of osteopontin and BMP2 expression (315). This is mediated by sulfhydration of the transcription factor RUNX2 at Cys ${ }^{123}$ and $\mathrm{Cys}^{132}$ and results in elevated BMP2, osteopontin, and osteocalcin expression (Fig. 8A). The $\mathrm{H}_{2} \mathrm{~S}$ donor GYY4137 induced the same sulfhydration- dependent induction, whereas mutation of these Cys residues on RUNX2 or treatment with the CSE inhibitor DLpropargylglycine prevented RUNX2 sulfhydration, nuclear localization, and transactivation. Delivery of CSE using an adenoviral vector facilitated healing of fractured femurs in treated rats (315). The contrast between this study and those already mentioned, suggesting inhibition of osteopontin expression by $\mathrm{H}_{2} \mathrm{~S}$, may reflect a biphasic dose response, wherein physiological $\mathrm{H}_{2} \mathrm{~S}$ induces osteopontin but supraphysiological concentrations are inhibitory.

Studies using bone marrow mesenchymal stem cells (MSCs) identified another sulfhydration target that controls the expression of osteopontin (145) (Fig. 8B). $\mathrm{H}_{2} \mathrm{~S}$ deficiency has been linked with a perturbed balance between osteoblast and osteoclast cells that leads to osteopenia and bone marrow MSC impairment in mice. Injection of the $\mathrm{H}_{2} \mathrm{~S}$ donor GYY4317 rescued abnormal osteoclast-mediated bone resorption and bone mineral density in $\mathrm{Cbs}^{+/-}$mice. The $\mathrm{H}_{2} \mathrm{~S}$ deficiency perturbed $\mathrm{Ca}^{2+}$ influx mediated by TRPV6, TRPV3, and TRPM4 channels, which are regulated via sulfhydration. Mass spectrometry identified sulfhydration of TRPV6 at $\mathrm{Cys}^{172}$ and $\mathrm{Cys}^{329}$. Overexpression of the double mutant TRPV6 ${ }^{\mathrm{C} 172+\mathrm{C} 329 \mathrm{mu}}$ reduced $\mathrm{H}_{2} \mathrm{~S}$ donor-induced protein kinase $\mathrm{C}$ phosphorylation and downstream ERKdependent activation of $\beta$-catenin, which induces RUNX2 and in vitro osteogenic differentiation. These data suggest 

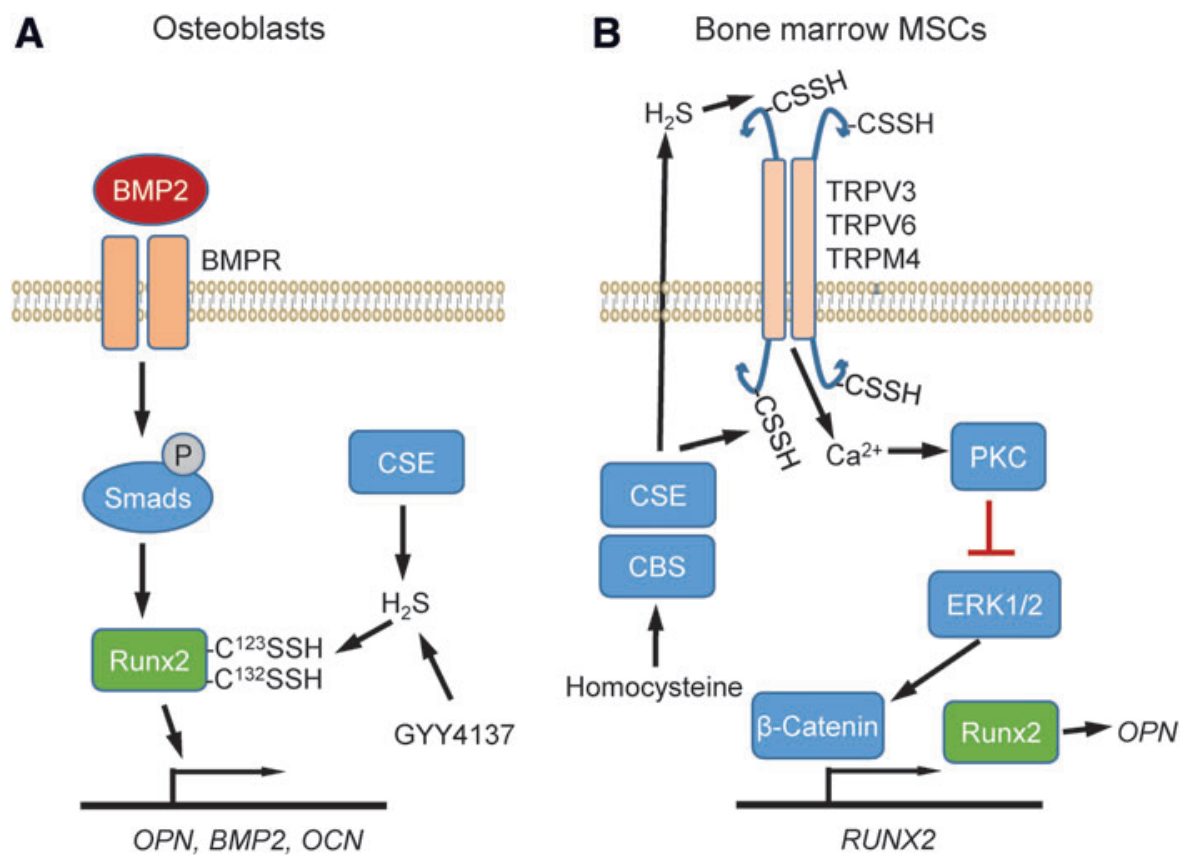

FIG. 8. Regulation of osteopontin expression by $\mathbf{H}_{2}$ S. (A) Studies in osteoblasts identified CSE as the major source of endogenous $\mathrm{H}_{2} \mathrm{~S}$ biosynthesis mediating induction of $O P N, B M P 2$, and $O C N$. BMP2 induces these genes via SMAD signaling that activates the transcription factor RUNX2, but this induction is impaired if $\mathrm{H}_{2} \mathrm{~S}$ synthesis is inhibited. Cys ${ }^{123}$ and Cys ${ }^{132}$ were identified as sulfhydration targets on RUNX2 that mediate this activity. (B) In bone marrow mesenchymal stem cells, $\mathrm{H}_{2} \mathrm{~S}$ sulfhydrates Cys residues on the calcium channels TRPV3, TRPV6, and TRPM4. This modification controls calcium influx, which controls transcriptional activation of the RUNX2 gene via PKC and the MAP kinase ERK1/2. BMP2, bone morphogenetic protein-2; $O C N$, osteocalcin; $O P N$, osteopontin; PKC, protein kinase C. To see this illustration in color, the reader is referred to the web version of this article at www.liebertpub.com/ars

that $\mathrm{H}_{2} \mathrm{~S}$ is essential for maintaining a homeostatic function of osteopontin for differentiation of MSCs during osteogenesis.

\section{B. Tenascin $C$}

Complementary to regulation of $\mathrm{H}_{2} \mathrm{~S}$ production and signaling by TSP1 in the extracellular matrix, several recent studies implicate $\mathrm{H}_{2} \mathrm{~S}$ as an important regulator of extracellular matrix remodeling that may involve additional matricellular proteins. $\mathrm{H}_{2} \mathrm{~S}$ treatment of spontaneous hypertensive rats and isolated VSMCs inhibited collagen levels and hydroxyproline secretion (312). $\mathrm{H}_{2} \mathrm{~S}$ treatment also protected lung tissues from ventilator-induced lung injury (249). Gene enrichment analysis of microarray data showed significant regulation of extracellular matrix remodeling pathways, including altered expression of the matricellular protein tenascin $\mathrm{C}$.

Chronic lung fibrotic diseases increase deposition of extracellular matrix, including collagens, proteoglycans, and adhesive glycoproteins. These structural alternations in lung tissues resemble those found in hibernating animals during the transition from torpor to arousal state. The golden Syrian hamster is an accepted model for lung remodeling during hibernation (265). Cooling of hamster cells increased endogenous $\mathrm{H}_{2} \mathrm{~S}$ production by CBS. During the torpor phase, $\mathrm{H}_{2} \mathrm{~S}$ suppressed immune responses and elevated collagen and CBS expression, which became normalized during euthermia or arousal state. Treating golden Syrian hamsters with exogenous $\mathrm{H}_{2} \mathrm{~S}$ inhibited gelatinase activity, potentially by quenching of $\mathrm{Zn}^{2+}$ and increased expression of CBS (264). This suggests a central role for lung extracellular matrix remodeling in the protective function of $\mathrm{H}_{2} \mathrm{~S}$ during hibernation.

\section{Laminin $-\gamma 1$}

$\mathrm{H}_{2} \mathrm{~S}$ inhibited glucose-induced laminin $\gamma 1$ synthesis in mouse podocytes and kidney proximal tubular epithelial cells via the mammalian target of rapamycin complex 1 (mTORC1)-AMP kinase pathway (131). CBS and CSE expression was significantly reduced in mice with type 1 or type 2 diabetes. The resulting deficiency in $\mathrm{H}_{2} \mathrm{~S}$ led to increased glucose-dependent inhibition of AMP kinase and activation of mTORC1. This dysregulation, in turn, resulted in increased synthesis of extracellular matrix proteins and renal cell hypertrophy. Similar results were reported for mouse glomerular endothelial cells cultured with low and high glucose, wherein $\mathrm{H}_{2} \mathrm{~S}$ treatment downregulated matrix protein expression induced by high glucose (118). $\mathrm{H}_{2} \mathrm{~S}$ treatment increased phosphorylation of LKB1-AMPK and induction of several autophagy genes. The latter result suggests a mechanistic link between the ability of TSP1/CD47 signaling to inhibit both $\mathrm{H}_{2} \mathrm{~S}$ biosynthesis (164) and autophagy responses (244).

NO and cGMP signaling also regulates the expression of laminin $\gamma 1$ and other extracellular matrix proteins in an AMP kinase-dependent manner (130). In some contexts, $\mathrm{H}_{2} \mathrm{~S}$ enhances NO signaling (262). Further studies are needed to determine how simultaneous regulation of $\mathrm{NO}$ and $\mathrm{H}_{2} \mathrm{~S}$ signaling by TSP1/CD47 influences the cross-talk between these 
pathways. In addition, the proangiogenic effects of $\mathrm{H}_{2} \mathrm{~S}$, by increasing VEGF expression and VEGFR2 phosphorylation in endothelial cells and decreasing levels of the antiangiogenic soluble fms-like tyrosine kinase 1 (sFlt1), may be relevant to this model $(79,289)$.

\section{TSP1 Regulation of ROS}

\section{A. TSP1 and ROS signaling in inflammatory cells}

1. Historical context. Studies have identified roles for several matricellular proteins in regulating intracellular or extracellular ROS production, although the chemical identity of that ROS often remains unclear (Table 1). TSP1 enhanced the production of extracellular superoxide by neutrophils stimulated by the bacterial chemoattractant peptide fMLP (257). The identity of superoxide was confirmed by superoxide dismutase (SOD) inhibition of the detected reduction of cytochrome C. A similar enhancement was found when TSP1-treated monocytes were exposed to TSP1 antibodies (224). A subsequent study using fMLP-stimulated PMN from a patient with leukocyte adhesion deficiency suggested that the ability of PMN to spread on a substrate coated with TSP1 regulated superoxide production (256).

Leukocyte adhesion deficiency is caused by defective $\beta 2$ integrin function, suggesting that TSP1 may regulate PMN superoxide production through integrin signaling. However, another study localized the adhesion activity of TSP1 for PMNs to its $140 \mathrm{kDa}$ C-terminal region and provided evidence that this was not mediated by a $\beta 2$ integrin or the known RGD integrin binding site in this region of TSP1 (258). Although these earlier studies established that TSP1 has a supportive role to stimulate production of ROS by PMN, a direct role for TSP1 in this process remained unclear.

2. Roles of TSP1 receptors. Several studies have examined a potential role of the TSP1 receptor CD36 in regulating ROS production by monocytes. Antibody cross-linking of CD36 on human mononuclear cells induced a strong oxidative burst, characterized by measurement of SODinhibitable cytochrome $\mathrm{C}$ reduction (277) and by chemiluminescence (225). Treatment of these cells with TSP1 alone did not induce an oxidative response, but cross-linking TSP1 bound to the surface, or two treatments with TSP1 (225), enhanced oxidative burst in a CD36-independent manner (225).

More recent studies suggest indirect mechanisms by which TSP1 signaling through CD36 can regulate oxidative inflammatory responses in macrophages. One mechanism involves TSP1 induction of toll-like receptor 4 expression on

Table 1. Matricellular Proteins and Reactive Oxygen Species Characterization

\begin{tabular}{|c|c|c|c|c|}
\hline Cell type & $\begin{array}{l}\text { Matricellular } \\
\text { protein }\end{array}$ & $\begin{array}{c}\text { Reactive } \\
\text { oxygen species }^{\mathrm{a}}\end{array}$ & ROS characterization & Reference \\
\hline Neutrophil & TSP1 & Superoxide $^{\mathrm{b}}$ & Cytochrome c & (257) \\
\hline Monocytes & TSP1 & ROS & Luminol & (224) \\
\hline Neutrophils & TSP1 & $\mathrm{H}_{2} \mathrm{O}_{2}$ & $\begin{array}{l}\text { Scopoletin oxidation by } \\
\text { horseradish peroxidase }\end{array}$ & (256) \\
\hline Monocytes & TSP1 & Superoxide ${ }^{b}$ & Cytochrome c & $(225,277)$ \\
\hline Macrophages & TSP1 & Superoxide ${ }^{b}$ & Luminol & (154) \\
\hline Macrophages & $\begin{array}{l}\text { IgV domain } \\
\text { of CD47 }\end{array}$ & ROS & Nitroblue tetrazolium assay & (5) \\
\hline Macrophages & $\begin{array}{l}\text { SIRP- } \alpha- \\
\quad \text { target SHP2 }\end{array}$ & ROS & Luminol & (136) \\
\hline $\begin{array}{l}\text { Pulmonary } \\
\text { endothelial cells }\end{array}$ & $\begin{array}{l}\text { TSP1 } \\
\text { (hypoxia } \\
\text { induced) }\end{array}$ & Superoxide $^{c}$ & Dihydroethidium fluorescence & (11) \\
\hline Arterial VSMCs & TSP1 & Superoxide & Cytochrome c & (36) \\
\hline Aortic rings & TSP1 & Superoxide & Electron paramagnetic resonance & (36) \\
\hline Arterial VSMCs & $\begin{array}{l}\text { CD47 WT vs. } \\
\text { null cells }\end{array}$ & Superoxide $^{c}$ & Mitosox & (56) \\
\hline Aortic rings & TSP1 & ROS & Tempol & (11) \\
\hline Coronary arterioles & TSP1 & Superoxide $^{c}$ & Dihydroethidium fluorescence & (182) \\
\hline Liver & CD47 & Superoxide $^{c}$ & Dihydroethidium fluorescence & $(303,304)$ \\
\hline Fibroblasts & $\mathrm{CCN} 1$ & ROS & DCFDA fluorescence & (101) \\
\hline Fibroblasts & $\mathrm{CCN} 2$ & ROS & DCFDA fluorescence & (101) \\
\hline Hepatocytes & CCN1 & ROS & Dihydrocalcein-AM fluorescence & (27) \\
\hline Myofibroblasts & CCN1 & ROS & DCFDA fluorescence & (15) \\
\hline Endothelial cells & Periostin & No ROS & DCFDA fluorescence & (316) \\
\hline
\end{tabular}

${ }^{a}$ ROS indicates general detection of oxidants. Although authors often presume detection of specific oxidant species, most fluorescent dyes or other assays are not specific for detecting superoxide. Intracellular DCFDA fluorescence produced by intracellular oxidation of 5/6chloromethyl-2,7-dichlorodihydrofluorescein diacetate and related derivatives is not specific for superoxide.

${ }^{\mathrm{b}}$ Extracellular superoxide confirmed by loss of signal after SOD treatment.

${ }^{\mathrm{c}}$ Dihydroethidium and Mitosox are selectively oxidized by superoxide to yield red fluorescent 2-OH-ethidium ${ }^{+}$. However, in the absence of supporting chemical characterization of the fluorescent product, other oxidants including $\mathrm{OH}^{\bullet}$ and $\mathrm{HOCl}$ can generate similar fluorescent products and can indicate activation of myeloperoxidases rather than NADPH oxidases (150).

DCFDA, 2,7-dichlorofluorescein diacetate; ROS, reactive oxygen species; SOD, superoxide dismutase; VSMCs, vascular smooth muscle cells; WT, wild type. 
macrophages (137). TLR4-deficient macrophages did not respond to TSP1, and activation was partially inhibited by a peptide or antibody that blocks binding of TSP1 to CD36. In another study, a recombinant TSR domain of TSP1 that contains its CD36 binding site enhanced the inflammasomedependent maturation of IL- $1 \beta$ in human THP- 1 monocytederived macrophages (254). ROS production is an effector pathway induced by inflammasome activation (1), suggesting that TSP1 signaling through CD36 could increase ROS production by this mechanism.

In contrast to these proinflammatory effects of TSP1 signaling through CD36, the resolution of LPS-induced lung injury was found to be delayed in Thbs ${ }^{-/-}$mice, which was associated with defective macrophage production of IL-10 (314). Administration of recombinant IL-10 to the Thbs $1^{-/}$ mice corrected this defect in vivo. IL-10 production by Thbs $1^{-1-}$ macrophages in vitro could be restored by a recombinant TSP1 TSR construct, and siRNA knockdown of CD36 in macrophages inhibited IL-10 production, confirming an inhibitory role for TSP1-CD36 signaling in macrophage inflammatory responses. TSP1 signaling via CD47 may also contribute to IL-10 regulation in macrophages because circulating IL-10 levels were elevated in $\mathrm{Cd}_{47^{-1-}}$ mice infected with Candida albicans (180), and TSP1 inhibited IL10 expression in irradiated ANA-1 macrophages (204). TSP1 at $2.2 \mathrm{n} M$ also inhibited IL-10 mRNA expression in Jurkat T cells but not in a CD47-deficient mutant, demonstrating that TSP1 signaling through CD47 can also regulate expression of this anti-inflammatory cytokine (204).

Further insights into TSP1 regulation of macrophage ROS signaling were obtained by investigating how TSP1 regulates macrophage killing of tumor cells (154). Treatment of interferon- $\gamma$-differentiated U937 cells, monocytes, and murine macrophages with TSP1 $(\sim 10 \mathrm{nM})$ for $40-130 \mathrm{~min}$ (depending on cell type) augmented phorbol ester-mediated superoxide production as characterized by luminol-enhanced chemiluminescence, whereas treatment with exogenous SOD quenched the ROS signal (154).

A recombinant N-terminal domain of TSP1, but not the TSR or C-terminal domains, partially recapitulated the effect of TSP1 to increase phorbol ester-stimulated superoxide production. The $\mathrm{N}$-terminal domain contains binding sites for several $\beta 1$ integrins. A function-blocking antibody to integrin $\alpha 6 \beta 1$ and an $\alpha 6 \beta 1$-binding peptide derived from this domain of TSP1 partially suppressed the TSP1-induced production of superoxide by differentiated U937 cells. The ability of TSP1 to enhance ROS depended on intracellular $\mathrm{Ca}^{2+}$ and was inhibited in the presence of extracellular ethylene glycol-bis $(\beta$ aminoethyl ether)-N,N, $\mathrm{N}^{\prime}, \mathrm{N}^{\prime}$-tetraacetic acid. The cytotoxic activity of activated macrophages for tumor cells in these experiments depended on extracellular release of superoxide. TSP1 consequently enhanced the killing of target tumor cells by human and murine macrophages.

3. Role of CD47 counter-receptor SIRP $\alpha$. Studies of signal regulatory protein $\alpha(\operatorname{SIRP} \alpha)$ signaling in macrophages indicate that this counter-receptor for CD47 can regulate superoxide production in a cell autonomous manner, wherein CD47 serves as the ligand that activates SIRP $\alpha$ via cell-cell interactions $(5,136)$. One mechanism involves reverse CD47$\operatorname{SIRP} \alpha$ signaling (5). Binding of the $\operatorname{IgV}$ domain of CD47 to SIRP $\alpha$ on macrophages recruits Janus kinase (JAK) and induces

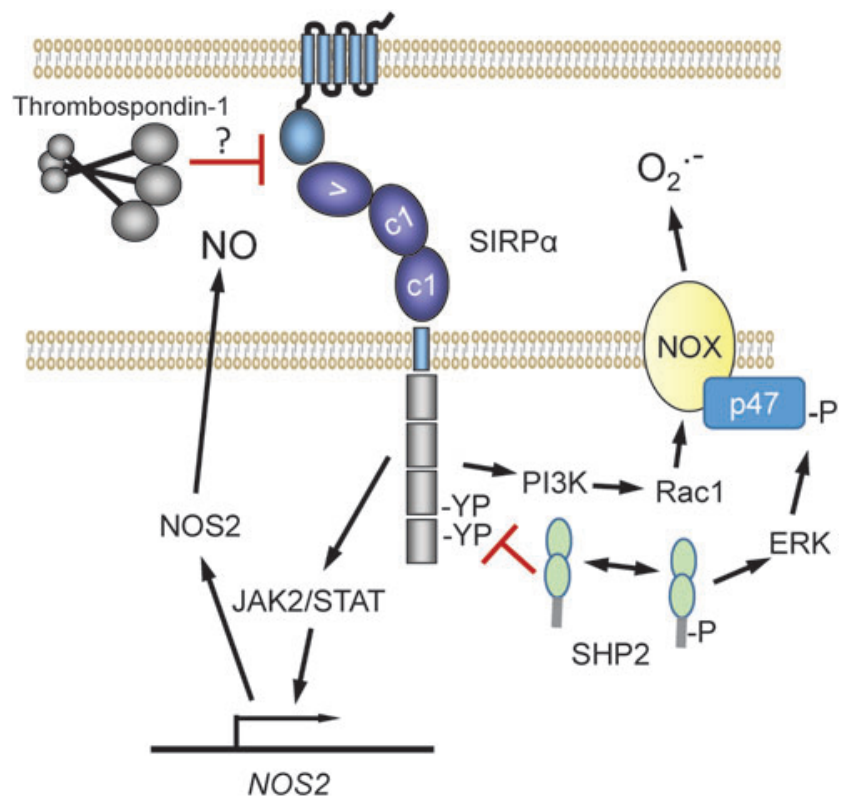

FIG. 9. Model for TSP1 modulation of SIRP $\alpha$ mediated ROS and NO production. Binding of CD47 to the extracellular V-domain of SIRP $\alpha$ induces tyrosine phosphorylation of the cytoplasmic domain, which recruits the phosphatase SHP2. Binding of its counter-receptor also increases JAK2/STAT signaling to induce NOS2 expression and PI-3-kinase-dependent Rac1 recruitment to Nox1, which activates it to produce extracellular superoxide. Because TSP1 inhibits the interaction of the extracellular domain of SIRP $\alpha$ to CD47 in biochemical assays (84), TSP1 has the potential to inhibit these SIRP $\alpha$ signaling pathways independent of its CD47-mediated modulation of redox signaling. $\operatorname{SIRP} \alpha$, signal regulatory protein $\alpha$. To see this illustration in color, the reader is referred to the web version of this article at www.liebertpub.com/ars

its Tyr phosphorylation (Fig. 9). This results in JAK/signal transducer and activator of transcription (STAT)-mediated induction of NOS2 expression, and the resulting released $\mathrm{NO}$ can react with superoxide to form the nitrosating species $\mathrm{N}_{2} \mathrm{O}_{3}$. In parallel, SIRP $\alpha$ ligation induces phosphatidylinositol 3-kinasedependent Rac1 recruitment to Nox1, increasing superoxide production. A subsequent study reported that the phosphatase SHP2 stimulates ROS production, measured by enhanced luminol chemiluminescence \pm diphenyleneiodonium chloride, by dephosphorylating SIRP $\alpha$ and activating ERK (136), which can activate Nox1 by phosphorylation of p47phox (152) (Fig. 9).

Further studies are needed to determine whether this mechanism is also relevant in nonmyeloid cell types. In addition, given that TSP1 can inhibit binding of recombinant SIRP $\alpha$ to cell surface CD47 (84), the possibility should be considered that TSP1 can inhibit this signaling in cells that express $\operatorname{SIRP} \alpha$ by preventing CD47 counter-receptor binding (Fig. 9).

\section{B. TSP1 and ROS signaling in vascular and renal cells}

Distinct from the innate immune function of extracellular ROS production by inflammatory cells, intracellular ROS production plays important roles in signal transduction through reversible oxidation of reactive thiols on signaling proteins, including tyrosine phosphatases (282). TSP1 expression and intracellular superoxide levels were increased in 
primary human pulmonary arterial endothelial cells exposed to short-term hypoxia $\left(1 \% \mathrm{FiO}_{2}, 12 \mathrm{~h}\right)$ (11). Conversely, hypoxia-mediated increases in superoxide were abrogated by treating cells with a CD47 antibody (clone B6H12, $1 \mu \mathrm{g} / \mathrm{ml}$ ) or with the NOS inhibitor L-NAME, suggesting that eNOS was the source of ROS under these conditions. Interestingly, siRNA suppression of caveolin-1 (Cav-1) restored hypoxiamediated ROS levels in endothelial cells treated with a CD47 antibody, suggesting that TSP1-CD47 dysregulation of Cav1 participated in ROS production by these cells (Fig. 10).

Direct evidence that TSP1 treatment stimulates superoxide production was provided in human aortic VSMCs. Treating cells with $2.2 \mathrm{n} M$ TSP1, which selectively engages CD47 but does not result in significant occupancy of other known TSP1 receptors, for $60 \mathrm{~min}$ resulted in a significant increase in superoxide (36) (Fig. 10). Interestingly, this effect was lost at TSP1 concentrations $>11 \mathrm{n} M$, which are sufficient to activate TSP1 receptors other than CD47. Treatment with a CD47-suppressing morpholino oligonucleotide or a CD47 antibody (clone B6H12) blocked the TSP1-mediated increase in superoxide.

Treating cells with TSP1 resulted in increased phosphorylation of the Nox1 organizer subunit $\mathrm{p} 47^{\text {phox }}$, whereas pharmacological inhibition of protein kinase $\mathrm{C}$ abrogated

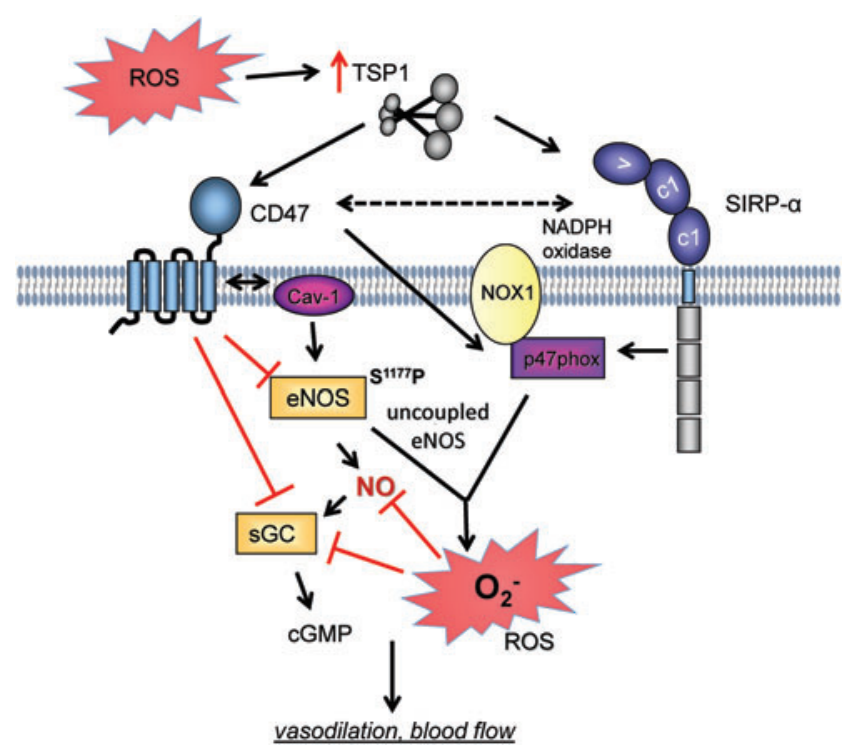

FIG. 10. TSP1 via CD47 and SIRP $\alpha$ stimulates increased superoxide production. TSP1 $(2.2 \mathrm{n} M)$, a concentration found in human plasma in disease, interacts with cell receptors CD47 as well as SIRP- $\alpha$ to stimulate increased superoxide levels. The Nox assembly subunit p47phox is activated (phosphorylated) in cells treated with TSP1 concurrent with increased superoxide. Suppressing Nox1, or interfering with TSP1 interactions with CD47 and SIRP- $\alpha$, abrogates TSP1-mediated increases in superoxide. In hypoxic endothelial cells TSP1 via CD47 dysregulates caveolin 1 (Cav-1) and eNOS, and is associated with increased superoxide. Superoxide may in a feedback manner interact with $\mathrm{NO}$ and sGC to limit NO signaling, and in a feed forward manner to possibly stimulate TSP1 expression. Together these pathways function to limit arterial vasodilation and impede blood flow. To see this illustration in color, the reader is referred to the web version of this article at www.liebertpub .com/ars
TSP1-stimulated increases in superoxide (36). A similar effect was found in arterial tissue. Treating endothelialdenuded murine aortic rings with $2.2 \mathrm{n} M$ TSP1 for $60 \mathrm{~min}$ resulted in increased superoxide levels that were inhibitable by pretreating with a CD47 antibody (clone 301), as confirmed by electron paramagnetic resonance. Similarly, TSP1mediated increases in superoxide were abated in VSMCs treated with NADPH oxidase 1 (Nox1) siRNA or in aortic rings from Nox $^{-/-}$mice but not in cells treated with control siRNA or in aortic rings from WT mice. In renal tubular epithelial cells, TSP1 also increased Nox1-derived superoxide levels and this involved interaction with $\operatorname{SIRP} \alpha$ (307). Superoxide levels represent a balance between enzymatic production and catabolism by SOD. Interestingly, treating VSMCs with TSP1 $(2.2 \mathrm{n} M)$ for 1 and $2 \mathrm{~h}$ did not change SOD expression or activity (36). It remains to be determined whether TSP1-mediated increases in superoxide via SIRP $\alpha$ are independent of, or through, CD47 cross-talk.

TSP1 signaling via CD47 may also increase superoxide production by mitochondria. Aortic VSMCs from young WT mice displayed increased ROS levels compared with cells from arteries from $C d 47^{\prime-}$ mice, as characterized by Mitosox fluorescence (56). Additional chromatographic analysis of the fluorescent product would be required to confirm that CD47 regulates mitochondrial superoxide production rather than other mitochondrial ROS (42). Despite a higher mitochondrial density in skeletal muscle, young $c d 47^{-1}$ mice consumed less oxygen and produced less heat than WT mice, suggesting that mitochondrial coupling is more efficient in the absence of CD47, which is consistent with the decreased ROS production. It is not known whether TSP1 signaling through CD47 similarly controls mitochondrial-derived ROS production in other cell types.

Ex vivo myography experiments in isolated systemic arterial rings indicate a role for TSP1 to inhibit vasodilation in conditions of oxidative stress. TSP1 $(2.2 \mathrm{n} M)$ decreased NOmediated vasodilation of aortic rings from WT and Thbs $1^{-1-}$ mice but not $C d 47^{--}$mice (11). Treatment of WT murine vessels with the membrane-permeable superoxide scavenger 4-hydroxy-2,2,6,6-tetramethylpiperidin-1-oxyl (Tempol) partially reversed the inhibitory actions of TSP1 (307). Tempol can inhibit the Fenton reaction, a source of hydroxyl radical that limits arterial vasodilation (263). This may be clinically relevant in conditions of dysregulated iron metabolism such as sickle cell disease wherein Fenton chemistry and circulating TSP1 are enhanced $(184,203)$.

In ex vivo myography studies of the microcirculation, TSP1 limited coronary arteriole vasodilation, and ROS scavenging again partially reversed the inhibitory effect of TSP1 (182). Unexpectedly, the inhibitory activity of TSP1 noted in arterioles from aged rats, while trending toward, did not reach significance in arterioles from young rats. In these experiments, effects were reported only in vessels from female animals (182). TSP1 also inhibited NO-mediated vasodilation of pulmonary arterial rings from mice as well as rats (214), indicating that TSP1 limits vasodilation of the systemic and pulmonary vasculature. It remains to be seen whether the pulmonary arterial effects of TSP1 are secondary to increased ROS.

TSP1 may also function as an enhancer of and/or a direct vasoconstrictor as murine aortic and pulmonary arterial segments from WT mice treated with TSP1 and phenylephrine (PE) (10) or endothelin-1 (ET-1) (214) demonstrated 
increased contraction (Fig. 11). In the case of ET-1, TSP1 treatment was associated with increased vessel constriction at baseline (214). PE-stimulated vasoconstriction of aortic rings exposed in vivo to angiotensin II (Ang II) was dampened by a panel of ROS mitigators, including catalase, apocynin (a nonspecific Nox inhibitor), ML-171 (a specific Nox1 inhibitor), and Mito-TEMPO (a mitochondrial superoxide scavenger) (72). In mesenteric arteries exposed to ischemiareperfusion in vivo, ET-1-mediated vasoconstriction, as assessed with ex vivo myography, was inhibited by superoxide scavenging with SOD (156). Whether TSP1 alteration in basal tone of ET-1-treated arteries is via increased Nox signaling or some other mechanism requires further research. Interestingly, PE-mediated vasoconstriction was increased in aortic rings from WT mice compared with that from $T h s b 1^{-/}$and $C d 47^{-/}$ mice, and this deficit was corrected after treating null vessels with L-NAME (10).

\section{TSP1 and ROS signaling in vivo}

In vivo, studies in Thbs ${ }^{-/-}$and $C d 47^{/-}$mice indicate that the TSP1-CD47 axis limits blood flow and tissue survival under conditions of fixed ischemia $(85,100 a)$ as well as ischemia-reperfusion $(36,271,307)$, situations characterized by significant oxidative stress. Conversely, suppressing CD47 expression using an adenoviral siRNA vector protected myocardial tissue from ischemia-reperfusion injury in rats while elevating eNOS phosphorylation and NO production, decreasing gp91 ${ }^{\text {phox }}$ and superoxide, decreasing tissue malondialdehyde, and increasing SOD activity (288). Tissue malondialdehyde levels, produced by lipid oxidation, were

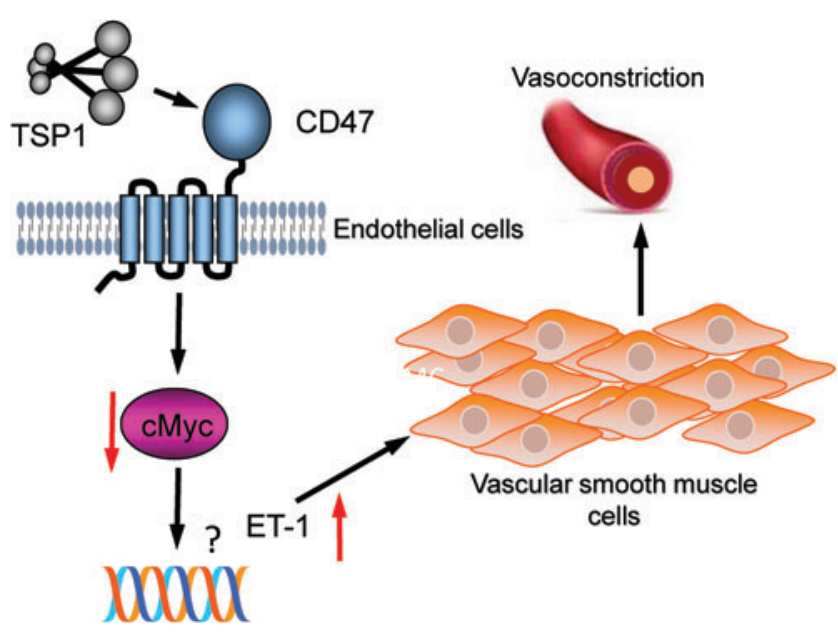

FIG. 11. Pulmonary TSP1-CD47 signaling regulates vasoconstriction via endothelin-1. Pulmonary endothelial cells express ET-1 that alters pulmonary tone acutely and stimulates vasculature remodeling chronically. Smooth muscle cells are paracrine targets of ET-1, whereas in pulmonary hypertension ET-1 receptors are targets for current human therapies. Under hypoxic stress, TSP1 acts via CD47 to repress pulmonary endothelial cMyc via mechanism yet to be defined, thus derepressing ET-1 and promoting arterial vasoconstriction. Conversely, blockade of TSP1-CD47 signaling elevates pulmonary cMyc and decreases ET-1 (not shown). ET-1, endothelin-1. To see this illustration in color, the reader is referred to the web version of this article at www.liebertpub.com/ars correspondingly lower in a rat soft tissue flap ischemiareperfusion model after postreperfusion treatment with a CD47 antibody (clone OX101) (159). Tissue survival was also improved in this ischemia-reperfusion model. Furthermore, exogenous TSP1 (60 $\mu \mathrm{g} / \mathrm{kg}$ body weight) administered via bolus intravenous injection decreased hind limb reperfusion in rats in a Nox1-dependent manner, whereas pretreatment with a CD47 antibody (clone OX101, $0.4 \mu \mathrm{g} / \mathrm{g}$ body weight i.p.) restored the reperfusion deficit induced by exogenous TSP1 (36). Ischemia-reperfusion injury stimulates substantial oxidative stress and contributes to organ failure in clinical transplantation. Mice (217) and rats (140) treated with CD47 antibodies sustained less injury after syngeneic renal transplantation, and in rats this was associated with increased blood flow $24 \mathrm{~h}$ post-transplantation. In healthy and steatotic rat liver transplantation ischemia-reperfusion models, pretreatment with a CD47 antibody (mAb400) was associated with improved animal survival, less organ injury, and lower superoxide levels, as characterized by dihydroethidium fluorescence of liver tissue sections $(303,304)$.

TSP1 is a stress response gene and often upregulated under conditions of increased inflammation. For example, multiple studies have reported TSP1 induction under hypoxia (11, $123,185,187)$ and in response to ischemia $(52,219,241$, 260) or ischemia-reperfusion injuries $(89,125,138,215$, $217,228,271)$, situations well known to upregulate ROS. This raises the intriguing hypothesis that ROS signaling may increase TSP1 expression. Arterial smooth muscle cells from mice overexpressing a nonfunctional form of Nox4 showed decreased TSP1 mRNA and protein expression (275), suggesting that Nox4 is a proximate driver of TSP1 expression. Fibroblasts treated with doxorubicin displayed increased ROS levels and TSP1 protein expression (269).

Conversely, in astrocytes, $\mathrm{CoCl}_{2}$-mediated increases in ROS were associated with decreased TSP1 mRNA and protein levels, and these changes were blocked by pretreating cells with with $\mathrm{N}$-acetylcysteine but not resveratrol (29). Curiously, treatment of astrocytes with resveratrol alone significantly increased TSP1 mRNA levels (29), whereas others have found that $\beta$-amyloid inhibits TSP1 release from astrocytes (200). These findings may be relevant to the accumulating evidence linking the neurodegenerative condition, Alzheimer's disease and TSP1 (19, 200, 232). Further studies employing exogenous ROS and gene silencing of ROS enzymatic sources would be useful to evaluate possible ROS-stimulated feed-forward induction of TSP1.

\section{ROS Regulation by Other Matricellular Proteins}

\section{A. $C \mathrm{CN} 1$}

CCN1 (CYR61), a member of the CCN family of matricellular proteins, plays an essential role in TNF $\alpha$-induced apoptosis. This activity is mediated by binding to its cell surface integrin receptors $\alpha \mathrm{v} \beta 5$ and $\alpha 6 \beta 1$ and the heparan sulfate proteoglycan syndecan- 4 to induce the accumulation of a high level of ROS through 5-lipoxygenase and mitochondria, accompanied by cytochrome c release (28) (Fig. 12). Within $10 \mathrm{~min}$, CCN1 activates neutral sphingomyelinase-1, which is a major source of CCN1-induced superoxide and hydrogen peroxide (detection methods given in Table 1), driven by a synergism between CCN1 and Fas ligand (101). CCN2 (CTGF) also synergizes with Fas ligand to induce 


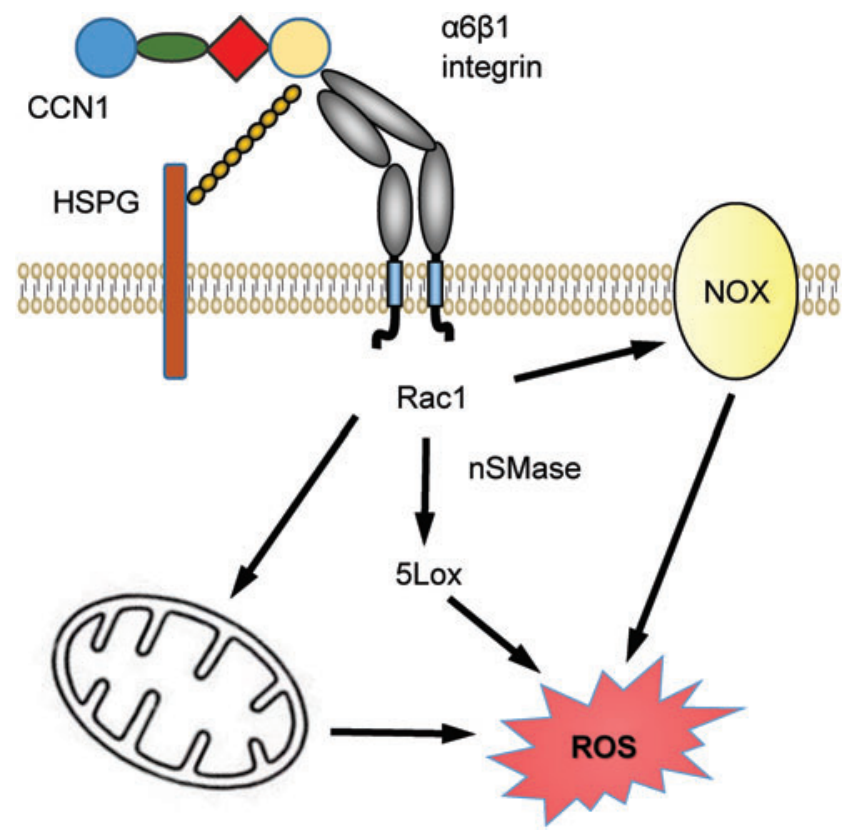

FIG. 12. Regulation of ROS signaling by CCN1. CCN1 signaling mediated by binding of its C-terminal domain to $\alpha 6 \beta 1$ integrin and a cell surface HSPG increases ROS production via Rac-1-mediated activation of Nox, nSMase-dependent activation of 5Lox, and activation of mitochondrial ROS production. 5Lox, 5-lipoxygenase; HSPG, heparan sulfate proteoglycan; nSMase, neutral sphingomyelinase. To see this illustration in color, the reader is referred to the web version of this article at www.liebertpub.com/ars

apoptosis by elevating cellular ROS levels (101). Binding to LRP1 is required as a coreceptor for CCN1-induced ROS generation (102). CCN1 inhibited EGF receptor-dependent hepatocyte proliferation through $\alpha 6 \beta 1$ integrin-mediated accumulation of ROS, and this was attenuated by treatment with apocynin or the Rac guanine nucleotide exchange factor inhibitor NSC23766 (27). Loss of this signal in $C c n 1^{d m / d m}$ mice, in which CCN1 lacks $\alpha 6 \beta 1$ integrin binding, decreased hepatocyte proliferation through an ROS-mediated increase in p53 and increased hepatic carcinogenesis.

Three of the CCN1 receptors identified in these studies (LRP1, heparan sulfate proteoglycan, and $\alpha 6 \beta 1$ integrin) also function as TSP1 receptors, and as discussed previously, $\alpha 6 \beta 1$ integrin is required for TSP1 to augment phorbol esterstimulated superoxide production by macrophages (154). Therefore, different matricellular proteins may utilize convergent receptor signaling pathways to regulate ROS production.

A recent study demonstrated that $\mathrm{CCN} 1$ expression is induced by oxidative stress in human dermal fibroblasts (198). Treatment with $\mathrm{N}$-acetyl-L-cysteine significantly reduced CCN1 expression and prevented ROS-induced loss of type I collagen in dermal fibroblasts and human skin in vivo. Increased CCN1 expression was also reported in activated hepatic stellate cells and portal myofibroblasts (15). Adenoviral-mediated overexpression of CCN1 in myofibroblasts significantly inhibited production of collagen type I while inducing intracellular ROS production assessed by oxidation of $2^{\prime}, 7^{\prime}$-dichlorofluorescein (15). These studies suggest that CCN1 is part of a feedback loop involving bidirectional signaling between $\mathrm{CCN} 1$ and $\mathrm{ROS}$ that mediates its antifibrotic activity.

\section{B. Periostin}

Periostin is a matricellular protein that is induced at sites of inflammation and in the tumor microenvironment (142). Several studies have implicated ROS as a target of periostin signaling and in regulating periostin expression, but the nature of this regulation may be tissue specific. Cyp $1 b 1^{-1-}$ mice exhibited decreased expression of periostin, increased lipid peroxidation, and abnormalities in their trabecular meshwork tissue (313). Trabecular meshwork cells from $C y p l b 1^{-1-}$ mice had increased ROS levels detected by dihydroethidium fluorescence and decreased periostin expression and increased levels of the lipid peroxidation by-product 4-hydroxyl-2noneal on tissue section staining. Inhibition of ROS using Nacetylcysteine reversed this phenotype, but a direct role of ROS in regulating periostin was not established. In contrast, periostin was induced by oxidative stress in fibrotic hypertensive hearts, and pretreating fibroblasts with $\mathrm{N}$-acetylcysteine inhibited angiotensin II-induced oxidative stress and periostin expression (301).

Conversely, periostin inhibits glucose-induced ROS production in endothelial cells (316). Growth of human umbilical vein endothelial cells in medium containing $33 \mathrm{~m} M$ glucose for 2 days induced periostin expression and apoptosis. However, overexpression of periostin in the endothelial cells protected them from apoptosis induced by subsequent exposure to high glucose. This protective activity of periostin was associated with upregulation of heme oxygenase- 1 , which produces the immunosuppressive gasotransmitter $\mathrm{CO}$, and siRNA knockdown of heme oxygenase- 1 restored the induction of ROS detected as 2,7-dichlorofluorescein diacetate (DCFDA) and apoptosis in high-glucose medium. Periostin was also demonstrated to protect mitochondrial function in cells exposed to high glucose as assessed by preservation of mitochondrial $\Delta \psi \mathrm{m}$, increased Bcl 2 expression, and decreased Bax expression.

\section{Tenascin-C}

The ability of antioxidants such as N-acetyl-L-cysteine, catalase, and 1,2-dihydroxy-benzene-3,5-disulfonate to inhibit the induction of tenascin-C by mechanical strain in neonatal rat cardiac myocytes suggests that this matricellular protein is also a target of redox signaling (305).

\section{Caveats}

Most studies to date of matricellular proteins and ROS relied on fluorogenic cell-permeable dyes to assess intracellular ROS production (Table 1). Although this is an acceptable starting point, methods exist that enable precise characterization of ROS. Detailed chemical and biophysical characterization of ROS has been reported for some TSP1 studies $(36,307)$, but this remains to be addressed for other matricellular proteins.

\section{CD47 Regulation of Redox Homeostasis in Irradiated Cells}

\section{A. NO and radiosensitivity}

Although NO under some conditions has a radioprotective activity (299), NO can also be a radiosensitizer (296), and current data do not support an NO-dependent mechanism to account for the increased radioresistance of CD47-deficient 
cells or WT cells in which CD47 expression was suppressed (160). Treating human umbilical vein endothelial cells with the NO donor DETA/NO or elevating its downstream effector cGMP by treating cells with 8-Br-cGMP did not confer radioprotection to the same cells that were protected by blocking CD47. Conversely, inhibiting NO production in the cells using L-NAME did not prevent the radioprotection caused by CD47 blockade. Therefore, enhancing NO/cGMP signaling is neither necessary nor sufficient to confer the radioprotection obtained by blocking CD47.

Other studies established that blocking CD47 signaling augments autophagy in irradiated cells and mice $(244,245)$. Inhibiting this protective autophagy response eliminates the survival advantage of irradiated CD47-deficient cells. A role for redox signaling in this radioprotective mechanism has not been identified, but redox signaling plays a well-established role in regulation of autophagy (306).

\section{B. CD47-dependent regulation of redox metabolites in irradiated cells}

Additional metabolic pathways through which CD47 blockade confers radioprotection were revealed through a global analysis of the metabolic changes that are induced after exposure to ionizing radiation in WT cells versus a CD47deficient somatic mutant of Jurkat $\mathrm{T}$ cells. This analysis identified several metabolic pathways that are basally regulated by CD47 as well as a global stabilization of metabolism in irradiated CD47-deficient cells (165) (Fig. 13). Of the 342 named metabolites quantified, 27 were significantly altered at $2 \mathrm{~h}$ and 112 at $8 \mathrm{~h}$ after irradiation in WT cells. Of these, the majority progressively fell below baseline levels $(81 \%$ at $2 \mathrm{~h}$ and $98 \%$ at $8 \mathrm{~h}$, respectively). In contrast, the metabolome of irradiated CD47-deficient cells was remarkably stable, with only 6 metabolite levels significantly altered at $2 \mathrm{~h}$ and $29(8 \%)$ at $8 \mathrm{~h}$. Furthermore, $86 \%$ of the metabolites that were altered at $8 \mathrm{~h}$ in CD47-deficient cells showed increased rather than decreased abundance. Thus, CD47-deficient cells are globally resistant to the metabolic changes caused by ionizing radiation. Moreover, the preponderance of elevated metabolites at $8 \mathrm{~h}$ suggested that CD47-deficient cells actively compensate for radiation stress by increasing levels of key metabolites.

Metabolic pathways required for controlling oxidative stress and mediating DNA repair were generally enhanced in irradiated CD47-deficient cells, and the global declines in glycolytic and tricarboxylic acid cycle metabolites characteristic of normal cell and tissue responses to ionizing radiation were prevented in the absence of CD47 (165). Basal glucose uptake was higher in CD47-deficient cells, and uptake remained higher after irradiation. This was reflected by higher expression of the glucose transporter Glut1 in irradiated CD47-deficient cells. Thus, CD47 mediates signaling from the extracellular matrix that coordinately regulates basal metabolism and cytoprotective responses to radiation injury. Specific preservation of metabolites involved in de novo nucleotide biosynthesis, methyl group metabolism, glutathione homeostasis, and the glyoxalase system indicates an enhanced detoxification and repair capacity in irradiated CD47-deficient cells.

Exposure to ionizing radiation depletes cellular glutathione as it is consumed in the repair of damage caused by the resulting oxidative stress $(133,190)$. Levels of oxidized and

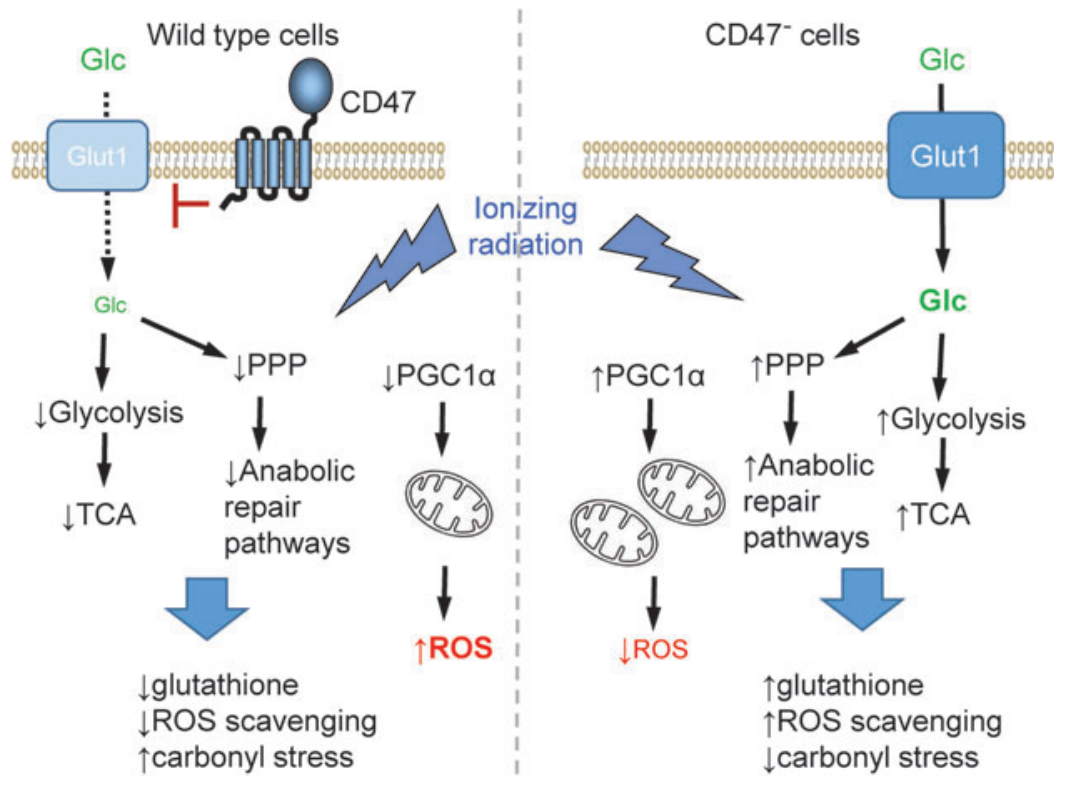

FIG. 13. Radioprotection by loss/blockade of CD47 and ROS. Genotoxic stress caused by ionizing radiation results in opposing global metabolic responses in cells that express or lack expression of CD47 (165). Irradiated WT cells lose capacity for glucose uptake associated with loss of the glucose transporter Glut1. Decreased flux through glycolysis, the TCA cycle, and the PPP lead to impaired anabolic pathways required to repair free radical damage of critical cell macromolecules and loss of glutathione and glyoxalase pathway scavenging of reactive carbonyl metabolites generated by radiation-induced free radicals. All of these repair pathways are preserved in CD47-deficient cells. In addition, PGC1 $\alpha$ dependent support of mitochondrial function and numbers is enhanced in the absence of CD47 and minimizes mitochondrial production of ROS (56). PPP, pentose phosphate pathway; TCA, tricarboxylic acid cycle; WT, wild type. To see this illustration in color, the reader is referred to the web version of this article at www.liebertpub.com/ars 
reduced glutathione fell progressively as expected in irradiated WT cells but were preserved in irradiated CD47-deficient cells (165). The half-cell potential of the glutathione redox couple $\left(\mathrm{E}_{\mathrm{GSH}}\right)$ slightly decreased in irradiated WT cells but increased at $2 \mathrm{~h}$ before returning to basal levels in irradiated CD47-deficient cells. Consistent with the improved preservation of glutathione levels, total free thiol concentrations in cell lysates were lower basally in CD47-deficient cells and remained stable for $8 \mathrm{~h}$ after irradiation, whereas glutathione levels fell sharply at $2 \mathrm{~h}$ in irradiated WT cells. The acute loss of glutathione in the irradiated WT cells was consistent with the observed suppression of glycolysis in the same cells (139).

Several metabolic precursors of glutathione including cystathionine, glutamate, $\gamma$-glutamylcysteine, and 5-oxoproline fell progressively after irradiation in WT cells, but were preserved or elevated in irradiated CD47-deficient cells, and $\gamma$-glutamylcysteine levels were elevated above baseline at $8 \mathrm{~h}$. $\gamma$-Glutamylcysteine is the immediate precursor of glutathione, and its elevated level indicates a higher capacity for biosynthetic replenishment of glutathione after irradiation of the CD47-deficient cells.

Accumulation of 2-oxoaldehydes such as methylglyoxal causes damage to cells by reacting with DNA and proteins and generating advanced glycation end products, and the glyoxalase is critical to limit this damage under conditions of oxidative stress such as caused by ionizing radiation (25, 273). Furthermore, methylglyoxal can activate Nox in certain cells to increase superoxide, leading to induction of specific matrix molecules including fibronectin (74, 120). Methylglyoxal accumulates after radiation-induced redox stress, and glutathione is required for its metabolism to lactate via Slactoylglutathione and glyoxalase I. Ionizing radiation induces glyoxalases I and II (230). Levels of S-lactoylglutathione fell dramatically in irradiated WT cells but were preserved in irradiated CD47-deficient cells (165), which may be enabled by the preservation of glutathione homeostasis in irradiated CD47-deficient cells. Therefore, an enhanced glyoxalase pathway may enable irradiated cells more effectively limit carbonyl stress in the absence of CD47.

\section{CD47 regulation of mitochondrial redox}

Some of the metabolic advantages involving mitochondrial metabolism may be mediated by CD47 regulation of the transcription factor peroxisome proliferator-activated receptor gamma coactivator $1-\alpha(\mathrm{PGC} 1 \alpha)$. CD47 signaling regulates expression of PGC1 $\alpha$ in skeletal muscle (56), and its expression is induced by irradiation in CD47-deficient but not in WT Jurkat cells (165). PGC1 $\alpha$ positively regulates several of the genes that were selectively induced in irradiated CD47-deficient cells, including glutathione peroxidase-1 (Gpxl). Cytosolic and mitochondrial Gpx1 is cytoprotective against oxidative stress by limiting hydrogen peroxide accumulation (148). Therefore, Gpx1 induction may contribute to the increased radioresistance of $C D 47^{-1}$ cells. This and other transcriptional targets of PGC $1 \alpha$, by inhibiting the generation of mitochondrial-driven ROS (251), may account for the maintenance of a favorable redox environment in irradiated CD47-deficient cells.

As discussed hereunder, CD47 also regulates cMyc, and cMyc controls several metabolic pathways that regulate radioresistance, including glucose uptake and glutathione homeostasis $(64,168)$. Further studies are needed to deter- mine whether TSP1-mediated increases in ROS separate from irradiation stress occur through suppression of counterregulator systems such as Gpx1.

\section{TSP1/CD47 Regulation of Stem Cells and Tissue Self-Renewal}

\section{A. Redox signaling in stem cells}

To date, most investigations of the functions of TSP1 in redox signaling have focused on differentiated vascular and immune cells. However, several of the redox pathways regulated by TSP1 also play important roles in stem cell selfrenewal and differentiation (Fig. 14A). Stem cells can be quiescent or proliferative by a process of asymmetric division wherein one of the daughter cells is a stem cell that preserves the DNA of the parent stem cell and the other contains newly synthesized DNA and commits to a differentiation pathway determined by its tissue context.

$\mathrm{NO}$ has been proposed to stimulate self-renewal in several cell types (12) (Fig. 14B). The general prosurvival effects of low concentrations of NO extend to stem cells. Murine bone marrow stromal (OP9) cell apoptosis was reduced in cells treated with the NO donor S-nitroso-N-acetylpenicillamine or YC-1 (300). In embryonic stem cells, treatment with low concentrations of an NO donor delayed the process of differentiation and maintained expression of the key self-renewal transcription factors: octamer-binding transcription factor 4 (Oct4), Nanog, and sex determining region Y-box 2 (Sox2) (270). Hematopoietic stem cell sensitivity to the self-renewal effects of NO may decrease with cell age (99). In vitro, treatment with the NO donor linsidomine (3-morpholinosydnonimine, SIN-1) stimulated proliferation of muscle satellite cells (a precursor muscle cell type), and this was inhibited by concurrent treatment with L-NAME (20). Hematopoietic stem cells treated with an NO donor proliferated faster and had increased expression of the self-renewal transcription factor cMyc (183). Thus, multiple stem cell populations are sensitive to the proliferative/cell cycle stimulating effects of NO.

A link between ROS/Nox and self-renewal is emerging (Fig. 14B). siRNA suppression of Nox 2 and Nox4 was associated with a decrease in murine-induced pluripotent stem cells in culture as well as a decrease in Sox 2 and Oct 4 expression compared with control siRNA transfected cells (106). Loss of ROS homeostasis and defense mechanisms such as transcriptional regulators that control ROS scavenging enzymes deterred the proliferative capacity of stem cells (167), whereas suppression of the scavenging enzyme Mn-SOD was associated with decreased expression of several pluripotent genes (235). Movement of stem cells to areas of ischemic muscle injury was decreased in Nox $2^{-/-}$mice (281). As with NO, ROS control of self-renewal appears to be concentration dependent and temporally dependent.

\section{B. TSP1 and CD47 in stem cell self-renewal and tissue regeneration}

The first indications that TSP1-CD47 signaling limits stem cell self-renewal came from experiments employing endothelial cell cultures from lungs of young male WT and $C d 47^{-1}$ mice. $C d 47^{-1}$ cells could be passaged continuously upward of 6 months with no loss of proliferative capacity. In contrast, lung endothelial cells from WT mice could not be 

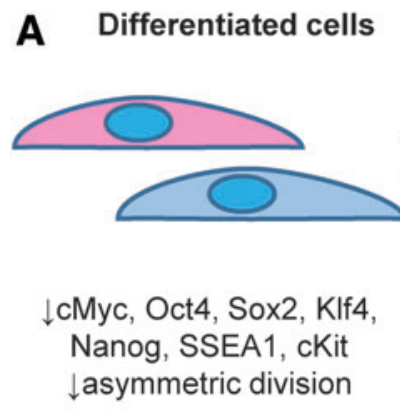

\section{Stem cells}

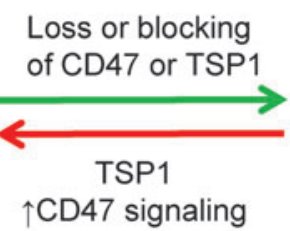

$\uparrow \mathrm{cMyc}$, Oct4, Sox2, Klf4
Nanog, SSEA1, CKit
$\uparrow$ asymmetric division

B
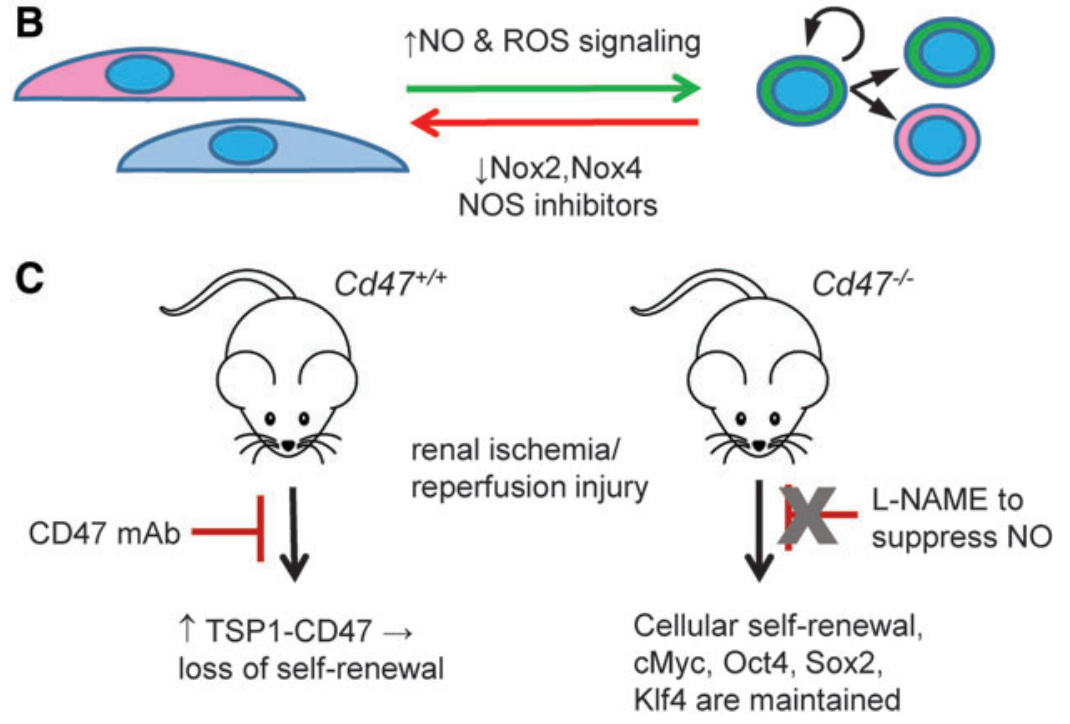

FIG. 14. Regulation of stem cell self-renewal and differentiation by TSP1/CD47 and redox signaling. (A) Loss of TSP1 or CD47 induces spontaneous conversion of differentiated cells to a stem cell state with enhanced expression of the stem cell transcription factors cMyc, Sox2, Oct4, and Klf4 and an increased frequency of asymmetric cell division (113). Conversely, increased CD47 expression or exposure to the ligand TSP1 suppresses stem cells. (B) Consistent with the increased NO signaling in $\mathrm{Cd}_{4} 7^{-1}$ and $\mathrm{Thbs}^{-/-}$cells, NO donors promote stem cell self-renewal, and NOS inhibitors promote differentiation (12). (C) In vivo, $C d 47^{-1}$ mice are protected from renal ischemia/reperfusion injury and exhibit increased expression of the stem cell transcription factors (217). Conversely, loss of stem cell transcription factors and selfrenewal in injured WT mice can be prevented by treating with a CD47 antibody that blocks TSP1 binding. However, pansuppression of NOS activity oral L-NAME does not decrease the enhanced transcription factor expression in kidneys in $C d 47^{-1-}$ mice at baseline or after ischemia-reperfusion injury. Therefore, the preservation of self-renewal in $C d 47^{-1-}$ mice is probably independent of enhanced NO biosynthesis. L-NAME, $\mathrm{L}-\mathrm{N}^{\mathrm{G}}$-nitroarginine methyl ester. To see this illustration in color, the reader is referred to the web version of this article at www.liebertpub.com/ars

passaged more than three or four times before becoming senescent as assessed by induction of senescence-associated $\beta$-galactosidase activity (113). Null cells continued to display normal endothelial cell morphology even after extended passage. A similar proliferative advantage was observed using Thbs $1^{-1-}$ lung endothelial cells.

The absence of CD47 was associated with increased expression of four critical stem cell transcription factors: Oct4, Sox2, Kruppel-like factor 4 (Klf4), and cMyc (Fig. 14A). Treatment with exogenous TSP1 $(2.2 \mathrm{nM})$ decreased cMyc mRNA in WT Jurkat $\mathrm{T}$ cells but not in a somatic mutant lacking CD47. Re-expression of CD47 in the CD47-deficient Jurkat cells suppressed cMyc expression. Conversely, in lossof-function experiments, suppression of CD47 with a morpholino oligonucleotide in isolated endothelial cells and in mice increased mRNA expression of several self-renewal transcription factors (113).

These findings have since been confirmed in murine brain microvascular endothelial cells, as endogenous TSP1 in WT cells was associated with fewer S phase cells than $C d 47^{-1-}$ cells over several passage events (60).The effects of TSP1 on self-renewal and differentiation are not limited to endothelial cells. Bronchioalveolar stem cell lineage-specific differentiation was found to be supported by TSP1 (132). Furthermore, renal tubule epithelial cells harvested from kidneys of young male $C d 47^{-}$mice had constitutive upregulation of stem cell transcription factors compared with cells from kidneys from WT mice (217). However, the implications of these cell studies for self-renewal after injury were not clear. Pretreatment of WT mice with a CD47 antibody preserved organ function after syngeneic survival renal transplant and this was associated with increased expression of Sox 2 and cMyc (217).

Surprisingly, $C d 47^{-}$mice given L-NAME in their drinking water $(0.5 \mathrm{mg} / \mathrm{ml})$ for $48 \mathrm{~h}$ to limit $\mathrm{NO}$ production were nonetheless protected from renal ischemia-reperfusion injury, and this was associated with preservation of cell selfrenewal as characterized by stem cell transcription factor 
protein expression and increased $\mathrm{Ki}^{+}$cells (217), suggesting that TSP1-CD47 signaling may inhibit self-renewal independently of its established inhibitory effects on NO. Further studies are needed to test whether the advantage in self-renewal found in cells from young mice that lack CD47 persists with advancing age, as other work indicates that the increased number of mitochondria and size in skeletal muscle from young $C d 47^{-1}$ mice were lost in aged mice (56).

\section{Therapeutic Opportunities to Improve Redox Signaling}

\section{A. Dysregulation of NO signaling by TSP1/CD47 in clinical disease}

1. Association of elevated TSP1 with impaired NO signaling in cardiovascular disease. Hyperactive TSP1 signaling is associated with clinical diseases known to have loss of NO signaling and resistance to NO pathway supplementation. An earlier study of patients with peripheral vascular disease and end-stage critical limb ischemia demonstrated markedly increased ( 20-fold) expression of TSP1 via in situ hybridization of muscle samples from amputated distal limbs compared with those from proximal limb muscle samples (52). Interestingly, TSP1 induction in amputated limb samples was localized to vascular endothelial cells and to macrophages adjacent to the vascular compartment. TSP1 expression was essentially undetectable in muscle samples from the proximal healthier limb areas.

Likewise, plasma TSP1 levels, quantified by an aptamerbased assay, were increased in ST-elevation myocardial infarction subjects with high atherosclerotic plaque burden than in healthy controls (100). Elevated plasma TSP1 levels were independently associated with coronary artery disease in a diabetic population (30). This finding is not unexpected given data showing that TSP1 is upregulated by glucose $(151,195$, 201, 292) and increased in individuals with diabetesassociated renal disease (75).

2. Genetic dysregulation of thrombospondins in cardiovascular disease. A missense mutation of TSP1 $\left(\mathrm{N}^{700} \mathrm{~S}\right)$ was associated with increased risk of premature coronary artery disease $(276,317)$. However, in individuals homozygous for mutation, plasma TSP1 levels were decreased (276), leaving indeterminate whether the mutation provides gain or loss of TSP1 function. However, in vitro studies indicated that treatment with $10 \mu \mathrm{g} / \mathrm{ml}$ of mutant $\mathrm{N}^{700} \mathrm{~S}$ TSP1 enhanced platelet aggregation and surface binding compared with that of nonmutant TSP1, suggesting a gain of function, but was itself more susceptible to proteolysis (177). Assessment of the status of the relevant TSP1 receptors in this population would likely provide further insights.

In a related direction of research, a missense variant of TSP4 $\left(\mathrm{A}^{387} \mathrm{P}\right)$ was associated with myocardial infarction (276), a finding subsequently confirmed $(35,297)$. Elevated levels of the TSP1 paralog TSP2 were associated with mortality and adverse cardiovascular events in individuals with heart failure (HF) with preserved ejection fraction (114) as well as in individuals with HF and reduced ejection fraction (70). The findings of associations between TSP2 and TSP4 mutations and cardiovascular risk are likely important as both can interact via CD47, although with less affinity as compared with TSP1, to limit NO signaling in vascular cells (84).
It is not known whether $\mathrm{N}^{700} \mathrm{~S}$ TSP1 or mutant TSP2 and TSP4 limit NO signaling.

3. Circulating TSP1 as a biomarker of redox dysregulation. Plasma TSP1 is also upregulated in patients with stroke and predicted mortality and poor outcome, as defined as an elevated Rankin score, recurrent stroke, or a new cardiovascular event (59). However, it is not clear what this means in relation to TSP1 expression in the brain or cerebral spinal fluid. TSP1 is too large to cross the normal blood brain barrier, but might do so under inflammation-associated alterations in barrier function. Furthermore, plasma TSP2 levels are elevated in stroke patients than in controls (181). In pediatric sickle cell disease, subjects' elevated plasma TSP1 levels are positively associated with silent cerebral infarction (51).

In adult sickle cell disease subjects, plasma TSP1 is increased in vaso-occlusive events (VOEs) (184). Patients experiencing active VOEs had significantly elevated plasma TSP1 levels [median (IQ range) $=898 \mathrm{ng} / \mathrm{ml}(381-1657)$ ] versus sickle cell disease patients not in VOEs $[303 \mathrm{ng} / \mathrm{ml}$ (187-939) and healthy controls (239 ng/ml (125-344) $p=0.001]$ ) (184). As TSP1 is found preformed in platelets, these studies in sickle cell disease cohorts are important in that these authors observed a protocol to mitigate platelet activation during blood collection and processing.

Increased TSP1 signaling concurrent with dysregulation of the systemic vasculature is increasingly demonstrated. In vastus lateralis muscle samples from subjects with essential hypertension, TSP1 protein levels, as characterized by Western immunoblot, trended higher than those in controls but did not reach significance (62). In patients with hypertension, elevated plasma TSP1 was noted in association with decreased forearm-mediated vasodilation (18). However, in this study, TSP1 levels appeared elevated in controls compared to TSP1 levels reported in controls elsewhere (184), suggesting possible confounding by platelet activation. Nonetheless, elevation of plasma TSP1 in individuals with hypertension has been confirmed $(80,241)$, although interpretation of these other studies is complicated by the presence of other cardiovascular comorbidities. It is not clear whether TSP1 is functioning as a direct presser in hypertension or is elevated secondary to other factors, including deregulation of the angiotensin-renin axis, as angiotensin II stimulates TSP1 production in some cells (175).

4. TSP1 in pulmonary disease. At the same time, a link between TSP1 and dysregulation of the pulmonary circulation has been proposed $(116,212)$. PH is a rapidly fatal disease that is characterized by loss of NO signaling, increased ROS, pulmonary vascular rarefaction, and remodeling and subsequent right HF. In a prospective cohort of PH patients, elevated plasma TSP1 correlated with the degree of PH and with mortality (103). In a small longitudinal $(n=8)$ cohort, plasma TSP1 levels increased coincident with the development of scleroderma-associated PH (117). TSP1 and CD47 protein are increased in lungs and distal pulmonary arteries from $\mathrm{PH}$ patients compared with samples from non-PH controls (214). Bias-reduced logistic regression analysis found significant positive relationships $(p<0.05)$ between parenchymal and pulmonary arterial TSP1 protein expression and PH. Interestingly, treatment of healthy human distal 
pulmonary arteries with exogenous TSP1 $(2.2 \mathrm{n} M)$ inhibited NO-mediated vasodilation, whereas treatment with a CD47 antibody (clone B6H12) improved NO-mediated vasodilation in distal pulmonary arteries from end-stage $\mathrm{PH}$ lungs (214).

In individuals with sickle cell disease-associated PH, single nucleotide polymorphisms in TSP1 (rs1478605 and rs 1478604) are associated with changes in pulmonary arterial systolic pressure, as characterized by Doppler determination of tricuspid regurgitant jet velocity (98). Since the variants localize proximate to the start sight of transcription, it would be important to determine whether they alter TSP1 transcription. The finding of increased TSP1 and CD47 expression in lungs and pulmonary arterial vascular cells from a sickle cell disease patient with end-stage PH (216) underscores the possible importance of this.

5. TSP1 and heart disease. Left ventricular (LV) HF affects $>650,000$ people in the United Sates annually (115, 253). NO dysregulation contributes to LV HF (221), and $\mathrm{Nos}^{-/-}$mice experience more LV dysfunction and fibrosis after LV pressure overload than controls (220). TSP1 but not CD47 protein was induced in the left ventricles of WT mice after 4 weeks of transverse aortic constriction (TAC) concurrent with increased histone deacetylase 3 (HDAC3) and calcium/calmodulin-dependent protein kinase II expression, and LV hypertrophy and dysfunction (229). Conversely, $\mathrm{Cd} 47^{-}$ mice did not develop LV hypertrophy and dysfunction and had less LV HDAC3 expression both before and after TAC.

The role of NO in this process is uncertain, as cardiac myocytes treated with exogenous $\mathrm{NO} \pm \mathrm{CD} 47$-binding peptide $7 \mathrm{~N} 3$ $(10 \mu M)$ did not show significant changes in either phosphorylated or total HADC3. Nonetheless, WT mice treated with a HDAC3 oligonucleotide morpholino to suppress protein levels or a CD47 antibody responded to TAC with less LV hypertrophy and stiffness ( $\mathrm{dP} / \mathrm{dt} \mathrm{min})$. Together, these findings suggest TSP via CD47 and HDAC3 drives TAC-mediated LV HF.

Other TSPs have been linked to LV HF, but their functions diverge from that of TSP1. Thbs $4^{-/-}$mice developed more LV hypertrophy and fibrosis than controls after 2 weeks of TAC (57), with null mice displaying maladaptation to TAC within as little as 2 days (32). Isolated cardiac trabecular muscle from Thbs $4^{-1-}$ mice showed minimal calcium flux with sustained stretch (32). Conversely, treatment with the CD47-binding peptide $7 \mathrm{~N} 3(10 \mu M)$ stimulated a rapid calcium flux in isolated rat neonatal cardiac myocytes (229). Furthermore, $T h b s 2^{-1-}$ mice were more sensitive to doxorubicin-mediated cardiomyopathy than WT mice (284). These results indicate cardioprotective roles for TSPs other than TSP1 under some conditions. Further studies are needed to assess whether TSP1 and CD47 expression and signaling are adversely altered to contribute to disease in Thbs $2^{-/-}$and $T h b s 4^{-1}$ animals.

The role of other matricellular proteins in pressure overload LV HF from TAC is yet to be studied. In an ex vivo cardiac ischemia-reperfusion model, the absence of CCN1 was associated with greater infarction (311). CCN2 levels were increased in hearts from mutant mice that spontaneously develop cardiac hypertrophy and failure, and CCN2 stimulated increased TSP1 and TSP4 expression in isolated myocytes (278). Mice lacking periostin $\left(\right.$ Postn $\left.^{-/}\right)$showed poorer healing after cardiac infarction (238). Ischemia/ reperfusion and infarction, although inducing oxidative stress in the heart and contributing to HF, are not comparable with pressure overload. Although they could indirectly regulate NO levels via their effects on ROS production, there is no evidence that CCNs or periostin directly alter NO signaling. Further investigation is needed to define whether these stressresponsive matricellular proteins play a role in pressure overload LV HF.

Chronic Ang II signaling also induces LV hypertrophy and $\mathrm{HF}$ in rodents $(71,188)$, and Ang II can stimulate Noxassociated oxidative stress (43). This is interesting in view of findings that Jurkat cells treated with Ang II display inhibition of sGC through increasing calcium flux (202). The same cells treated with the recombinant domain of TSP1 that targets CD47 showed calcium flux and sGC inhibition (202). Together these findings suggest several reasons for possible resistance to Ang II-mediated vasoconstriction in arteries from $T h b s 1^{-/}$and $C d 47^{-1}$ mice, a hypothesis waiting to be tested.

6. TSP1 in aging. Aging is associated with cellular senescence, decreased self-renewal, loss of healing capacity, and altered blood flow. Aging is being reassessed as not only a causative factor in many chronic diseases but perhaps a disease in itself. However, the concept that matricellular proteins may be induced simply by aging is only now being considered (infra vide and Table 2). In associative findings, omentum-derived senescent human mesothelial cells produced significantly more TSP1 than nonsenescent cells (161). That aging alone may induce matricellular expression in people was recently suggested by findings of upregulation of platelet TSP1 in otherwise healthy adults compared with healthy children (33). TSP1 and CD47 expression in the skin of WT mice increased with age and was associated with a loss in tissue blood flow (213), whereas skeletal muscle blood flow in response to ischemia or vasodilators was not diminished in aged $\mathrm{Thbs1^{-/ }}$ and $\mathrm{Cd} 47^{-1}$ mice (86).

\section{B. Therapeutic targeting of the TSP1 receptor CD47}

1. Applications for cardiovascular disease. Because TSP1 is chronically overexpressed in major diseases of aging that are associated with impaired NO production and signaling (Table 2), therapeutics that target the inhibitory receptor

TABle 2. Thrombospondin 1 Is Overexpressed and Predicts Morbidity in Age-Associated Diseases IN PeOPle

Disease Studies linking TSP1

Diabetes and metabolic to disease with aging syndrome

Hypertension, pulmonary hypertension

Peripheral vascular disease and atherosclerosis

Stroke and Alzheimer's disease

Coronary vascular disease, myocardial infarction

Renal failure

$(158,285)$

Glaucoma

$(11,18,103,117$, 214, 216)

$(4,22,39,52,78$, 207, 241)

$(24,45,51,59,232)$

$(41,100,197)$

$(75,80,286)$

Venous stasis ulcers 
CD47 could potentially restore physiological functions of $\mathrm{NO}$ as well as limit some sources of ROS production in these diseases. Antibodies can target CD47 efficiently. However, because of potential agonist/antagonist activity, the effects upon NO and ROS signaling will likely need to be determined for each molecule. In contrast, in preclinical studies, CD47 morpholinos have uniformly improved cell and tissue responses to stress. Both antibodies and morpholinos have been administered chronically to people. However, CD47specific targeting agents should be administered in longterm treatment experiments in mammalian models of cardiovascular and age-related diseases.

Insight into the effects of inhibiting the TSP1-CD47 axis in people may be gathered from current and possible future clinical trials employing CD47 antibodies to suppress tumor growth. Attention to changes in blood pressure, wound healing, and metabolism combined, where possible, with analysis of platelet-poor plasma samples for TSP1 and the blood cell fraction for NO/ROS signaling, would be useful to understanding in human subjects the potential implications of CD47 targeting on homeostasis and cardiovascular health.

2. Therapeutic applications for cancer. The abnormal vasculature of tumors tends to be unresponsive to NO (88), but the ability of CD47 blockade to modulate responses to radiation and redox signaling involved in innate and adaptive antitumor immunity provides therapeutic opportunities for improving the activities of both conventional cytotoxic therapies and immunotherapy of cancer $(134,147,157,248)$. Several companies are developing biologics targeting CD47 that are designed to inhibit its interactions with $\operatorname{SIRP} \alpha$, and several of these have entered human clinical trials for cancer patients (NCT02216409, NCT02678338, NCT02953509, NCT02953782, NCT02367196, NCT02488811, and NCT02641002).

CD47 antibodies have been demonstrated to enhance phagocytic killing of tumor cells by macrophages, but based on the effects of TSP1 and CD47 on ROS production and of TSP1 on oxidative tumor cell killing, complementary therapeutics that selectively inhibit the TSP1/CD47 interaction may also have efficacy. The role of $\mathrm{H}_{2} \mathrm{~S}$ and $\mathrm{NO}$ signaling in $\mathrm{T}$ cell activation combined with evidence that TSP1/CD47 signaling limits $\mathrm{T}$ cell activation and $\mathrm{CD}^{+} \mathrm{T}$ cell killing of target tumor cells also justifies the development of therapeutic inhibitors of TSP1 and CD47 as cancer therapeutics (248). Such TSP1-CD47 targeting therapies are envisioned to have the important added benefit of preventing damaging side effects from radiation and chemotherapy in nonmalignant tissues.

Although CD47/SIRP $\alpha$ inhibitors show antitumor efficacy in a number of xenograft models in Nod/SCID mice, and two $\mathrm{SIRP} \alpha$ decoy receptors are in clinical trials (NCT02663518 and NCT03013218), it is important to recognize that Nod encodes a variant $\operatorname{SIRP} \alpha$ with supraphysiological affinity for human CD47 (122). Therefore, this model creates a strong bias for agents that block the CD47/SIRP $\alpha$ interaction, which is enhanced by interspecies markers of nonself that remain intact in the Nod/SCID model. Indeed, antibody blocking or knockdown of CD47 in immune competent syngeneic mouse tumor models generally does not significantly inhibit tumor growth $(160,242,246,268)$. Thus, it seems unlikely that the CD47 targeting biologics currently in clinical trials will have significant antitumor activities as single agents in human patients who all also bear syngenic tumors.

In contrast, combining CD47 knockdown or blockade with tumor irradiation or cytotoxic chemotherapy can effectively control tumor growth $(134,147,160,246)$. Although autophagy is required for the cytoprotective effect of CD47 blockade in nonmalignant tissue (244), mechanisms by which blockade may sensitize tumor cells to radiation and chemotherapy remain to be identified. Generation of free radicals is central to the antitumor activities of anthracyclines and ionizing radiation. Therefore, understanding how blocking TSP1/CD47 signaling alters the redox environment in tumor versus nonmalignant tissue is important for advancing the clinical applications of such combination therapies.

Studies using hepatocellular and breast carcinoma stem cells have identified genes that exhibit altered expression when CD47 is knocked down or ligated by a therapeutic antibody $(109,134)$. These include regulators of $\mathrm{NF}-\kappa \mathrm{B}$ in the hepatocellular carcinoma (134), which control oxidative stress responses. The same study reported CD47-dependent expression of thioredoxin-interacting protein (TXNIP), and TXNIP was upregulated by treatment with the CD47 antibody B6H12 in triple negative breast cancer stem cells (109). In part by inhibiting the antioxidant function of thioredoxin-2 (Trx2) in the mitochondria, TXNIP limits resistance to oxidative stress, and deletion of TXNIP-protected mice from ischemia-reperfusion injury $(308,309)$. Further studies are needed to test the hypothesis that CD47-mediated upregulation of TXNIP in cancer stem cells could sensitize them to the oxidative stress caused by radiation or anthracyclines.

\section{Conclusions and Outlook}

Matricellular proteins play important roles in higher animals to mediate communication between cells and their microenvironment. Redox signaling is both a target of matricellular protein signaling and a regulator of the expression of several matricellular proteins. TSP1, and to some extent osteopontin and ADAMTS1, regulates the production of NO in specific cell types, although by different mechanisms. Controlling the production of NO is one mechanism to regulate NO signaling, but to date only TSP1 is known to also regulate the ability of cells to respond to exogenous NO (Fig. 5).

Conversely, NO signaling controls the expression of many matricellular proteins, including TSP1, TSP2, SPARC, SMOC1, ADAMTS-2, and ADAMTS5. $\mathrm{H}_{2} \mathrm{~S}$ and ROS signaling likewise control the expression of many matricellular and extracellular matrix proteins, but only TSP1 has been demonstrated to control $\mathrm{H}_{2} \mathrm{~S}$ production and responses to exogenous $\mathrm{H}_{2} \mathrm{~S}$. TSP1, CCN1, and periostin are the known matricellular regulators to date of ROS production (Fig. 2), although the latter functions to suppress rather than increase oxidative stress.

Our understanding of function of matricellular proteins has evolved from their initial roles in altering cell adhesion to recognizing matricellular proteins as physiologically relevant activators of maladaptive redox signaling involved in cellular responses to stress. Dysregulated redox signaling contributes to the pathogenesis of many acute and chronic diseases. $\mathrm{NO}, \mathrm{H}_{2} \mathrm{~S}$, $\mathrm{CO}$, and ROS each play roles in mediating intracellular and paracellular signaling that contributes to these processes. 
Impaired NO signaling is a key contributor to age-related deficiencies in tissue repair and maintenance of vascular perfusion.

Matricellular proteins play important roles in redox homeostasis in acute injury and chronic disease. Dysregulation of TSP1 and other matricellular protein expression and function increases with age (Table 2) and coincides with progressive impairment of NO signaling. The improved recovery from ischemic injury and elevated tissue cGMP in aged $T h b s 1^{-/-}$and $C d 47^{--}$mice provides strong genetic evidence that this pathway plays a major role in age-related loss of NO/cGMP signaling. The ability of a CD47 antibody and antisense morpholino suppression of CD47 to restore normal ischemic injury responses to aged WT mice is proof of principle that therapeutics targeting this pathway could have broad clinical applications $(86,213)$.

Several of the CD47 redox signaling targets discussed here coincide with genes that exhibit significantly altered expression in a global transcriptome analysis of WT versus $C d 47^{-}$ mouse lung endothelial cells, including Nos, Txnip, and NADPH oxidase genes (113). However, examination of the resulting regulatory network reveals a larger number of CD47dependent genes for which we currently have no understanding of how TSP1 and CD47 regulate their expression (Fig. 15). Therefore, many important questions remain to be addressed to achieve a comprehensive understanding of even one of the signaling receptors that mediates responses to TSP1. It is safe to assume that a similar number of important questions remain to understand the function of the other matricellular proteins in the context of redox signaling.
TSP1 signaling through CD47 has also emerged as an inhibitor of stem and nonstem cell self-renewal and the genes that coordinate this process $(112,113,217)$, which has implications for age-related loss in healing capacity and for tissue regeneration using stem cell therapy and in tissue bioengineering. It will be necessary to fully define how CD47 functions to balance and, when activated by ligands such as TSP1, imbalance these multiple pathways. Because other matricellular proteins can also regulate redox signaling, it will be important to determine whether each protein acts alone or in cooperation with each other and with TSP1. The knowledge gained from such studies could lead to additional therapeutic possibilities.

Dysregulation of matricellular protein expression is also a common feature in cancer and has been linked to risk for carcinogenesis, malignant progression, and metastatic disease $(88,174,236,247,250)$. Although correlations have been clearly established with altered redox signaling, a causal relationship between aberrant matricellular protein expression and impaired redox homeostasis in cancer remains largely unknown. Given the multiplicity of matricellular protein receptors, it is likely that redox-dependent and redox-independent signaling contributes to the observed changes in any specific cell type, and experimental design must account for this complexity to advance our understanding of mechanism and enable successful translational applications for treatment.

Two classes of biologics targeting CD47, humanized antiCD47 antibodies, and bivalent recombinant $\operatorname{SIRP} \alpha$ are advancing in clinical trials for cancer patients $(144,192,194)$.

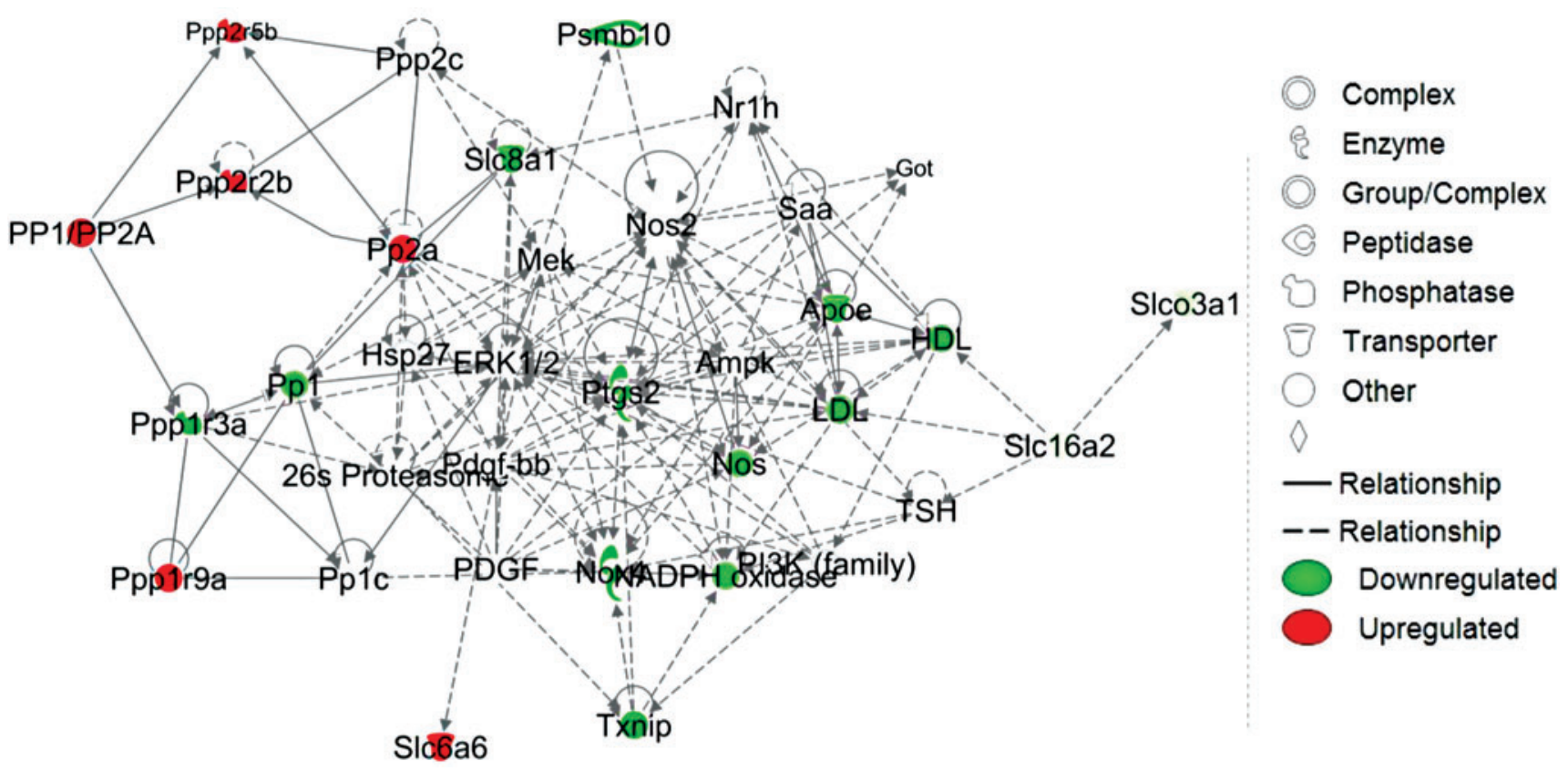

FIG. 15. Network analysis of CD47-dependent gene expression in primary lung endothelial cells. A set of redox pathway-related genes (65) was used to analyze published microarray data comparing WT and $C d 47^{-1}$ mouse lung endothelial cells (113). Extracted data for genes on this list were subjected to Ingenuity pathway analysis. The canonical pathway for production of nitric oxide and reactive oxygen species gave a z-score -1.342 for CD47 dependence ( $p$-value: $\left.1.74 \times 10^{-5}\right)$. Upregulated genes in CD47-deficient cells are labeled red and downregulated genes are labeled green. In addition to elements of the NO and ROS pathways, this analysis identifies several protein phosphatases as potential transcriptional targets of CD47 signaling, which could also be regulated post-translationally by CD47-dependent ROS and sulfhydration. To see this illustration in color, the reader is referred to the web version of this article at www .liebertpub.com/ars 
The intended/expected activity of both classes of therapeutics is to enhance phagocytic clearance of tumor cells by macrophages by inhibiting the CD47-SIRP $\alpha$ interaction (157), but understanding the role of CD47 in redox signaling can illuminate potential side effects of these therapeutics.

Preclinical data for CD47 antibodies that inhibit CD47$\mathrm{SIRP} \alpha$ interaction have generally found that TSP1-CD47 interactions are also inhibited, and such antibodies consequently alter blood pressure by an NO-dependent mechanism when injected intravenously (10) and, by enhancing red blood cell clearance, can induce anemia (144, 194, 239). Thus, systemic cardiovascular side effects need to be considered and monitored. Based on the sensitivity of $C d 47^{-1-}$ mice to anesthesia (91), surgical procedures may be contraindicated for patients enrolled in these clinical trials. Platelet aggregation is another concern for patients treated with humanized CD47 antibodies and antagonists $(192,194)$, and the CD47 antagonism of antithrombotic NO signaling in platelets provides a mechanistic basis for this side effect (95).

More broadly, CD47-targeting drugs for cancer should be viewed as immune checkpoint inhibitors that enhance adaptive as well as innate antitumor immunity (248). Regulation of $\mathrm{NO}$ and $\mathrm{H}_{2} \mathrm{~S}$ signaling in T cells by CD47 likely contributes to their adaptive immune checkpoint function, and assessment of these pathways in circulating $\mathrm{T}$ cells could be useful surrogate biomarkers to evaluate CD47-targeting therapeutics in clinical trials.

\section{Acknowledgments}

This work was supported by the Intramural Research Program of the NIH/NCI (D.D.R.) and by 2P01HL103455, R01 HL-108954, and 1R01HL112914 (J.S.I.). This work was also supported by the Institute for Transfusion Medicine, the Hemophilia Center of Western Pennsylvania, and the Heart, Lung, Blood, and Vascular Medicine Institute of the University of Pittsburgh School of Medicine (J.S.I.).

\section{Author Disclosure Statement}

J.S.I. serves as Chair of the Scientific Advisory Board of Radiation Control Technologies, Inc. (RCTI, Garden City, NJ) and has equity interest in RCTI and Tioma Therapeutics (St. Louis, MO) that have licensed CD47 technology for development. The other authors have no competing financial interests to disclose.

\section{References}

1. Abais JM, Xia M, Zhang Y, Boini KM, and Li PL. Redox regulation of NLRP3 inflammasomes: ROS as trigger or effector? Antioxid Redox Signal 22: 1111-1129, 2015.

2. Adams JC and Lawler J. The thrombospondins. Cold Spring Harb Perspect Biol 3: a009712, 2011.

3. Agah A, Kyriakides TR, Lawler J, and Bornstein P. The lack of thrombospondin-1 (TSP1) dictates the course of wound healing in double-TSP1/TSP2-null mice. Am J Pathol 161: 831-839, 2002.

4. Aird AL, Nevitt CD, Christian K, Williams SK, Hoying $\mathrm{JB}$, and LeBlanc AJ. Adipose-derived stromal vascular fraction cells isolated from old animals exhibit reduced capacity to support the formation of microvascular networks. Exp Gerontol 63: 18-26, 2015.
5. Alblas J, Honing H, de Lavalette CR, Brown MH, Dijkstra $\mathrm{CD}$, and van den Berg TK. Signal regulatory protein alpha ligation induces macrophage nitric oxide production through JAK/STAT- and phosphatidylinositol 3-kinase/ $\mathrm{Rac}$ /NAPDH oxidase $/ \mathrm{H}_{2} \mathrm{O}_{2}$-dependent pathways. $\mathrm{Mol}$ Cell Biol 25: 7181-7192, 2005.

6. Arafat HA, Katakam AK, Chipitsyna G, Gong Q, Vancha AR, Gabbeta J, and Dafoe DC. Osteopontin protects the islets and beta-cells from interleukin-1 beta-mediated cytotoxicity through negative feedback regulation of nitric oxide. Endocrinology 148: 575-584, 2007.

7. Bai YP, Xiao S, Tang YB, Tan Z, Tang H, Ren Z, Zeng H, and Yang Z. Shear stress-mediated upregulation of GTP cyclohydrolase/tetrahydrobiopterin pathway ameliorates hypertension-related decline in reendothelialization capacity of endothelial progenitor cells. J Hypertens 35: 784-797, 2017.

8. Bancroft T, Bouaouina M, Roberts S, Lee M, Calderwood DA, Schwartz M, Simons M, Sessa WC, and Kyriakides TR. Up-regulation of thrombospondin-2 in Akt1-null mice contributes to compromised tissue repair due to abnormalities in fibroblast function. J Biol Chem 290: 409-422, 2015.

9. Barazi HO, Li Z, Cashel JA, Krutzsch HC, Annis DS, Mosher DF, and Roberts DD. Regulation of integrin function by CD47 ligands. Differential effects on $\alpha \mathrm{v} \beta 3$ and $\alpha 4 \beta 1$ integrin-mediated adhesion. J Biol Chem 277: 42859-42866, 2002.

10. Bauer EM, Qin Y, Miller TW, Bandle RW, Csanyi G, Pagano PJ, Bauer PM, Schnermann J, Roberts DD, and Isenberg JS. Thrombospondin-1 supports blood pressure by limiting eNOS activation and endothelial-dependent vasorelaxation. Cardiovasc Res 88: 471-481, 2010.

11. Bauer PM, Bauer EM, Rogers NM, Yao M, FeijooCuaresma M, Pilewski JM, Champion HC, Zuckerbraun BS, Calzada MJ, and Isenberg JS. Activated CD47 promotes pulmonary arterial hypertension through targeting caveolin-1. Cardiovasc Res 93: 682-693, 2012.

12. Bonafe F, Guarnieri C, and Muscari C. Nitric oxide regulates multiple functions and fate of adult progenitor and stem cells. J Physiol Biochem 71: 141-153, 2015.

13. Bonnefoy A, Moura R, and Hoylaerts MF. The evolving role of thrombospondin-1 in hemostasis and vascular biology. Cell Mol Life Sci 65: 713-727, 2008.

14. Boo YC, Kim HJ, Song H, Fulton D, Sessa W, and Jo H. Coordinated regulation of endothelial nitric oxide synthase activity by phosphorylation and subcellular localization. Free Radic Biol Med 41: 144-153, 2006.

15. Borkham-Kamphorst E, Schaffrath C, Van de Leur E, Haas U, Tihaa L, Meurer SK, Nevzorova YA, Liedtke C, and Weiskirchen R. The anti-fibrotic effects of CCN1/ CYR61 in primary portal myofibroblasts are mediated through induction of reactive oxygen species resulting in cellular senescence, apoptosis and attenuated TGF-beta signaling. Biochim Biophys Acta 1843: 902-914, 2014.

16. Bornstein P. Diversity of function is inherent in matricellular proteins: an appraisal of thrombospondin 1. $J$ Cell Biol 130: 503-506, 1995.

17. Bouvet C, Gilbert LA, Girardot D, deBlois D, and Moreau P. Different involvement of extracellular matrix components in small and large arteries during chronic NO synthase inhibition. Hypertension 45: 432-437, 2005.

18. Buda V, Andor M, Petrescu L, Cristescu C, Baibata DE, Voicu M, Munteanu M, Citu I, Muntean C, Cretu O, and 
Tomescu MC. Perindopril induces TSP-1 expression in hypertensive patients with endothelial dysfunction in chronic treatment. Int J Mol Sci 18: pii: E348, 2017.

19. Buee L, Hof PR, Roberts DD, Delacourte A, Morrison JH, and Fillit HM. Immunohistochemical identification of thrombospondin in normal human brain and in Alzheimer's disease. Am J Pathol 141: 783-788, 1992.

20. Buono R, Vantaggiato C, Pisa V, Azzoni E, Bassi MT, Brunelli S, Sciorati C, and Clementi E. Nitric oxide sustains long-term skeletal muscle regeneration by regulating fate of satellite cells via signaling pathways requiring Vang12 and cyclic GMP. Stem Cells 30: 197-209, 2012.

21. Calzada MJ, Annis DS, Zeng B, Marcinkiewicz C, Banas B, Lawler J, Mosher DF, and Roberts DD. Identification of novel beta1 integrin binding sites in the type 1 and type 2 repeats of thrombospondin-1. J Biol Chem 279: 4173441743, 2004.

22. Canfield AE, Farrington C, Dziobon MD, Boot-Handford RP, Heagerty AM, Kumar SN, and Roberts IS. The involvement of matrix glycoproteins in vascular calcification and fibrosis: an immunohistochemical study. J Pathol 196: 228-234, 2002.

23. Carlson CB, Lawler J, and Mosher DF. Structures of thrombospondins. Cell Mol Life Sci 65: 672-686, 2008.

24. Cevik O, Baykal AT, and Sener A. Platelets proteomic profiles of acute ischemic stroke patients. PLoS One 11: e0158287, 2016.

25. Chakraborty S, Karmakar K, and Chakravortty D. Cells producing their own nemesis: understanding methylglyoxal metabolism. IUBMB Life 66: 667-678, 2014.

26. Chanana B, Graf R, Koledachkina T, Pflanz R, and Vorbruggen G. AlphaPS2 integrin-mediated muscle attachment in Drosophila requires the ECM protein Thrombospondin. Mech Dev 124: 463-475, 2007.

27. Chen CC, Kim KH, and Lau LF. The matricellular protein CCN1 suppresses hepatocarcinogenesis by inhibiting compensatory proliferation. Oncogene 35: 1314-1323, 2016.

28. Chen CC, Young JL, Monzon RI, Chen N, Todorovic V, and Lau LF. Cytotoxicity of $\mathrm{TNF} \alpha$ is regulated by integrin-mediated matrix signaling. EMBO $J$ 26: 12571267, 2007.

29. Chen JK, Zhan YJ, Yang CS, and Tzeng SF. Oxidative stress-induced attenuation of thrombospondin-1 expression in primary rat astrocytes. $J$ Cell Biochem 112: 59-70, 2011.

30. Choi KY, Kim DB, Kim MJ, Kwon BJ, Chang SY, Jang SW, Cho EJ, Rho TH, and Kim JH. Higher plasma thrombospondin1 levels in patients with coronary artery disease and diabetes mellitus. Korean Circ J 42: 100-106, 2012.

31. Chung J, Gao AG, and Frazier WA. Thrombspondin acts via integrin-associated protein to activate the platelet integrin $\alpha \mathrm{IIb} \beta 3$. J Biol Chem 272: 14740-14746, 1997.

32. Cingolani OH, Kirk JA, Seo K, Koitabashi N, Lee DI, Ramirez-Correa G, Bedja D, Barth AS, Moens AL, and Kass DA. Thrombospondin-4 is required for stretchmediated contractility augmentation in cardiac muscle. Circ Res 109: 1410-1414, 2011.

33. Cini C, Yip C, Attard C, Karlaftis V, Monagle P, Linden $\mathrm{M}$, and Ignjatovic V. Differences in the resting platelet proteome and platelet releasate between healthy children and adults. J Proteomics 123: 78-88, 2015.

34. Colon S, Page-McCaw P, and Bhave G. Role of hypohalous acids in basement membrane homeostasis. Antioxid Redox Signal 2017 (in press).
35. Corsetti JP, Ryan D, Moss AJ, McCarthy J, Goldenberg I, Zareba W, and Sparks CE. Thrombospondin-4 polymorphism (A387P) predicts cardiovascular risk in postinfarction patients with high HDL cholesterol and C-reactive protein levels. Thromb Haemost 106: 1170-1178, 2011.

36. Csanyi G, Yao M, Rodriguez AI, Al Ghouleh I, SharifiSanjani M, Frazziano G, Huang X, Kelley EE, Isenberg JS, and Pagano PJ. Thrombospondin-1 regulates blood flow via CD47 receptor-mediated activation of NADPH oxidase 1. Arterioscler Thromb Vasc Biol 32: 2966-2973, 2012.

37. Dawson DW, Pearce SF, Zhong R, Silverstein RL, Frazier WA, and Bouck NP. CD36 mediates the In vitro inhibitory effects of thrombospondin-1 on endothelial cells. J Cell Biol 138: 707-717, 1997.

38. DeLeon-Pennell KY, Tian Y, Zhang B, Cates CA, Iyer RP, Cannon P, Shah P, Aiyetan P, Halade GV, Ma Y, Flynn E, Zhang Z, Jin YF, Zhang H, and Lindsey ML. CD36 is a matrix metalloproteinase-9 substrate that stimulates neutrophil apoptosis and removal during cardiac remodeling. Circ Cardiovasc Genet 9: 14-25, 2016.

39. Della-Morte D, Beecham A, Dong C, Wang L, McClendon MS, Gardener H, Blanton SH, Sacco RL, and Rundek T. Association between variations in coagulation system genes and carotid plaque. J Neurol Sci 323: 93-98, 2012.

40. Denhardt DT, Burger EH, Kazanecki C, Krishna S, Semeins CM, and Klein-Nulend J. Osteopontin-deficient bone cells are defective in their ability to produce NO in response to pulsatile fluid flow. Biochem Biophys Res Commun 288: 448-453, 2001.

41. Devaux Y, Azuaje F, Vausort M, Yvorra C, and Wagner DR. Integrated protein network and microarray analysis to identify potential biomarkers after myocardial infarction. Funct Integr Genomics 10: 329-337, 2010.

42. Dikalov SI and Harrison DG. Methods for detection of mitochondrial and cellular reactive oxygen species. Antioxid Redox Signal 20: 372-382, 2014.

43. Dikalova AE, Gongora MC, Harrison DG, Lambeth JD, Dikalov S, and Griendling KK. Upregulation of Nox1 in vascular smooth muscle leads to impaired endotheliumdependent relaxation via eNOS uncoupling. Am J Physiol Heart Circ Physiol 299: H673-H679, 2010.

44. Dong R, Wang X, Wang H, Liu Z, Liu J, and Saavedra JE. Effects of JS-K, a novel anti-cancer nitric oxide prodrug, on gene expression in human hepatoma Hep3B cells. Biomed Pharmacother 88: 367-373, 2017.

45. Dong XQ, Yu WH, Zhu Q, Cheng ZY, Chen YH, Lin XF, Ten XL, Tang XB, and Chen J. Changes in plasma thrombospondin-1 concentrations following acute intracerebral hemorrhage. Clin Chim Acta 450: 349-355, 2015.

46. Dorahy DJ, Thorne RF, Fecondo JV, and Burns GF. Stimulation of platelet activation and aggregation by a carboxyl-terminal peptide from thrombospondin binding to the integrin-associated protein receptor. $\mathrm{J}$ Biol Chem 272: 1323-1330, 1997.

47. Dreieicher E, Beck KF, Lazaroski S, Boosen M, TsalastraGreul W, Beck M, Fleming I, Schaefer L, and Pfeilschifter J. Nitric oxide inhibits glomerular TGF-beta signaling via SMOC-1. J Am Soc Nephrol 20: 1963-1974, 2009.

48. Duquette M, Nadler M, Okuhara D, Thompson J, Shuttleworth T, and Lawler J. Members of the thrombospondin gene family bind stromal interaction molecule 1 and regulate calcium channel activity. Matrix Biol 37: 15-24, 2014.

49. Eroglu C, Allen NJ, Susman MW, O'Rourke NA, Park CY, Ozkan E, Chakraborty C, Mulinyawe SB, Annis DS, 
Huberman AD, Green EM, Lawler J, Dolmetsch R, Garcia KC, Smith SJ, Luo ZD, Rosenthal A, Mosher DF, and Barres BA. Gabapentin receptor alpha2delta-1 is a neuronal thrombospondin receptor responsible for excitatory CNS synaptogenesis. Cell 139: 380-392, 2009.

50. Fatma N, Kubo E, Toris CB, Stamer WD, Camras CB, and Singh DP. PRDX6 attenuates oxidative stress- and TGFbeta-induced abnormalities of human trabecular meshwork cells. Free Radic Res 43: 783-795, 2009.

51. Faulcon LM, Fu Z, Dulloor P, Barron-Casella E, Savage W, Jennings JM, Van Eyk JE, Debaun M, Casella JF, and Everett A. Thrombospondin-1 and L-selectin are associated with silent cerebral infarct in children with sickle cell anaemia. Br J Haematol 162: 421-424, 2013.

52. Favier J, Germain S, Emmerich J, Corvol P, and Gasc JM. Critical overexpression of thrombospondin 1 in chronic leg ischaemia. J Pathol 207: 358-366, 2005.

53. Fei P, Zaitoun I, Farnoodian M, Fisk DL, Wang S, Sorenson CM, and Sheibani N. Expression of thrombospondin1 modulates the angioinflammatory phenotype of choroidal endothelial cells. PLoS One 9: e116423, 2014.

54. Floquet N, Dedieu S, Martiny L, Dauchez M, and Perahia D. Human thrombospondin's (TSP-1) C-terminal domain opens to interact with the CD-47 receptor: a molecular modeling study. Arch Biochem Biophys 478: 103-109, 2008.

55. Forstermann U and Sessa WC. Nitric oxide synthases: regulation and function. Eur Heart $J$ 33: 829-837, 37a37d, 2012.

56. Frazier EP, Isenberg JS, Shiva S, Zhao L, Schlesinger P, Dimitry J, Abu-Asab MS, Tsokos M, Roberts DD, and Frazier WA. Age-dependent regulation of skeletal muscle mitochondria by the thrombospondin-1 receptor CD47. Matrix Biol 30: 154-161, 2011.

57. Frolova EG, Sopko N, Blech L, Popovic ZB, Li J, Vasanji A, Drumm C, Krukovets I, Jain MK, Penn MS, Plow EF, and Stenina OI. Thrombospondin-4 regulates fibrosis and remodeling of the myocardium in response to pressure overload. FASEB J 26: 2363-2373, 2012.

58. Gao A-G, Lindberg FP, Finn MB, Blystone SD, Brown EJ, and Frazier WA. Integrin-associated protein is a receptor for the C-terminal domain of thrombospondin. $J$ Biol Chem 271: 21-24, 1996.

59. Gao JB, Tang WD, Wang HX, and Xu Y. Predictive value of thrombospondin-1 for outcomes in patients with acute ischemic stroke. Clin Chim Acta 450: 176-180, 2015.

60. Gao Q, Chen K, Gao L, Zheng Y, and Yang YG. Thrombospondin-1 signaling through CD47 inhibits cell cycle progression and induces senescence in endothelial cells. Cell Death Dis 7: e2368, 2016.

61. Giachelli CM, Bae N, Almeida M, Denhardt DT, Alpers $\mathrm{CE}$, and Schwartz SM. Osteopontin is elevated during neointima formation in rat arteries and is a novel component of human atherosclerotic plaques. J Clin Invest 92: 1686-1696, 1993.

62. Gliemann L, Buess R, Nyberg M, Hoppeler H, Odriozola A, Thaning P, Hellsten Y, Baum O, and Mortensen SP. Capillary growth, ultrastructure remodelling and exercise training in skeletal muscle of essential hypertensive patients. Acta Physiol (Oxf) 214: 210-220, 2015.

63. Gonzalez-Domenech CM and Munoz-Chapuli R. Molecular evolution of nitric oxide synthases in metazoans. Comp Biochem Physiol Part D Genomics Proteomics 5: 295-301, 2010.
64. Gordan JD, Thompson CB, and Simon MC. HIF and cMyc: sibling rivals for control of cancer cell metabolism and proliferation. Cancer Cell 12: 108-113, 2007.

65. Gornicka A, Morris-Stiff G, Thapaliya S, Papouchado BG, Berk M, and Feldstein AE. Transcriptional profile of genes involved in oxidative stress and antioxidant defense in a dietary murine model of steatohepatitis. Antioxid Redox Signal 15: 437-445, 2011.

66. Greiner R, Palinkas Z, Basell K, Becher D, Antelmann H, Nagy P, and Dick TP. Polysulfides link H2S to protein thiol oxidation. Antioxid Redox Signal 19: 1749-1765, 2013.

67. Guo H, Cai CQ, Schroeder RA, and Kuo PC. Osteopontin is a negative feedback regulator of nitric oxide synthesis in murine macrophages. J Immunol 166: 1079-1086, 2001.

68. Guo N, Zabrenetzky VS, Chandrasekaran L, Sipes JM, Lawler J, Krutzsch HC, and Roberts DD. Differential roles of protein kinase $\mathrm{C}$ and pertussis toxin-sensitive $\mathrm{G}$ binding proteins in modulation of melanoma cell proliferation and motility by thrombospondin-1. Cancer Res 58 : 3154-3162, 1998.

69. Gutierrez LS, Ling J, Nye D, Papathomas K, and Dickinson C. Thrombospondin peptide ABT-898 inhibits inflammation and angiogenesis in a colitis model. World $J$ Gastroenterol 21: 6157-6166, 2015.

70. Hanatani S, Izumiya Y, Takashio S, Kimura Y, Araki S, Rokutanda T, Tsujita K, Yamamoto E, Tanaka T, Yamamuro M, Kojima S, Tayama S, Kaikita K, Hokimoto S, and Ogawa H. Circulating thrombospondin-2 reflects disease severity and predicts outcome of heart failure with reduced ejection fraction. Circ J 78: 903-910, 2014.

71. Hein L, Stevens ME, Barsh GS, Pratt RE, Kobilka BK, and Dzau VJ. Overexpression of angiotensin AT1 receptor transgene in the mouse myocardium produces a lethal phenotype associated with myocyte hyperplasia and heart block. Proc Natl Acad Sci U S A 94: 63916396, 1997.

72. Hernanz R, Martinez-Revelles S, Palacios R, Martin A, Cachofeiro V, Aguado A, Garcia-Redondo L, Barrus MT, de Batista PR, Briones AM, Salaices M, and Alonso MJ. Toll-like receptor 4 contributes to vascular remodelling and endothelial dysfunction in angiotensin II-induced hypertension. Br J Pharmacol 172: 3159-3176, 2015.

73. Hirano Y, Aziz M, Yang WL, Ochani M, and Wang P. Neutralization of Osteopontin Ameliorates Acute Lung Injury Induced by Intestinal Ischemia-Reperfusion. Shock 46: 431-438, 2016.

74. Ho C, Lee PH, Huang WJ, Hsu YC, Lin CL, and Wang JY. Methylglyoxal-induced fibronectin gene expression through Ras-mediated NADPH oxidase activation in renal mesangial cells. Nephrology (Carlton) 12: 348356, 2007.

75. Hohenstein B, Daniel C, Hausknecht B, Boehmer K, Riess $\mathrm{R}$, Amann KU, and Hugo CP. Correlation of enhanced thrombospondin-1 expression, TGF-beta signalling and proteinuria in human type-2 diabetic nephropathy. $\mathrm{Ne}$ phrol Dial Transplant 23: 3880-3887, 2008.

76. Hohenstein B, Daniel C, Wittmann S, and Hugo C. PDE-5 inhibition impedes TSP-1 expression, TGF-beta activation and matrix accumulation in experimental glomerulonephritis. Nephrol Dial Transplant 23: 3427-3436, 2008.

77. Hoier B, Nordsborg N, Andersen S, Jensen L, Nybo L, Bangsbo J, and Hellsten Y. Pro- and anti-angiogenic factors in human skeletal muscle in response to acute exercise and training. J Physiol 590: 595-606, 2012. 
78. Hoier B, Walker M, Passos M, Walker PJ, Green A, Bangsbo J, Askew CD, and Hellsten Y. Angiogenic response to passive movement and active exercise in individuals with peripheral arterial disease. J Appl Physiol (1985) 115: 1777-1787, 2013.

79. Holwerda KM, Burke SD, Faas MM, Zsengeller Z, Stillman IE, Kang PM, van Goor H, McCurley A, Jaffe IZ, Karumanchi SA, and Lely AT. Hydrogen sulfide attenuates sFlt1-induced hypertension and renal damage by upregulating vascular endothelial growth factor. J Am Soc Nephrol 25: 717-725, 2014.

80. Huang CL, Jong YS, Wu YW, Wang WJ, Hsieh AR, Chao CL, Chen WJ, and Yang WS. Association of plasma thrombospondin-1 level with cardiovascular disease and mortality in hemodialysis patients. Acta Cardiol Sin 31: 113-119, 2015.

81. Huang H, Du W, and Brekken RA. Extracellular matrix induction of intracellular reactive oxygen species. Antioxid Redox Signal 2017 (in press).

82. Hwang SM, Lopez CA, Heck DE, Gardner CR, Laskin DL, Laskin JD, and Denhardt DT. Osteopontin inhibits induction of nitric oxide synthase gene expression by inflammatory mediators in mouse kidney epithelial cells. $J$ Biol Chem 269: 711-715, 1994.

83. Ida T, Sawa T, Ihara H, Tsuchiya Y, Watanabe Y, Kumagai Y, Suematsu M, Motohashi H, Fujii S, Matsunaga T, Yamamoto M, Ono K, Devarie-Baez NO, Xian M, Fukuto JM, and Akaike T. Reactive cysteine persulfides and S-polythiolation regulate oxidative stress and redox signaling. Proc Natl Acad Sci U S A 111: 7606-7611, 2014.

84. Isenberg JS, Annis DS, Pendrak ML, Ptaszynska M, Frazier WA, Mosher DF, and Roberts DD. Differential interactions of thrombospondin-1, -2 , and -4 with CD47 and effects on cGMP signaling and ischemic injury responses. J Biol Chem 284: 1116-1125, 2009.

85. Isenberg JS, Hyodo F, Matsumoto K, Romeo MJ, AbuAsab M, Tsokos M, Kuppusamy P, Wink DA, Krishna MC, and Roberts DD. Thrombospondin-1 limits ischemic tissue survival by inhibiting nitric oxide-mediated vascular smooth muscle relaxation. Blood 109: 1945-1952, 2007.

86. Isenberg JS, Hyodo F, Pappan LK, Abu-Asab M, Tsokos M, Krishna MC, Frazier WA, and Roberts DD. Blocking thrombospondin-1/CD47 signaling alleviates deleterious effects of aging on tissue responses to ischemia. Arterioscler Thromb Vasc Biol 27: 2582-2588, 2007.

87. Isenberg JS, Jia Y, Fukuyama J, Switzer CH, Wink DA, and Roberts DD. Thrombospondin-1 inhibits nitric oxide signaling via CD36 by inhibiting myristic acid uptake. $J$ Biol Chem 282: 15404-15415, 2007.

88. Isenberg JS, Martin-Manso G, Maxhimer JB, and Roberts DD. Regulation of nitric oxide signalling by thrombospondin 1: implications for anti-angiogenic therapies. Nat Rev Cancer 9: 182-194, 2009.

89. Isenberg JS, Maxhimer JB, Powers P, Tsokos M, Frazier WA, and Roberts DD. Treatment of ischemia/reperfusion injury by limiting thrombospondin-1/CD47 signaling. Surgery 144: 752-761, 2008.

90. Isenberg JS, Pappan LK, Romeo MJ, Abu-Asab M, Tsokos M, Wink DA, Frazier WA, and Roberts DD. Blockade of thrombospondin-1-CD47 interactions prevents necrosis of full thickness skin grafts. Ann Surg 247: 180-190, 2008.

91. Isenberg JS, Qin Y, Maxhimer JB, Sipes JM, Despres D, Schnermann J, Frazier WA, and Roberts DD.
Thrombospondin-1 and CD47 regulate blood pressure and cardiac responses to vasoactive stress. Matrix Biol 28: 110-119, 2009.

92. Isenberg JS, Ridnour LA, Dimitry J, Frazier WA, Wink DA, and Roberts DD. CD47 is necessary for inhibition of nitric oxide-stimulated vascular cell responses by thrombospondin-1. J Biol Chem 281: 26069-26080, 2006.

93. Isenberg JS, Ridnour LA, Perruccio EM, Espey MG, Wink DA, and Roberts DD. Thrombospondin-1 inhibits endothelial cell responses to nitric oxide in a cGMPdependent manner. Proc Natl Acad Sci U S A 102: 1314113146, 2005.

94. Isenberg JS, Romeo MJ, Abu-Asab M, Tsokos M, Oldenborg A, Pappan L, Wink DA, Frazier WA, and Roberts DD. Increasing survival of ischemic tissue by targeting CD47. Circ Res 100: 712-720, 2007.

95. Isenberg JS, Romeo MJ, Yu C, Yu CK, Nghiem K, Monsale J, Rick ME, Wink DA, Frazier WA, and Roberts DD. Thrombospondin-1 stimulates platelet aggregation by blocking the antithrombotic activity of nitric oxide/cGMP signaling. Blood 111: 613-623, 2008.

96. Isenberg JS, Wink DA, and Roberts DD. Thrombospondin1 antagonizes nitric oxide-stimulated vascular smooth muscle cell responses. Cardiovasc Res 71: 785-793, 2006.

97. Isenberg JS, Yu C, and Roberts DD. Differential effects of ABT-510 and a CD36-binding peptide derived from the type 1 repeats of thrombospondin-1 on fatty acid uptake, nitric oxide signaling, and caspase activation in vascular cells. Biochem Pharmacol 75: 875-882, 2008.

98. Jacob SA, Novelli EM, Isenberg JS, Garrett ME, Chu Y, Soldano K, Ataga KI, Telen MJ, Ashley-Koch A, Gladwin MT, Zhang Y, and Kato GJ. Thrombospondin-1 gene polymorphism is associated with estimated pulmonary artery pressure in patients with sickle cell anemia. Am J Hematol 92: E31-E34, 2017.

99. Jalnapurkar S, Singh S, Devi MR, Limaye L, and Kale V. Nitric oxide has contrasting age-dependent effects on the functionality of murine hematopoietic stem cells. Stem Cell Res Ther 7: 171, 2016.

100. Ji K, de Carvalho LP, Bi X, Seneviratnankn A, Bhakoo K, Chan M, and Yau Li SF. Highly sensitive and quantitative human thrombospondin-1 detection by an M55 aptasensor and clinical validation in patients with atherosclerotic disease. Biosens Bioelectron 55: 405-411, 2014.

100a. Jin G, Tsuji K, Xing C, Yang YG, Wang X, Lo EH. CD47 gene knockout protects against transient focal cerebral ischemia in mice. Exp Neurol 217: 165-70, 2009.

101. Juric V, Chen CC, and Lau LF. Fas-mediated apoptosis is regulated by the extracellular matrix protein CCN1 (CYR61) in vitro and in vivo. Mol Cell Biol 29: 3266-3279, 2009.

102. Juric V, Chen CC, and Lau LF. TNFalpha-induced apoptosis enabled by CCN1/CYR61: pathways of reactive oxygen species generation and cytochrome c release. PLoS One 7: e31303, 2012.

103. Kaiser R, Frantz C, Bals R, and Wilkens H. The role of circulating thrombospondin-1 in patients with precapillary pulmonary hypertension. Respir Res 17: 96, 2016.

104. Kanagy NL, Szabo C, and Papapetropoulos A. Vascular biology of hydrogen sulfide. Am J Physiol Cell Physiol 312: C537-C549, 2017.

105. Kang DH, Anderson S, Kim YG, Mazzalli M, Suga S, Jefferson JA, Gordon KL, Oyama TT, Hughes J, Hugo C, Kerjaschki D, Schreiner GF, and Johnson RJ. Impaired angiogenesis in the aging kidney: vascular endothelial 
growth factor and thrombospondin-1 in renal disease. Am J Kidney Dis 37: 601-611, 2001.

106. Kang X, Wei X, Jiang L, Niu C, Zhang J, Chen S, and Meng D. Nox 2 and Nox4 regulate self-renewal of murine induced-pluripotent stem cells. IUBMB Life 68: 963-970, 2016.

107. Kanno S, Hirano S, Sagi M, Chiba S, Takeshita H, Ikawa T, Ichiba K, Nagai T, Takada M, Sakamoto K, and Mukai T. Sulfide induces apoptosis and Rho kinase-dependent cell blebbing in Jurkat cells. Arch Toxicol 87: 1245-1256, 2013.

108. Kaur S, Chang T, Singh SP, Lim L, Mannan P, Garfield SH, Pendrak ML, Soto-Pantoja DR, Rosenberg AZ, Jin S, and Roberts DD. CD47 signaling regulates the immunosuppressive activity of VEGF in T cells. J Immunol 193: 3914-3924, 2014.

109. Kaur S, Elkahloun AG, Singh SP, Chen QR, Meerzaman DM, Song T, Manu N, Wu W, Mannan P, Garfield SH, and Roberts DD. A function-blocking CD47 antibody suppresses stem cell and EGF signaling in triple-negative breast cancer. Oncotarget 7: 10133-52, 2016.

110. Kaur S, Kuznetsova SA, Pendrak ML, Sipes JM, Romeo MJ, Li Z, Zhang L, and Roberts DD. Heparan sulfate modification of the transmembrane receptor CD47 is necessary for inhibition of $\mathrm{T}$ cell receptor signaling by thrombospondin-1. J Biol Chem 286: 14991-15002, 2011.

111. Kaur S, Martin-Manso G, Pendrak ML, Garfield SH, Isenberg JS, and Roberts DD. Thrombospondin-1 inhibits vascular endothelial growth factor receptor-2 signaling by disrupting its association with CD47. J Biol Chem 285: 38923-38932, 2010.

112. Kaur S and Roberts DD. Divergent modulation of normal and neoplastic stem cells by thrombospondin-1 and CD47 signaling. Int J Biochem Cell Biol 81: 184-194, 2016.

113. Kaur S, Soto-Pantoja DR, Stein EV, Liu C, Elkahloun AG, Pendrak ML, Nicolae A, Singh SP, Nie Z, Levens D, Isenberg JS, and Roberts DD. Thrombospondin-1 signaling through CD47 inhibits self-renewal by regulating c-Myc and other stem cell transcription factors. Sci Rep 3: 1673, 2013.

114. Kimura Y, Izumiya Y, Hanatani S, Yamamoto E, Kusaka H, Tokitsu T, Takashio S, Sakamoto K, Tsujita K, Tanaka T, Yamamuro M, Kojima S, Tayama S, Kaikita K, Hokimoto $\mathrm{S}$, and Ogawa $\mathrm{H}$. High serum levels of thrombospondin-2 correlate with poor prognosis of patients with heart failure with preserved ejection fraction. Heart Vessels 31: 52-59, 2016.

115. Kirk R, Edwards LB, Kucheryavaya AY, Benden C, Christie JD, Dobbels F, Rahmel AO, Stehlik J, and Hertz MI. The Registry of the International Society for Heart and Lung Transplantation: Fourteenth Pediatric Heart Transplantation Report-2011. J Heart Lung Transplant 30: 1095-1103, 2011.

116. Kuebler WM. What mediates the effects of thrombospondin1 in pulmonary hypertension? New evidence for a dualpronged role of CD47. Cardiovasc Res 113: 3-5, 2017.

117. Kumar R, Mickael C, Kassa B, Gebreab L, Robinson JC, Koyanagi DE, Sanders L, Barthel L, Meadows C, Fox D, Irwin D, Li M, McKeon BA, Riddle S, Dale Brown R, Morgan LE, Evans CM, Hernandez-Saavedra D, Bandeira A, Maloney JP, Bull TM, Janssen WJ, Stenmark KR, Tuder RM, and Graham BB. TGF-beta activation by bone marrow-derived thrombospondin-1 causes Schistosomaand hypoxia-induced pulmonary hypertension. Nat Commun 8: 15494, 2017.
118. Kundu S, Pushpakumar S, Khundmiri SJ, and Sen U. Hydrogen sulfide mitigates hyperglycemic remodeling via liver kinase B1-adenosine monophosphate-activated protein kinase signaling. Biochim Biophys Acta 1843: 28162826, 2014.

119. Kunkemoeller B and Kyriakides TR. Redox signaling in diabetic wound healing regulates extracellular matrix deposition. Antioxid Redox Signal 2017 (in press).

120. Kuntz S, Kunz C, and Rudloff S. Carbonyl compounds methylglyoxal and glyoxal affect interleukin-8 secretion in intestinal cells by superoxide anion generation and activation of MAPK p38. Mol Nutr Food Res 54: 14581467, 2010

121. Kvansakul M, Adams JC, and Hohenester E. Structure of a thrombospondin C-terminal fragment reveals a novel calcium core in the type 3 repeats. EMBO J 23: 1223 1233, 2004.

122. Kwong LS, Brown MH, Barclay AN, and Hatherley D. Signal-regulatory protein alpha from the NOD mouse binds human CD47 with an exceptionally high affinityimplications for engraftment of human cells. Immunology 143: 61-67, 2014.

123. Labrousse-Arias D, Castillo-Gonzalez R, Rogers NM, Torres-Capelli M, Barreira B, Aragones J, Cogolludo A, Isenberg JS, and Calzada MJ. HIF-2alpha-mediated induction of pulmonary thrombospondin-1 contributes to hypoxia-driven vascular remodelling and vasoconstriction. Cardiovasc Res 109: 115-130, 2016.

124. Labrousse-Arias D, Martínez-Ruiz A, and Calzada MJ. Hypoxia and redox signaling on extracellular matrix remodeling: from the mechanisms to the pathological implications. Antioxid Redox Signal 2017 (in press).

125. Lario S, Bescos M, Campos B, Mur C, Luque P, Alvarez $\mathrm{R}$, and Campistol JM. Thrombospondin-1 mRNA expression in experimental kidney transplantation with heart-beating and non-heart-beating donors. J Nephrol 20: 588-595, 2007.

126. Lau LF. CCN1/CYR61: the very model of a modern matricellular protein. Cell Mol Life Sci 68: 3149-3163, 2011

127. Lawler J, Sunday M, Thibert V, Duquette M, George EL, Rayburn H, and Hynes RO. Thrombospondin-1 is required for normal murine pulmonary homeostasis and its absence causes pneumonia. J Clin Invest 101: 982-992, 1998.

128. LeBlanc AJ and Kelm NQ. Thrombospondin-1, free radicals, and the coronary microcirculation: the aging conundrum. Antioxid Redox Signal 2017 (in press).

129. Leclair P and Lim CJ. CD47-independent effects mediated by the TSP-derived 4N1K peptide. PLoS One 9: e98358, 2014

130. Lee HJ, Feliers D, Mariappan MM, Sataranatarajan K, Choudhury GG, Gorin Y, and Kasinath BS. Tadalafil integrates nitric oxide-hydrogen sulfide signaling to inhibit high glucose-induced matrix protein synthesis in podocytes. J Biol Chem 290: 12014-12026, 2015.

131. Lee HJ, Mariappan MM, Feliers D, Cavaglieri RC, Sataranatarajan K, Abboud HE, Choudhury GG, and Kasinath BS. Hydrogen sulfide inhibits high glucose-induced matrix protein synthesis by activating AMP-activated protein kinase in renal epithelial cells. J Biol Chem 287: 4451-4461, 2012.

132. Lee JH, Bhang DH, Beede A, Huang TL, Stripp BR, Bloch KD, Wagers AJ, Tseng YH, Ryeom S, and Kim CF. Lung stem cell differentiation in mice directed by endo- 
thelial cells via a BMP4-NFATc1-thrombospondin-1 axis. Cell 156: 440-455, 2014.

133. Lee R and Britz-McKibbin P. Metabolomic studies of radiation-induced apoptosis of human leukocytes by capillary electrophoresis-mass spectrometry and flow cytometry: adaptive cellular responses to ionizing radiation. Electrophoresis 31: 2328-2337, 2010.

134. Lee TK, Cheung VC, Lu P, Lau EY, Ma S, Tang KH, Tong M, Lo J, and Ng IO. Blockade of CD47-mediated cathepsin S/protease-activated receptor 2 signaling provides a therapeutic target for hepatocellular carcinoma. Hepatology 60: 179-191, 2014.

135. Legrand C, Morandi V, Mendelovitz S, Shaked H, Hartman JR, and Panet A. Selective inhibition of platelet macroaggregate formation by a recombinant heparinbinding domain of human thrombospondin. Arterioscler Thromb 14: 1784-1791, 1994.

136. Li XJ, Goodwin CB, Nabinger SC, Richine BM, Yang Z, Hanenberg H, Ohnishi H, Matozaki T, Feng GS, and Chan RJ. Protein-tyrosine phosphatase Shp2 positively regulates macrophage oxidative burst. J Biol Chem 290: 3894-3909, 2015.

137. Li Y, Qi X, Tong X, and Wang S. Thrombospondin 1 activates the macrophage Toll-like receptor 4 pathway. Cell Mol Immunol 10: 506-512, 2013.

138. Lin TN, Kim GM, Chen JJ, Cheung WM, He YY, and Hsu CY. Differential regulation of thrombospondin-1 and thrombospondin-2 after focal cerebral ischemia/reperfusion. Stroke 34: 177-186, 2003.

139. Lin X, Zhang F, Bradbury CM, Kaushal A, Li L, Spitz DR, Aft RL, and Gius D. 2-Deoxy-D-glucose-induced cytotoxicity and radiosensitization in tumor cells is mediated via disruptions in thiol metabolism. Cancer Res 63: 3413-3417, 2003.

140. Lin Y, Manning PT, Jia J, Gaut JP, Xiao Z, Capoccia BJ, Chen CC, Hiebsch RR, Upadhya G, Mohanakumar T, Frazier WA, and Chapman WC. CD47 blockade reduces ischemia-reperfusion injury and improves outcomes in a rat kidney transplant model. Transplantation 98: 394-401, 2014.

141. Lindsey ML, Zouein FA, Tian Y, Padmanabhan Iyer R, and de Castro Bras LE. Osteopontin is proteolytically processed by matrix metalloproteinase 9. Can J Physiol Pharmacol 93: 879-886, 2015.

142. Liu AY, Zheng H, and Ouyang G. Periostin, a multifunctional matricellular protein in inflammatory and tumor microenvironments. Matrix Biol 37: 150-156, 2014.

143. Liu J, Hughes TE, and Sessa WC. The first 35 amino acids and fatty acylation sites determine the molecular targeting of endothelial nitric oxide synthase into the Golgi region of cells: a green fluorescent protein study. J Cell Biol 137: 1525-1535, 1997.

144. Liu J, Wang L, Zhao F, Tseng S, Narayanan C, Shura L, Willingham S, Howard M, Prohaska S, Volkmer J, Chao M, Weissman IL, and Majeti R. Pre-clinical development of a humanized anti-CD47 antibody with anti-cancer therapeutic potential. PLoS One 10: e0137345, 2015.

145. Liu Y, Yang R, Liu X, Zhou Y, Qu C, Kikuiri T, Wang S, Zandi E, Du J, Ambudkar IS, and Shi S. Hydrogen sulfide maintains mesenchymal stem cell function and bone homeostasis via regulation of $\mathrm{Ca}(2+)$ channel sulfhydration. Cell Stem Cell 15: 66-78, 2014.

146. Liu YX, Wang J, Guo J, Wu J, Lieberman HB, and Yin Y. DUSP1 is controlled by p53 during the cellular response to oxidative stress. Mol Cancer Res 6: 624-633, 2008.
147. Lo J, Lau EY, So FT, Lu P, Chan VS, Cheung VC, Ching RH, Cheng BY, Ma MK, Ng IO, and Lee TK. Anti-CD47 antibody suppresses tumour growth and augments the effect of chemotherapy treatment in hepatocellular carcinoma. Liver Int 36: 737-745, 2016.

148. Lubos E, Loscalzo J, and Handy DE. Glutathione peroxidase-1 in health and disease: from molecular mechanisms to therapeutic opportunities. Antioxid Redox Signal 15: 1957-1997, 2011.

149. MacLauchlan S, Yu J, Parrish M, Asoulin TA, Schleicher M, Krady MM, Zeng J, Huang PL, Sessa WC, and Kyriakides TR. Endothelial nitric oxide synthase controls the expression of the angiogenesis inhibitor thrombospondin 2. Proc Natl Acad Sci U S A 108: E1137-E1145, 2011.

150. Maghzal GJ, Cergol KM, Shengule SR, Suarna C, Newington D, Kettle AJ, Payne RJ, and Stocker R. Assessment of myeloperoxidase activity by the conversion of hydroethidine to 2-chloroethidium. J Biol Chem 289: 55805595, 2014.

151. Maile LA, Allen LB, Hanzaker CF, Gollahon KA, Dunbar $\mathrm{P}$, and Clemmons DR. Glucose regulation of thrombospondin and its role in the modulation of smooth muscle cell proliferation. Exp Diabetes Res 2010: pii: 617052, 2010.

152. Makni-Maalej K, Chiandotto M, Hurtado-Nedelec M, Bedouhene S, Gougerot-Pocidalo MA, Dang PM, and ElBenna J. Zymosan induces NADPH oxidase activation in human neutrophils by inducing the phosphorylation of p47phox and the activation of Rac2: involvement of protein tyrosine kinases, PI3Kinase, PKC, ERK1/2 and p38MAPkinase. Biochem Pharmacol 85: 92-100, 2013.

153. Mariggio MA, Minunno V, Riccardi S, Santacroce R, De Rinaldis P, and Fumarulo R. Sulfide enhancement of PMN apoptosis. Immunopharmacol Immunotoxicol 20: 399408, 1998.

154. Martin-Manso G, Galli S, Ridnour LA, Tsokos M, Wink DA, and Roberts DD. Thrombospondin-1 promotes tumor macrophage recruitment and enhances tumor cell cytotoxicity by differentiated U937 cells. Cancer Res 68: 7090-7099, 2008.

155. Martinelli R, Newton G, Carman CV, Greenwood J, and Luscinskas FW. Novel role of CD47 in rat microvascular endothelium: signaling and regulation of T-cell transendothelial migration. Arterioscler Thromb Vasc Biol 33: 2566-2576, 2013.

156. Martinez-Revelles S, Caracuel L, Marquez-Martin A, Dantas A, Oliver E, D'Ocon P, and Vila E. Increased endothelin-1 vasoconstriction in mesenteric resistance arteries after superior mesenteric ischaemia-reperfusion. Br J Pharmacol 165: 937-950, 2012.

157. Matlung HL, Szilagyi K, Barclay NA, and van den Berg TK. The CD47-SIRPalpha signaling axis as an innate immune checkpoint in cancer. Immunol Rev 276: 145164, 2017.

158. Matsuo Y, Tanaka M, Yamakage H, Sasaki Y, Muranaka K, Hata H, Ikai I, Shimatsu A, Inoue M, Chun TH, and Satoh-Asahara N. Thrombospondin 1 as a novel biological marker of obesity and metabolic syndrome. Metabolism 64: 1490-1499, 2015.

159. Maxhimer JB, Shih HB, Isenberg JS, Miller TW, and Roberts DD. Thrombospondin-1-CD47 blockade following ischemia reperfusion injury is tissue protective. Plast Reconstr Surg 124: 1880-1889, 2009.

160. Maxhimer JB, Soto-Pantoja DR, Ridnour LA, Shih HB, DeGraff WG, Tsokos M, Wink DA, Isenberg JS, and 
Roberts DD. Radioprotection in normal tissue and delayed tumor growth by blockade of CD47 signaling. Sci Transl Med 1: 3ra7, 2009.

161. Mikula-Pietrasik J, Sosinska P, Janus J, Rubis B, Brewinska-Olchowik M, Piwocka K, and Ksiazek K. Bystander senescence in human peritoneal mesothelium and fibroblasts is related to thrombospondin-1-dependent activation of transforming growth factor-beta1. Int $J$ Biochem Cell Biol 45: 2087-2096, 2013.

162. Miller TW, Isenberg JS, and Roberts DD. Thrombospondin-1 is an inhibitor of pharmacological activation of soluble guanylate cyclase. Br J Pharmacol 159: 1542-1547, 2010.

163. Miller TW, Isenberg JS, Shih HB, Wang Y, and Roberts DD. Amyloid-beta inhibits No-cGMP signaling in a CD36- and CD47-dependent manner. PLoS One 5: e15686, 2010.

164. Miller TW, Kaur S, Ivins-O'Keefe K, and Roberts DD. Thrombospondin-1 is a CD47-dependent endogenous inhibitor of hydrogen sulfide signaling in $\mathrm{T}$ cell activation. Matrix Biol 32: 316-324, 2013.

165. Miller TW, Soto-Pantoja DR, Schwartz AL, Sipes JM, DeGraff WG, Ridnour LA, Wink DA, and Roberts DD. CD47 globally regulates metabolic pathways that control resistance to ionizing radiation. J Biol Chem 290: 2485824874, 2015.

166. Miller TW, Wang EA, Gould S, Stein EV, Kaur S, Lim L, Amarnath S, Fowler DH, and Roberts DD. Hydrogen sulfide is an endogenous potentiator of T cell activation. $J$ Biol Chem 287: 4211-4221, 2012.

167. Miyamoto K, Miyamoto T, Kato R, Yoshimura A, Motoyama N, and Suda T. FoxO3a regulates hematopoietic homeostasis through a negative feedback pathway in conditions of stress or aging. Blood 112: 4485-4493, 2008.

168. Morrish F, Isern N, Sadilek M, Jeffrey M, and Hockenbery DM. c-Myc activates multiple metabolic networks to generate substrates for cell-cycle entry. Oncogene 28: 2485-2491, 2009.

169. Mosher DF and Adams JC. Adhesion-modulating/ matricellular ECM protein families: a structural, functional and evolutionary appraisal. Matrix Biol 31: 155161, 2012.

170. Murphy-Ullrich JE, Pallero MA, Boerth N, Greenwood JA, Lincoln TM, and Cornwell TL. Cyclic GMPdependent protein kinase is required for thrombospondin and tenascin mediated focal adhesion disassembly. J Cell Sci 109: 2499-2508, 1996.

171. Murphy-Ullrich JE and Sage EH. Revisiting the matricellular concept. Matrix Biol 37: 1-14, 2014.

172. Mustafa AK, Gadalla MM, Sen N, Kim S, Mu W, Gazi SK, Barrow RK, Yang G, Wang R, and Snyder SH. H2S signals through protein S-sulfhydration. Sci Signal 2: ra72, 2009.

173. Mustafa AK, Gadalla MM, and Snyder SH. Signaling by gasotransmitters. Sci Signal 2: re2, 2009.

174. Nagaraju GP, Dontula R, El-Rayes BF, and Lakka SS. Molecular mechanisms underlying the divergent roles of SPARC in human carcinogenesis. Carcinogenesis 35: 967-973, 2014.

175. Naito T, Masaki T, Nikolic-Paterson DJ, Tanji C, Yorioka $\mathrm{N}$, and Kohno N. Angiotensin II induces thrombospondin1 production in human mesangial cells via p38 MAPK and JNK: a mechanism for activation of latent TGF-beta1. Am J Physiol Renal Physiol 286: F278-F287, 2004.
176. Namin SM, Nofallah S, Joshi MS, Kavallieratos K, and Tsoukias NM. Kinetic analysis of DAF-FM activation by NO: toward calibration of a NO-sensitive fluorescent dye. Nitric Oxide 28: 39-46, 2013.

177. Narizhneva NV, Byers-Ward VJ, Quinn MJ, Zidar FJ, Plow EF, Topol EJ, and Byzova TV. Molecular and functional differences induced in thrombospondin-1 by the single nucleotide polymorphism associated with the risk of premature, familial myocardial infarction. $J$ Biol Chem 279: 21651-21657, 2004.

178. Nastase M-V, Janicova A, Wygrecka M, and Schaefer L. Signaling at the crossroads: matrix-derived proteoglycan and reactive oxygen species signaling. Antioxid Redox Signal 2017 (in press).

179. Nathan C, Srimal S, Farber C, Sanchez E, Kabbash L, Asch A, Gailit J, and Wright SD. Cytokine-induced respiratory burst of human neutrophils: dependence on extracellular matrix proteins and CD11/CD18 integrins. $J$ Cell Biol 109: 1341-1349, 1989.

180. Navarathna DH, Stein EV, Lessey-Morillon EC, Nayak D, Martin-Manso G, and Roberts DD. CD47 Promotes protective innate and adaptive immunity in a mouse model of disseminated candidiasis. PLoS One 10: e0128220, 2015.

181. Navarro-Sobrino M, Rosell A, Hernandez-Guillamon M, Penalba A, Boada C, Domingues-Montanari S, Ribo M, Alvarez-Sabin J, and Montaner J. A large screening of angiogenesis biomarkers and their association with neurological outcome after ischemic stroke. Atherosclerosis 216: 205-211, 2011.

182. Nevitt C, McKenzie G, Christian K, Austin J, Hencke S, Hoying $J$, and LeBlanc A. Physiological levels of thrombospondin-1 decrease NO-dependent vasodilation in coronary microvessels from aged rats. Am J Physiol Heart Circ Physiol 310: H1842-H1850, 2016.

183. Nogueira-Pedro A, Dias CC, Regina H, Segreto C, Addios PC, Lungato L, D'Almeida V, Barros CC, Higa EM, Buri MV, Ferreira AT, and Paredes-Gamero EJ. Nitric oxideinduced murine hematopoietic stem cell fate involves multiple signaling proteins, gene expression, and redox modulation. Stem Cells 32: 2949-2960, 2014.

184. Novelli EM, Kato GJ, Ragni MV, Zhang Y, Hildesheim ME, Nouraie M, Barge S, Meyer MP, Hassett AC, Gordeuk VR, Gladwin MT, and Isenberg JS. Plasma thrombospondin-1 is increased during acute sickle cell vaso-occlusive events and associated with acute chest syndrome, hydroxyurea therapy, and lower hemolytic rates. Am J Hematol 87: 326-330, 2012.

185. Olfert IM, Breen EC, Gavin TP, and Wagner PD. Temporal thrombospondin-1 mRNA response in skeletal muscle exposed to acute and chronic exercise. Growth Factors 24: 253-259, 2006.

186. Oller J, Mendez-Barbero N, Ruiz EJ, Villahoz S, Renard M, Canelas LI, Briones AM, Alberca R, Lozano-Vidal N, Hurle MA, Milewicz D, Evangelista A, Salaices M, Nistal JF, Jimenez-Borreguero LJ, De Backer J, Campanero MR, and Redondo JM. Nitric oxide mediates aortic disease in mice deficient in the metalloprotease Adamts1 and in a mouse model of Marfan syndrome. Nat Med 23: 200-212, 2017.

187. Osada-Oka M, Ikeda T, Akiba S, and Sato T. Hypoxia stimulates the autocrine regulation of migration of vascular smooth muscle cells via HIF-1alpha-dependent expression of thrombospondin-1. J Cell Biochem 104: 1918-1926, 2008. 
188. Paradis P, Dali-Youcef N, Paradis FW, Thibault G, and Nemer M. Overexpression of angiotensin II type I receptor in cardiomyocytes induces cardiac hypertrophy and remodeling. Proc Natl Acad Sci U S A 97: 931-936, 2000.

189. Patouraux S, Rousseau D, Rubio A, Bonnafous S, Lavallard VJ, Lauron J, Saint-Paul MC, Bailly-Maitre B, Tran A, Crenesse D, and Gual P. Osteopontin deficiency aggravates hepatic injury induced by ischemia-reperfusion in mice. Cell Death Dis 5: e1208, 2014.

190. Patterson AD, Li H, Eichler GS, Krausz KW, Weinstein JN, Fornace AJ, Jr., Gonzalez FJ, and Idle JR. UPLC-ESITOFMS-based metabolomics and gene expression dynamics inspector self-organizing metabolomic maps as tools for understanding the cellular response to ionizing radiation. Anal Chem 80: 665-674, 2008.

191. Persy VP, Verhulst A, Ysebaert DK, De Greef KE, and De Broe ME. Reduced postischemic macrophage infiltration and interstitial fibrosis in osteopontin knockout mice. Kidney Int 63: 543-553, 2003.

192. Petrova PS, Viller NN, Wong M, Pang X, Lin GH, Dodge K, Chai V, Chen H, Lee V, House V, Vigo NT, Jin D, Mutukura T, Charbonneau M, Truong T, Viau S, Johnson LD, Linderoth E, Sievers EL, Maleki Vareki S, Figueredo R, Pampillo M, Koropatnick J, Trudel S, Mbong N, Jin L, Wang JC, and Uger RA. TTI-621 (SIRPalphaFc): a CD47blocking innate immune checkpoint inhibitor with broad antitumor activity and minimal erythrocyte binding. Clin Cancer Res 23: 1068-1079, 2017.

193. Phelan MW, Forman LW, Perrine SP, and Faller DV. Hypoxia increases thrombospondin-1 transcript and protein in cultured endothelial cells. J Lab Clin Med 132: 519-529, 1998.

194. Pietsch EC, Dong J, Cardoso R, Zhang X, Chin D, Hawkins R, Dinh T, Zhou M, Strake B, Feng PH, Rocca M, Santos CD, Shan X, Danet-Desnoyers G, Shi F, Kaiser E, Millar HJ, Fenton S, Swanson R, Nemeth JA, and Attar RM. Anti-leukemic activity and tolerability of anti-human CD47 monoclonal antibodies. Blood Cancer J 7: e536, 2017.

195. Poczatek MH, Hugo C, Darley-Usmar V, and MurphyUllrich JE. Glucose stimulation of transforming growth factor-beta bioactivity in mesangial cells is mediated by thrombospondin-1. Am J Pathol 157: 1353-1363, 2000.

196. Posey KL, Hankenson K, Veerisetty AC, Bornstein P, Lawler J, and Hecht JT. Skeletal abnormalities in mice lacking extracellular matrix proteins, thrombospondin-1, thrombospondin-3, thrombospondin-5, and type IX collagen. Am J Pathol 172: 1664-1674, 2008.

197. Prentice RL, Zhao S, Johnson M, Aragaki A, Hsia J, Jackson RD, Rossouw JE, Manson JE, and Hanash SM. Proteomic risk markers for coronary heart disease and stroke: validation and mediation of randomized trial hormone therapy effects on these diseases. Genome Med 5: 112, 2013.

198. Qin Z, Robichaud P, He T, Fisher GJ, Voorhees JJ, and Quan T. Oxidant exposure induces cysteine-rich protein 61 (CCN1) via c-Jun/AP-1 to reduce collagen expression in human dermal fibroblasts. PLoS One 9: e115402, 2014.

199. Radomski MW, Palmer RM, and Moncada S. An L-arginine/nitric oxide pathway present in human platelets regulates aggregation. Proc Natl Acad Sci U S A 87: 5193-5197, 1990.

200. Rama Rao KV, Curtis KM, Johnstone JT, and Norenberg MD. Amyloid-beta inhibits thrombospondin 1 release from cultured astrocytes: effects on synaptic protein expression. J Neuropathol Exp Neurol 72: 735-744, 2013.

201. Raman P, Krukovets I, Marinic TE, Bornstein P, and Stenina OI. Glycosylation mediates up-regulation of a potent antiangiogenic and proatherogenic protein, thrombospondin-1, by glucose in vascular smooth muscle cells. J Biol Chem 282: 5704-5714, 2007.

202. Ramanathan S, Mazzalupo S, Boitano S, and Montfort WR. Thrombospondin-1 and angiotensin II inhibit soluble guanylyl cyclase through an increase in intracellular calcium concentration. Biochemistry 50: 7787-7799, 2011.

203. Repka T and Hebbel RP. Hydroxyl radical formation by sickle erythrocyte membranes: role of pathologic iron deposits and cytoplasmic reducing agents. Blood 78: 2753-2758, 1991.

204. Ridnour LA, Cheng RY, Weiss JM, Kaur S, Soto-Pantoja DR, Basudhar D, Heinecke JL, Stewart CA, DeGraff W, Sowers AL, Thetford A, Kesarwala AH, Roberts DD, Young HA, Mitchell JB, Trinchieri G, Wiltrout RH, and Wink DA. NOS inhibition modulates immune polarization and improves radiation-induced tumor growth delay. Cancer Res 2015 (in press).

205. Ridnour LA, Isenberg JS, Espey MG, Thomas DD, Roberts DD, and Wink DA. Nitric oxide regulates angiogenesis through a functional switch involving thrombospondin-1. Proc Natl Acad Sci U S A 102: 13147-13152, 2005.

206. Ridnour LA, Windhausen AN, Isenberg JS, Yeung N, Thomas DD, Vitek MP, Roberts DD, and Wink DA. Nitric oxide regulates matrix metalloproteinase- 9 activity by guanylyl-cyclase-dependent and -independent pathways. Proc Natl Acad Sci U S A 104: 16898-16903, 2007.

207. Riessen R, Kearney M, Lawler J, and Isner JM. Immunolocalization of thrombospondin-1 in human atherosclerotic and restenotic arteries. Am Heart J 135: 357-364, 1998.

208. Roberts DD. Thrombospondins and their receptors: evolving functions. In: Evolution of Extracellular Matrix, Biology of Extracellular Matrix, edited by Keeley F, Mecham RP. Berlin Heidelberg: Springer-Verlag, 2013, pp. 221-242.

209. Roberts DD and Lau LF. Matricellular proteins. In: The Extracellular Matrix: An Overview, Biology of Extracellular Matrix, edited by Mecham RP. Berlin Heidelberg: Springer-Verlag, 2011, pp. 369-413.

210. Roberts DD, Miller TW, Rogers NM, Yao M, and Isenberg JS. The matricellular protein thrombospondin-1 globally regulates cardiovascular function and responses to stress. Matrix Biol 31: 162-169, 2012.

211. Rock MJ, Holden P, Horton WA, and Cohn DH. Cartilage oligomeric matrix protein promotes cell attachment via two independent mechanisms involving CD47 and alphaVbeta3 integrin. Mol Cell Biochem 338: 215-224, 2010.

212. Rogers NM, Ghimire K, Calzada MJ, and Isenberg JS. Matricellular protein thrombospondin-1 in pulmonary hypertension: multiple pathways to disease. Cardiovasc Res 2017 (in press).

213. Rogers NM, Roberts DD, and Isenberg JS. Age-associated induction of cell membrane CD47 limits basal and temperature-induced changes in cutaneous blood flow. Ann Surg 258: 184-191, 2013.

214. Rogers NM, Sharifi-Sanjani M, Yao M, Ghimire K, Bienes-Martinez R, Mutchler SM, Knupp HE, Baust J, Novelli EM, Ross M, St Croix C, Kutten JC, Czajka CA, Sembrat JC, Rojas M, Labrousse-Arias D, Bachman TN, 
Vanderpool RR, Zuckerbraun BS, Champion HC, Mora AL, Straub AC, Bilonick RA, Calzada MJ, and Isenberg JS. TSP1-CD47 signaling is upregulated in clinical pulmonary hypertension and contributes to pulmonary arterial vasculopathy and dysfunction. Cardiovasc Res 113: 15-29, 2017.

215. Rogers NM, Thomson AW, and Isenberg JS. Activation of parenchymal CD47 promotes renal ischemia-reperfusion injury. J Am Soc Nephrol 23: 1538-1550, 2012.

216. Rogers NM, Yao M, Sembrat J, George MP, Knupp H, Ross M, Sharifi-Sanjani M, Milosevic J, St Croix C, Rajkumar R, Frid MG, Hunter KS, Mazzaro L, Novelli EM, Stenmark KR, Gladwin MT, Ahmad F, Champion $\mathrm{HC}$, and Isenberg JS. Cellular, pharmacological, and biophysical evaluation of explanted lungs from a patient with sickle cell disease and severe pulmonary arterial hypertension. Pulm Circ 3: 936-951, 2013.

217. Rogers NM, Zhang ZJ, Wang JJ, Thomson AW, and Isenberg JS. CD47 regulates renal tubular epithelial cell self-renewal and proliferation following renal ischemia reperfusion. Kidney Int 90: 334-347, 2016.

218. Rollo EE, Laskin DL, and Denhardt DT. Osteopontin inhibits nitric oxide production and cytotoxicity by activated RAW264.7 macrophages. J Leukoc Biol 60: 397-404, 1996.

219. Roudier E, Milkiewicz M, Birot O, Slopack D, Montelius A, Gustafsson T, Paik JH, DePinho RA, Casale GP, Pipinos, II, and Haas TL. Endothelial FoxO1 is an intrinsic regulator of thrombospondin 1 expression that restrains angiogenesis in ischemic muscle. Angiogenesis 16: 759$772,2013$.

220. Ruetten H, Dimmeler S, Gehring D, Ihling C, and Zeiher AM. Concentric left ventricular remodeling in endothelial nitric oxide synthase knockout mice by chronic pressure overload. Cardiovasc Res 66: 444-453, 2005.

221. Ruiz-Hurtado G and Delgado C. Nitric oxide pathway in hypertrophied heart: new therapeutic uses of nitric oxide donors. J Hypertens 28 Suppl 1: S56-S61, 2010.

222. Saha S, Chakraborty PK, Xiong X, Dwivedi SK, Mustafi SB, Leigh NR, Ramchandran R, Mukherjee P, and Bhattacharya R. Cystathionine beta-synthase regulates endothelial function via protein S-sulfhydration. FASEB $J$ 30: 441-456, 2016.

223. Sakai LY, Keene DR, Renard M, and De Backer J. FBN1: the disease-causing gene for Marfan syndrome and other genetic disorders. Gene 591: 279-291, 2016.

224. Schuepp BJ and Jungi TW. Thrombospondin-exposed human monocytes display augmented luminol-enhanced chemiluminescence upon receptor triggering. Biochem Biophys Res Commun 177: 1087-1094, 1991.

225. Schuepp BJ, Pfister H, Clemetson KJ, Silverstein RL, and Jungi TW. CD36-mediated signal transduction in human monocytes by anti-CD36 antibodies but not by antithrombospondin antibodies recognizing cell membranebound thrombospondin. Biochem Biophys Res Commun 175: 263-270, 1991.

226. Scott JA, Weir ML, Wilson SM, Xuan JW, Chambers AF, and McCormack DG. Osteopontin inhibits inducible nitric oxide synthase activity in rat vascular tissue. Am J Physiol 275: H2258-H2265, 1998.

227. Seymour K, Han X, Sadowitz B, Maier KG, and Gahtan $\mathrm{V}$. Differential effect of nitric oxide on thrombospondin1-, PDGF- and fibronectin-induced migration of vascular smooth muscle cells. Am J Surg 200: 615-619, 2010.
228. Sezaki S, Hirohata S, Iwabu A, Nakamura K, Toeda K, Miyoshi T, Yamawaki H, Demircan K, Kusachi S, Shiratori Y, and Ninomiya Y. Thrombospondin-1 is induced in rat myocardial infarction and its induction is accelerated by ischemia/reperfusion. Exp Biol Med (Maywood) 230: 621-630, 2005.

229. Sharifi-Sanjani M, Shoushtari AH, Quiroz M, Baust J, Sestito SF, Mosher M, Ross M, McTiernan CF, St Croix CM, Bilonick RA, Champion HC, and Isenberg JS. Cardiac CD47 drives left ventricular heart failure through Ca2+-CaMKII-regulated induction of HDAC3. J Am Heart Assoc 3: e000670, 2014.

230. Sharma R and Kale RK. Effect of radiation on glyoxalase I and glyoxalase II activities in spleen and liver of mice. Int J Radiat Biol 63: 233-238, 1993.

231. Shen C, Yan J, Erkocak OF, Zheng XF, and Chen XD. Nitric oxide inhibits autophagy via suppression of JNK in meniscal cells. Rheumatology (Oxford) 53: 1022-1033, 2014.

232. Shen L, Liao L, Chen C, Guo Y, Song D, Wang Y, Chen Y, Zhang K, Ying M, Li S, Liu Q, and Ni J. Proteomics analysis of blood serums from Alzheimer's disease patients using iTRAQ labeling technology. J Alzheimers Dis 56: 361-378, 2017.

233. Shen X, Kolluru GK, Yuan S, and Kevil CG. Measurement of $\mathrm{H} 2 \mathrm{~S}$ in vivo and in vitro by the monobromobimane method. Methods Enzymol 554: 31-45, 2015.

234. Shen X, Pattillo CB, Pardue S, Bir SC, Wang R, and Kevil CG. Measurement of plasma hydrogen sulfide in vivo and in vitro. Free Radic Biol Med 50: 1021-1031, 2011.

235. Sheshadri P, Ashwini A, Jahnavi S, Bhonde R, Prasanna J, and Kumar A. Novel role of mitochondrial manganese superoxide dismutase in STAT3 dependent pluripotency of mouse embryonic stem cells. Sci Rep 5: 9516, 2015.

236. Shevde LA and Samant RS. Role of osteopontin in the pathophysiology of cancer. Matrix Biol 37: 131-141, 2014.

237. Shih B, Sultan MJ, Chaudhry IH, Tan KT, Johal KS, Marstan A, Tsai M, Baguneid M, and Bayat A. Identification of biomarkers in sequential biopsies of patients with chronic wounds receiving simultaneous acute wounds: a genetic, histological, and noninvasive imaging study. Wound Repair Regen 20: 757-769, 2012.

238. Shimazaki M, Nakamura K, Kii I, Kashima T, Amizuka N, Li M, Saito M, Fukuda K, Nishiyama T, Kitajima S, Saga Y, Fukayama M, Sata M, and Kudo A. Periostin is essential for cardiac healing after acute myocardial infarction. J Exp Med 205: 295-303, 2008.

239. Sikic BI, Narayanan S, Colevas AD, Padda SK, Fisher GA, Supan D, Wakelee HA, Aoki R, Pegram MD, Villalobos VM, Liu J, Chao M, Volkmer J-P, Majeti R, and Weissman IL. A first-in-human, first-in-class phase I trial of the anti-CD47 antibody Hu5F9-G4 in patients with advanced cancers. J Clin Oncol 34: abstr 3019, 2016.

240. Simmers P, Gishto A, Vyavahare N, and Kothapalli CR. Nitric oxide stimulates matrix synthesis and deposition by adult human aortic smooth muscle cells within threedimensional cocultures. Tissue Eng Part A 21: 14551470, 2015.

241. Smadja DM, d'Audigier C, Bieche I, Evrard S, Mauge L, Dias JV, Labreuche J, Laurendeau I, Marsac B, Dizier B, Wagner-Ballon O, Boisson-Vidal C, Morandi V, DuongVan-Huyen JP, Bruneval P, Dignat-George F, Emmerich 
$\mathrm{J}$, and Gaussem P. Thrombospondin-1 is a plasmatic marker of peripheral arterial disease that modulates endothelial progenitor cell angiogenic properties. Arterioscler Thromb Vasc Biol 31: 551-559, 2011.

242. Sockolosky JT, Dougan M, Ingram JR, Ho CC, Kauke MJ, Almo SC, Ploegh HL, and Garcia KC. Durable antitumor responses to $\mathrm{CD} 47$ blockade require adaptive immune stimulation. Proc Natl Acad Sci U S A 113: E2646-E2654, 2016.

243. Soto-Pantoja DR, Kaur S, and Roberts DD. CD47 signaling pathways controlling cellular differentiation and responses to stress. Crit Rev Biochem Mol Biol 50: 212 230, 2015.

244. Soto-Pantoja DR, Miller TW, Pendrak ML, Degraff WG, Sullivan C, Ridnour LA, Abu-Asab M, Wink DA, Tsokos M, and Roberts DD. CD47 deficiency confers cell and tissue radioprotection by activation of autophagy. Autophagy 8: 1628-1642, 2012.

245. Soto-Pantoja DR, Ridnour LA, Wink DA, and Roberts DD. Blockade of CD47 increases survival of mice exposed to lethal total body irradiation. Sci Rep 3: 1038, 2013.

246. Soto-Pantoja DR, Sipes JM, Ghosh A, Merino MJ, and Roberts DD. Therapeutic targeting of CD47 regulates cell bioenergetics and autophagy to reduce breast tumor growth and protect against anthracycline-mediated cardiac toxicity. Cancer Res 74: Abstract nr 2434, 2014.

247. Soto-Pantoja DR, Sipes JM, Martin-Manso G, Westwood B, Morris NL, Ghosh A, Emenaker NJ, and Roberts DD. Dietary fat overcomes the protective activity of thrombospondin-1 signaling in the Apc(Min/+) model of colon cancer. Oncogenesis 5: e230, 2016.

248. Soto-Pantoja DR, Terabe M, Ghosh A, Ridnour LA, DeGraff WG, Wink DA, Berzofsky JA, and Roberts DD. CD47 in the tumor microenvironment limits cooperation between antitumor T-cell immunity and radiotherapy. Cancer Res 74: 6771-6783, 2014.

249. Spassov S, Pfeifer D, Strosing K, Ryter S, Hummel M, Faller S, and Hoetzel A. Genetic targets of hydrogen sulfide in ventilator-induced lung injury-a microarray study. PLoS One 9: e102401, 2014.

250. Spenle C, Saupe F, Midwood K, Burckel H, Noel G, and Orend G. Tenascin-C: exploitation and collateral damage in cancer management. Cell Adh Migr 9: 141-153, 2015.

251. St-Pierre J, Drori S, Uldry M, Silvaggi JM, Rhee J, Jager S, Handschin C, Zheng K, Lin J, Yang W, Simon DK, Bachoo R, and Spiegelman BM. Suppression of reactive oxygen species and neurodegeneration by the PGC-1 transcriptional coactivators. Cell 127: 397-408, 2006.

252. Staines KA, MacRae VE, and Farquharson C. The importance of the SIBLING family of proteins on skeletal mineralisation and bone remodelling. J Endocrinol 214: 241-255, 2012.

253. Stehlik J, Edwards LB, Kucheryavaya AY, Benden C, Christie JD, Dobbels F, Kirk R, Rahmel AO, and Hertz MI. The Registry of the International Society for Heart and Lung Transplantation: Twenty-eighth Adult Heart Transplant Report-2011. J Heart Lung Transplant 30: 1078-1094, 2011.

254. Stein EV, Miller TW, Ivins-O'Keefe K, Kaur S, and Roberts DD. Secreted thrombospondin-1 regulates macrophage interleukin-1beta production and activation through CD47. Sci Rep 6: 19684, 2016.

255. Stevens AL, Wheeler CA, Tannenbaum SR, and Grodzinsky AJ. Nitric oxide enhances aggrecan degradation by aggrecanase in response to TNF-alpha but not IL-1beta treatment at a post-transcriptional level in bovine cartilage explants. Osteoarthritis Cartilage 16: 489-497, 2008.

256. Suchard SJ and Boxer LA. Exocytosis of a subpopulation of specific granules coincides with $\mathrm{H}_{2} \mathrm{O}_{2}$ production in adherent human neutrophils. J Immunol 152: 290-300, 1994.

257. Suchard SJ, Boxer LA, and Dixit VM. Activation of human neutrophils increases thrombospondin receptor expression. J Immunol 147: 651-659, 1991.

258. Suchard SJ, Burton MJ, Dixit VM, and Boxer LA. Human neutrophil adherence to thrombospondin occurs through a CD11/CD18-independent mechanism. J Immunol 146: 3945-3952, 1991.

259. Sun X, Skorstengaard K, and Mosher DF. Disulfides modulate RGD-inhibitable cell adhesive activity of thrombospondin. J Cell Biol 118: 693-701, 1992.

260. Suzuma K, Takagi H, Otani A, Oh H, and Honda Y. Expression of thrombospondin-1 in ischemia-induced retinal neovascularization. Am J Pathol 154: 343-354, 1999.

261. Szabo C. Gasotransmitters in cancer: from pathophysiology to experimental therapy. Nat Rev Drug Discov 15: 185-203, 2016.

262. Szabo C. Hydrogen sulfide, an enhancer of vascular nitric oxide signaling: mechanisms and implications. Am J Physiol Cell Physiol 312: C3-C15, 2017.

263. Takayama H, Hamner CE, Caccitolo JA, Hisamochi K, Pearson PJ, and Schaff HV. A novel antioxidant, EPC-K1, stimulates endothelial nitric oxide production and scavenges hydroxyl radicals. Circ J 67: 1046-1052, 2003.

264. Talaei F, Bouma HR, Hylkema MN, Strijkstra AM, Boerema AS, Schmidt M, and Henning RH. The role of endogenous $\mathrm{H} 2 \mathrm{~S}$ formation in reversible remodeling of lung tissue during hibernation in the Syrian hamster. J Exp Biol 215: 2912-2919, 2012.

265. Talaei F, Hylkema MN, Bouma HR, Boerema AS, Strijkstra AM, Henning RH, and Schmidt M. Reversible remodeling of lung tissue during hibernation in the Syrian hamster. J Exp Biol 214: 1276-1282, 2011.

266. Tang Y, Scheef EA, Gurel Z, Sorenson CM, Jefcoate CR, and Sheibani N. CYP1B1 and endothelial nitric oxide synthase combine to sustain proangiogenic functions of endothelial cells under hyperoxic stress. Am J Physiol Cell Physiol 298: C665-C678, 2010.

267. Tao BB, Liu SY, Zhang CC, Fu W, Cai WJ, Wang Y, Shen Q, Wang MJ, Chen Y, Zhang LJ, Zhu YZ, and Zhu YC. VEGFR2 functions as an H2S-targeting receptor protein kinase with its novel Cys1045-Cys1024 disulfide bond serving as a specific molecular switch for hydrogen sulfide actions in vascular endothelial cells. Antioxid Redox Signal 19: 448-464, 2013.

268. Tao H, Qian P, Wang F, Yu H, and Guo Y. Targeting CD47 enhances the efficacy of anti-PD-1 and CTLA-4 in esophageal squamous cell cancer preclinical model. Oncol Res 2017 [Epub ahead of print]; DOI: 10.3727/ $096504017 X 14900505020895$.

269. Tarasenko N, Kessler-Icekson G, Boer $P$, Inbal A, Schlesinger H, Phillips DR, Cutts SM, Nudelman A, and Rephaeli A. The histone deacetylase inhibitor butyroyloxymethyl diethylphosphate (AN-7) protects normal cells against toxicity of anticancer agents while augmenting their anticancer activity. Invest New Drugs 30: 130-143, 2012.

270. Tejedo JR, Tapia-Limonchi R, Mora-Castilla S, Cahuana GM, Hmadcha A, Martin F, Bedoya FJ, and Soria B. Low 
concentrations of nitric oxide delay the differentiation of embryonic stem cells and promote their survival. Cell Death Dis 1: e80, 2010.

271. Thakar CV, Zahedi K, Revelo MP, Wang Z, Burnham CE, Barone S, Bevans S, Lentsch AB, Rabb H, and Soleimani M. Identification of thrombospondin 1 (TSP-1) as a novel mediator of cell injury in kidney ischemia. $J$ Clin Invest 115: 3451-3459, 2005.

272. Thomas DD, Heinecke JL, Ridnour LA, Cheng RY, Kesarwala AH, Switzer CH, McVicar DW, Roberts DD, Glynn S, Fukuto JM, Wink DA, and Miranda KM. Signaling and stress: the redox landscape in NOS2 biology. Free Radic Biol Med 87: 204-225, 2015.

273. Thornalley PJ. Pharmacology of methylglyoxal: formation, modification of proteins and nucleic acids, and enzymatic detoxification - a role in pathogenesis and antiproliferative chemotherapy. Gen Pharmacol 27: 565573, 1996.

274. Toda N and Ayajiki K. Phylogenesis of constitutively formed nitric oxide in non-mammals. Rev Physiol Biochem Pharmacol 157: 31-80, 2006.

275. Tong X, Khandelwal AR, Qin Z, Wu X, Chen L, Ago T, Sadoshima J, and Cohen RA. Role of smooth muscle Nox4-based NADPH oxidase in neointimal hyperplasia. $J$ Mol Cell Cardiol 89: 185-194, 2015.

276. Topol EJ, McCarthy J, Gabriel S, Moliterno DJ, Rogers WJ, Newby LK, Freedman M, Metivier J, Cannata R, O'Donnell CJ, Kottke-Marchant K, Murugesan G, Plow EF, Stenina O, and Daley GQ. Single nucleotide polymorphisms in multiple novel thrombospondin genes may be associated with familial premature myocardial infarction. Circulation 104: 2641-2644, 2001.

277. Trezzini C, Jungi TW, Spycher MO, Maly FE, and Rao P. Human monocytes CD36 and CD16 are signaling molecules. Evidence from studies using antibody-induced chemiluminescence as a tool to probe signal transduction. Immunology 71: 29-37, 1990.

278. Tsoutsman T, Wang X, Garchow K, Riser B, Twigg S, and Semsarian C. CCN2 plays a key role in extracellular matrix gene expression in severe hypertrophic cardiomyopathy and heart failure. J Mol Cell Cardiol 62: 164-178, 2013.

279. Tulasne D, Judd BA, Johansen M, Asazuma N, Best D, Brown EJ, Kahn M, Koretzky GA, and Watson SP. Cterminal peptide of thrombospondin-1 induces platelet aggregation through the $\mathrm{Fc}$ receptor gamma-chainassociated signaling pathway and by agglutination. Blood 98: 3346-3352, 2001.

280. Tuszynski GP, Rothman VL, Murphy A, Siegler K, and Knudsen KA. Thrombospondin promotes platelet aggregation. Blood 72: 109-115, 1988.

281. Urao N, Inomata H, Razvi M, Kim HW, Wary K, McKinney R, Fukai T, and Ushio-Fukai M. Role of nox2based NADPH oxidase in bone marrow and progenitor cell function involved in neovascularization induced by hindlimb ischemia. Circ Res 103: 212-220, 2008.

282. Ushio-Fukai M. Compartmentalization of redox signaling through NADPH oxidase-derived ROS. Antioxid Redox Signal 11: 1289-1299, 2009.

283. Valitutti S, Castellino F, and Musiani P. Effect of sulfurous (thermal) water on $\mathrm{T}$ lymphocyte proliferative response. Ann Allergy 65: 463-468, 1990.

284. van Almen GC, Swinnen M, Carai P, Verhesen W, Cleutjens JP, D'Hooge J, Verheyen FK, Pinto YM,
Schroen B, Carmeliet P, and Heymans S. Absence of thrombospondin-2 increases cardiomyocyte damage and matrix disruption in doxorubicin-induced cardiomyopathy. J Mol Cell Cardiol 51: 318-328, 2011.

285. von Toerne C, Huth C, de Las Heras Gala T, Kronenberg F, Herder C, Koenig W, Meisinger C, Rathmann W, Waldenberger M, Roden M, Peters A, Thorand B, and Hauck SM. MASP1, THBS1, GPLD1 and ApoA-IV are novel biomarkers associated with prediabetes: the KORA F4 study. Diabetologia 59: 1882-1892, 2016.

286. Wahab NA, Schaefer L, Weston BS, Yiannikouris O, Wright A, Babelova A, Schaefer R, and Mason RM. Glomerular expression of thrombospondin-1, transforming growth factor beta and connective tissue growth factor at different stages of diabetic nephropathy and their interdependent roles in mesangial response to diabetic stimuli. Diabetologia 48: 2650-2660, 2005.

287. Walpen S, Beck KF, Eberhardt W, Apel M, Chatterjee PK, Wray GM, Thiemermann C, and Pfeilschifter J. Downregulation of SPARC expression is mediated by nitric oxide in rat mesangial cells and during endotoxemia in the rat. J Am Soc Nephrol 11: 468-476, 2000.

288. Wang HB, Yang J, Ding JW, Chen LH, Li S, Liu XW, Yang CJ, Fan ZX, and Yang J. RNAi-mediated downregulation of CD47 protects against ischemia/reperfusioninduced myocardial damage via activation of eNOS in a rat model. Cell Physiol Biochem 40: 1163-1174, 2016.

289. Wang MJ, Cai WJ, Li N, Ding YJ, Chen Y, and Zhu YC. The hydrogen sulfide donor NaHS promotes angiogenesis in a rat model of hind limb ischemia. Antioxid Redox Signal 12: 1065-1077, 2010.

290. Wang R. Physiological implications of hydrogen sulfide: a whiff exploration that blossomed. Physiol Rev 92: 791896, 2012.

291. Wang S, Shiva S, Poczatek MH, Darley-Usmar V, and Murphy-Ullrich JE. Nitric oxide and cGMP-dependent protein kinase regulation of glucose-mediated thrombospondin 1-dependent transforming growth factor-beta activation in mesangial cells. J Biol Chem 277: 9880-9888, 2002.

292. Wang S, Skorczewski J, Feng X, Mei L, and MurphyUllrich JE. Glucose up-regulates thrombospondin 1 gene transcription and transforming growth factor-beta activity through antagonism of cGMP-dependent protein kinase repression via upstream stimulatory factor 2. J Biol Chem 279: 34311-34322, 2004.

293. Wang S, Wu X, Lincoln TM, and Murphy-Ullrich JE. Expression of constitutively active cGMP-dependent protein kinase prevents glucose stimulation of thrombospondin 1 expression and TGF-beta activity. Diabetes 52: 2144-2150, 2003.

294. Wang Y, Wang X, Liang X, Wu J, Dong S, Li H, Jin M, Sun D, Zhang W, and Zhong X. Inhibition of hydrogen sulfide on the proliferation of vascular smooth muscle cells involved in the modulation of calcium sensing receptor in high homocysteine. Exp Cell Res 347: 184-191, 2016.

295. Wani J, Carl M, Henger A, Nelson PJ, and Rupprecht H. Nitric oxide modulates expression of extracellular matrix genes linked to fibrosis in kidney mesangial cells. Biol Chem 388: 497-506, 2007.

296. Wardman P, Rothkamm K, Folkes LK, Woodcock M, and Johnston PJ. Radiosensitization by nitric oxide at low radiation doses. Radiat Res 167: 475-484, 2007. 
297. Wessel J, Topol EJ, Ji M, Meyer J, and McCarthy JJ. Replication of the association between the thrombospondin-4 A387P polymorphism and myocardial infarction. Am Heart J 147: 905-909, 2004.

298. Whiteman M, Li L, Rose P, Tan CH, Parkinson DB, and Moore PK. The effect of hydrogen sulfide donors on lipopolysaccharide-induced formation of inflammatory mediators in macrophages. Antioxid Redox Signal 12: 1147-1154, 2010.

299. Wink DA, Hanbauer I, Krishna MC, DeGraff W, Gamson J, and Mitchell JB. Nitric oxide protects against cellular damage and cytotoxicity from reactive oxygen species. Proc Natl Acad Sci U S A 90: 9813-9817, 1993.

300. Wong JC and Fiscus RR. Essential roles of the nitric oxide (no)/cGMP/protein kinase $\mathrm{G}$ type-Ialpha (PKG-Ialpha) signaling pathway and the atrial natriuretic peptide (ANP)/cGMP/PKG-Ialpha autocrine loop in promoting proliferation and cell survival of OP9 bone marrow stromal cells. J Cell Biochem 112: 829-839, 2011.

301. Wu H, Chen L, Xie J, Li R, Li GN, Chen QH, Zhang XL, Kang LN, and $\mathrm{Xu}$ B. Periostin expression induced by oxidative stress contributes to myocardial fibrosis in a rat model of high salt-induced hypertension. Mol Med Rep 14: 776-782, 2016.

302. Wu SY, Pan CS, Geng B, Zhao J, Yu F, Pang YZ, Tang $\mathrm{CS}$, and Qi YF. Hydrogen sulfide ameliorates vascular calcification induced by vitamin D3 plus nicotine in rats. Acta Pharmacol Sin 27: 299-306, 2006.

303. Xiao Z, Banan B, Xu M, Jia J, Manning PT, Hiebsch RR, Gunasekaran M, Upadhya GA, Frazier WA, Mohanakumar T, Lin Y, and Chapman WC. Attenuation of ischemia-reperfusion injury and improvement of survival in recipients of steatotic rat livers using CD47 monoclonal antibody. Transplantation 100: 1480-1489, 2016.

304. Xiao ZY, Banan B, Jia J, Manning PT, Hiebsch RR, Gunasekaran M, Upadhya GA, Frazier WA, Mohanakumar T, Lin Y, and Chapman WC. CD47 blockade reduces ischemia/reperfusion injury and improves survival in a rat liver transplantation model. Liver Transpl 21: 468-477, 2015.

305. Yamamoto K, Dang QN, Kennedy SP, Osathanondh R, Kelly RA, and Lee RT. Induction of tenascin-C in cardiac myocytes by mechanical deformation. Role of reactive oxygen species. J Biol Chem 274: 21840-21846, 1999.

306. Yan Y and Finkel T. Autophagy as a regulator of cardiovascular redox homeostasis. Free Radic Biol Med 109: 108-113, 2016.

307. Yao M, Rogers NM, Csanyi G, Rodriguez AI, Ross MA, St Croix C, Knupp H, Novelli EM, Thomson AW, Pagano PJ, and Isenberg JS. Thrombospondin-1 activation of signal-regulatory protein-alpha stimulates reactive oxygen species production and promotes renal ischemia reperfusion injury. J Am Soc Nephrol 25: 1171-1186, 2014.

308. Yoshioka J, Chutkow WA, Lee S, Kim JB, Yan J, Tian R, Lindsey ML, Feener EP, Seidman CE, Seidman JG, and Lee RT. Deletion of thioredoxin-interacting protein in mice impairs mitochondrial function but protects the myocardium from ischemia-reperfusion injury. $J$ Clin Invest 122: 267-279, 2012.

309. Yoshioka J and Lee RT. Thioredoxin-interacting protein and myocardial mitochondrial function in ischemiareperfusion injury. Trends Cardiovasc Med 24: 75-80, 2014.
310. Zhang ZX, Shek K, Wang S, Huang X, Lau A, Yin Z, Sun H, Liu W, Garcia B, Rittling S, and Jevnikar AM. Osteopontin expressed in tubular epithelial cells regulates NK cell-mediated kidney ischemia reperfusion injury. $J$ Immunol 185: 967-973, 2010.

311. Zhao X, Ding EY, Yu OM, Xiang SY, Tan-Sah VP, Yung BS, Hedgpeth J, Neubig RR, Lau LF, Brown JH, and Miyamoto $\mathrm{S}$. Induction of the matricellular protein CCN1 through RhoA and MRTF-A contributes to ischemic cardioprotection. J Mol Cell Cardiol 75: 152161, 2014.

312. Zhao X, Zhang LK, Zhang CY, Zeng XJ, Yan H, Jin HF, Tang CS, and Du JB. Regulatory effect of hydrogen sulfide on vascular collagen content in spontaneously hypertensive rats. Hypertens Res 31: 1619-1630, 2008.

313. Zhao Y, Wang S, Sorenson CM, Teixeira L, Dubielzig RR, Peters DM, Conway SJ, Jefcoate CR, and Sheibani N. Cyp1b1 mediates periostin regulation of trabecular meshwork development by suppression of oxidative stress. Mol Cell Biol 33: 4225-4240, 2013.

314. Zhao Y, Xiong Z, Lechner EJ, Klenotic PA, Hamburg BJ, Hulver M, Khare A, Oriss T, Mangalmurti N, Chan Y, Zhang Y, Ross MA, Stolz DB, Rosengart MR, Pilewski J, Ray P, Ray A, Silverstein RL, and Lee JS. Thrombospondin-1 triggers macrophage IL-10 production and promotes resolution of experimental lung injury. Mucosal Immunol 7: 440-448, 2014.

315. Zheng Y, Liao F, Lin X, Zheng F, Fan J, Cui Q, Yang J, Geng B, and Cai J. Cystathionine gamma-lyase-hydrogen sulfide induces runt-related transcription factor 2 dulfhydration, thereby increasing osteoblast activity to promote bone fracture healing. Antioxid Redox Signal 2017 [Epub ahead of print]; DOI: 10.1089/ars.2016.6826.

316. Zhong ZY and Tang Y. Upregulation of periostin prevents high glucose-induced mitochondrial apoptosis in human umbilical vein endothelial cells via activation of Nrf2/HO1 signaling. Cell Physiol Biochem 39: 71-80, 2016.

317. Zwicker JI, Peyvandi F, Palla R, Lombardi R, Canciani MT, Cairo A, Ardissino D, Bernardinelli L, Bauer KA, Lawler J, and Mannucci P. The thrombospondin-1N700S polymorphism is associated with early myocardial infarction without altering von Willebrand factor multimer size. Blood 108: 1280-1283, 2006.

Address correspondence to: Dr. David D. Roberts Laboratory of Pathology Center for Cancer Research National Cancer Institute National Institutes of Health Building 10 Room 2S235, 10 Center Drive MSC1500 Bethesda, MD 20892-1500

E-mail: droberts@helix.nih.gov

Dr. Jeffrey S. Isenberg Division of Pulmonary, Allergy, and Critical Care Heart, Lung, Blood, and Vascular Medicine Institute University of Pittsburgh School of Medicine E1258, BST, 200 Lothrop Street Pittsburgh, PA 15261

E-mail: jsi5@pitt.edu 
Date of first submission to ARS Central, April 28, 2017; date of final revised submission, July 11, 2017; date of acceptance, July 13, 2017.

\section{Abbreviations Used}

ADAMTS $=$ a disintegrin and metalloproteinase with thrombospondin motifs

Ang II = angiotensin II

$\mathrm{CBS}=$ cystathionine $\beta$-synthase

$\mathrm{CCN}=\mathrm{CYR61}$, CTGF (connective tissue growth factor), and NOV (nephroblastoma overexpressed gene)

$\mathrm{CD} 36=$ fatty acid translocase, scavenger receptor class B member 3

$\mathrm{CD} 47=$ integrin-associated protein, thrombospondin-1 receptor

$\mathrm{cMyc}=$ cellular myelocytomatosis oncogene

$\mathrm{COMP}=$ cartilage oligomeric matrix protein

$\mathrm{CSE}=$ cystathionine $\gamma$-lyase

DCFDA $=2$,7-dichlorofluorescein diacetate

DETA/NO $=$ diethyltriamine NONOate

$\mathrm{E} 3 \mathrm{CaG} 1=$ recombinant $\mathrm{C}$-terminal signature domain of thrombospondin-1

$\mathrm{EGF}=$ epidermal growth factor

eNOS $=$ endothelial nitric oxide synthase

$\mathrm{ERK}=$ extracellular-regulated protein kinase

ET-1 = endothelin-1

$\mathrm{fMLP}=$ formyl-Met-Leu-Phe

Gpx $1=$ glutathione peroxidase- 1

HDAC3 = histone deacetylase 3

$\mathrm{HF}=$ heart failure

$\mathrm{IL}=$ interleukin

iNOS $=$ inducible nitric oxide synthase

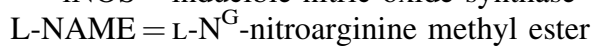

LPS $=$ lipopolysaccharide

LRP1 = low-density lipoprotein receptor-related protein-1

$\mathrm{LV}=$ left ventricular

$\mathrm{MEK}=$ mitogen-activated protein kinase kinase
MKP1/DUSP1 = MAP kinase phosphatase-1

MSCs $=$ mesenchymal stem cells

$\mathrm{mTOR}=$ mammalian target of rapamycin

mTORC1 $=$ mammalian target of rapamycin complex 1

$\mathrm{NF}-\kappa \mathrm{B}=$ nuclear factor kappa $\mathrm{B}$

$\mathrm{NK}=$ natural killer

NOS $=$ nitric oxide synthase

Nox $=$ NADPH oxidase

$\mathrm{ODQ}=1 \mathrm{H}-[1,2,4]$ oxadiazole[4,3-a]quinoxalin1-one

$\mathrm{PE}=$ phenylephrine

$\operatorname{PGC} 1 \alpha=$ peroxisome proliferator-activated receptor gamma coactivator $1-\alpha$

$\mathrm{PH}=$ pulmonary hypertension

$\mathrm{PMN}=$ polymorphonuclear cells

RNS $=$ reactive nitrogen species

ROS $=$ reactive oxygen species

$\mathrm{sGC}=$ soluble guanylate cyclase

SIBLING $=$ small integrin-binding ligand $\mathrm{N}$-linked glycoprotein

$\operatorname{SIRP} \alpha=$ signal regulatory protein $\alpha$

SMOC1 $=$ secreted modular calcium-binding protein 1

SOD $=$ superoxide dismutase

Sox $2=$ sex determining region Y-box 2

$\mathrm{SPARC}=$ secreted protein acidic and rich in cysteine

$\mathrm{TAC}=$ transverse aortic constriction

TGF $\beta=$ transforming growth factor- $\beta 1$

$\mathrm{TNF} \alpha=$ tumor necrosis factor- $\alpha$

TSP1 $=$ thrombospondin- 1

$\mathrm{TSR}=$ type 1 thrombospondin repeat

TXNIP $=$ thioredoxin-interacting protein

VEGF $=$ vascular endothelial growth factor

VEGFR2 $=$ VEGF receptor-2

VOEs $=$ vaso-occlusive events

VSMCs $=$ vascular smooth muscle cells

$\mathrm{WT}=$ wild type 